\title{
Platelet-associated hypercoagulability in patients with Essential Thrombocythemia and Polycythemia Vera
}

Citation for published version (APA):

Panova-Noeva, M. (2012). Platelet-associated hypercoagulability in patients with Essential Thrombocythemia and Polycythemia Vera. [Doctoral Thesis, Maastricht University]. Maastricht University. https://doi.org/10.26481/dis.20121129mp

Document status and date:

Published: 01/01/2012

DOI:

10.26481/dis.20121129mp

Document Version:

Publisher's PDF, also known as Version of record

\section{Please check the document version of this publication:}

- A submitted manuscript is the version of the article upon submission and before peer-review. There can be important differences between the submitted version and the official published version of record.

People interested in the research are advised to contact the author for the final version of the publication, or visit the DOI to the publisher's website.

- The final author version and the galley proof are versions of the publication after peer review.

- The final published version features the final layout of the paper including the volume, issue and page numbers.

Link to publication

\footnotetext{
General rights rights.

- You may freely distribute the URL identifying the publication in the public portal. please follow below link for the End User Agreement:

www.umlib.nl/taverne-license

Take down policy

If you believe that this document breaches copyright please contact us at:

repository@maastrichtuniversity.nl

providing details and we will investigate your claim.
}

Copyright and moral rights for the publications made accessible in the public portal are retained by the authors and/or other copyright owners and it is a condition of accessing publications that users recognise and abide by the legal requirements associated with these

- Users may download and print one copy of any publication from the public portal for the purpose of private study or research.

- You may not further distribute the material or use it for any profit-making activity or commercial gain

If the publication is distributed under the terms of Article $25 \mathrm{fa}$ of the Dutch Copyright Act, indicated by the "Taverne" license above, 


\section{PLATELET-ASSOCIATED HYPERCOAGULABILITY IN PATIENTS WITH ESSENTIAL THROMBOCYTHEMIA AND POLYCYTHEMIA VERA}


(C) Marina Panova-Noeva, Maastricht 2012

Thesis Maastricht University

ISBN:

978-9989-57-865-6

Layout by:

Cover design by:

Marina Panova-Noeva and Igor Noev

Igor Noev

Printed by:

Printing facility of the Ospedali Riuniti of Bergamo, Italy

All rights reserved. No part of the thesis may be reproduced, stored in a retrieval system or transmitted in any form or by any means, without the permission in writing from the author, or, when appropriate, of the publishers of the publication. 


\section{Platelet-associated hypercoagulability In patients with Essential Thrombocythemia And Polycythemia Vera}

\section{PROEFSCHRIFT}

ter verkrijging van de graad van doctor aan de Universiteit Maastricht op gezag van de Rector Magnificus, Prof. dr. L.L.G.Soete, volgens het besluit van het College van Decanen, in het openbaar te verdedigen op

Donderdag 29 November 2012 om 10.00 uur

door

Marina Panova-Noeva 


\section{Promotor}

Prof. dr. H. ten Cate

\section{Copromotors}

Dr. A. Falanga

Dr. M. Marchetti

\section{Beoordelingscommissie}

Prof. dr. J. Rosing (Chairman)

Prof. dr. H.C.J. Eikenboom (Leids Universitair Centrum)

Prof. dr. S. Middeldorp (AMC Amsterdam)

Prof. dr. H.C. Schouten

Dr. W. van Werkum (St. Antonius Ziekenhuis Nieuwegein)

The research described in this thesis was partially supported by a grant of the Annadal Foundation of Maastricht (The Netherlands) and of the Italian Association for Cancer Research (AIRC, Milan, Italy). 
To my father 



\section{Contents}

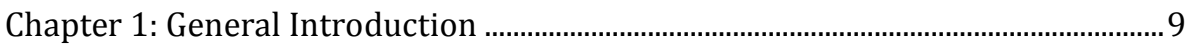

PART ONE Pathogenesis and treatment of thrombosis in cancer

Chapter 2: Procoagulant mechanisms in tumour cells ..............................................2

Chapter 3: Treatment of thromboembolism in cancer patients............................... 43

\section{PART TWO}

Chapter 4: Monitoring thrombin generation: is addition of corn trypsin inhibitor needed?

PART THREE Hypercoagulability in essential thrombocythemia and polycythemia vera

Chapter 5: Platelet-induced thrombin generation by the calibrated automated thrombogram assay is increased in patients with essential thrombocythemia and polycythemia vera

Chapter 6: JAK2V617F mutation and hydroxyurea treatment as determinants of immature platelet parameters in essential thrombocythemia and polycythemia vera patients

Chapter 7: Evaluation of Aspirin use on Platelet Function by Platelet Function Analyser and Thrombin Generation Assay in patients with Essential Thrombocythemia and Polycythemia Vera

Chapter 8: ADP-induced whole blood aggregation and platelet-associated thrombin generation (TG) are increased in Essential Thrombocythemia (ET) and Polycythemia Vera (PV) patients

Chapter 9: Nitric oxide derivatives and soluble plasma selectins in patients with myeloproliferative neoplasms.

Chapter 10: Summary, general discussion and conclusions. 159

Curriculum Vitae.

Publications 

CHAPTER 1

General Introduction 


\section{Thrombosis and cancer}

Thrombosis and cancer are among the most frequent diseases in the developed world of today. According to the latest publication by the World Health Organization (WHO) on global burden of disease, ischemic heart diseases followed by cancer are the leading causes of death in developed countries.[1] The association between thrombosis and cancer is complex, and the interacting mechanisms include non-specific factors related to the host response to tumor (i.e. inflammation, paraproteinemia and venous stasis), anti-cancer treatment and cancer-cell prothrombotic activities.

Venous thromboembolism (VTE), including deep vein thrombosis (DVT) and pulmonary embolism (PE), is a significant cause of morbidity and mortality in cancer patients.[2-3] Patients with active cancer have a 6 - 7 times increased risk of developing symptomatic VTE compared to noncancer patients.[4-5] In addition, VTE can be the first symptom of an occult cancer. In the large population-based studies, from $10 \%$ to $20 \%$ of all patients presenting with an idiopathic or unprovoked VTE were diagnosed with underlying cancer within the next 1-2 years.[6-7]

The risk of developing VTE varies according to the type of malignancy, being highest in patients with malignant brain tumors, hematological malignancies, and tumors of the pancreas, uterus, ovary, stomach, lung, and kidney.[4, 8-10]

Conventional cytotoxic chemotherapy is an independent risk factor for thrombosis with an incidence rate between $10-20 \%$ per year. $[5,11]$ Recently, a predictive model for a symptomatic VTE during the first four cycles of chemotherapy has been established, grouping the patients into three categories based on their total risk score. [12]

Primary anticoagulant prophylaxis is recommended in all cancer patients hospitalized for medical or surgical reasons.[13] The initial treatment of acute VTE in cancer patients is identical as in non-cancer patients. Differently, for the long term therapy of VTE in cancer, low-molecular-weight heparin (LMWH) is preferred as monotherapy for at least 3 months followed by LMWH or warfarin as long as the cancer is active.[14]

\section{Thrombosis in Essential Thrombocythemia and Polycythemia Vera}

Essential thrombocythemia (ET) and Polycythemia Vera (PV) are two Myeloproliferative Neoplasms (MPNs) characterized by an excessive hematopoietic progenitor cell proliferation leading to an overproduction of one or more circulating blood cells.[15] ET patients typically present with high platelet count and PV patients with high red cell count. Diagnosis of ET and PV is currently accord- 
ing to WHO criteria, based on clinical and laboratory criteria (Figure 1). PV diagnosis requires meeting either both major criteria and one minor criterion or the first major criterion and two minor criteria. ET diagnosis requires meeting all four major criteria.[16] The clinical course of ET and PV is frequently complicated by thrombotic events, progression to myelofibrosis, and hemorrhages responsible for $41 \%, 13 \%$ and $4 \%$ of patients' mortality, respectively.[17]

Figure 1. 2008 WHO diagnostic criteria for ET and PV.

$$
\text { Major criteria }
$$

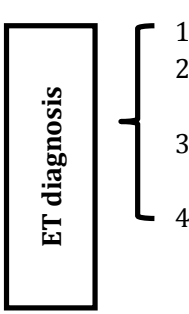

1. Sustained platelet count $>450 \times 10^{9} / \mathrm{L}$.

2. Megakaryocyte proliferation with large and mature morphology.

3. Not meeting WHO criteria for CML, PV, PMF, MDS, or other myeloid neoplasm

4. Demonstration of JAK2V617F or other clonal marker or no evidence of reactive thrombocytosis.

\section{Minor criteria}

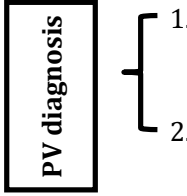

$P M F=$ primary myelofibrosis, $C M L=$ chronic myelogenous leukemia, $M D S=$ myelodysplastic syndrome

$\mathrm{Hgb}>18.5 \mathrm{~g} / \mathrm{dL}(\mathrm{men})>16.5 \mathrm{~g} / \mathrm{dL}$ red cell volume. mutation. (women) or other evidence of increased

Presence of JAK2V617F or JAK2 exon 12

Arterial thrombosis, including coronary, cerebral and peripheral artery occlusions, is more frequent than venous thrombosis and accounts for $60 \%$ of all vascular events.[18] Venous thrombosis is more frequent in PV patients accounting for approximately one-third of total vascular events.[17] Most common are deep venous thrombosis of the lower limbs, which may cause pulmonary embolism, and superficial vein phlebitis of the legs. The occurrence of thrombosis in unusual sites, i.e splanchnic and cerebral vein thrombosis, is not rare as in the general population and is often the presenting feature of an undiagnosed MPN. In addition, these latter events have been often reported as a severe complication in relatively young female patients.[19-20] Microcirculatory disturbances such as erythromelalgia, Raynaud phenomenon and transient neurological events are more common in ET patients due to platelet rich microthrombi occlusion of the end arterial circulation.[21]

Multiple factors have been associated with the pathogenesis of thrombosis in MPN patients. The hypercoagulable state in these patients has been attributed to blood hyperviscosity, particularly in PV patients, due to overproduction of red blood cells and platelets. Recently, a high leukocyte count and the presence 
of the somatic V617F mutation of the Janus 2 tyrosine kinase (JAK2) gene have been associated with an increased thrombotic risk in both ET and PV patients.[22-24] Many studies have investigated the contribution of platelets in the onset of the thrombophilic state in these diseases, and it is now clear that the increased platelet count is not a major element in the risk of thrombosis.[25] Rather, platelet qualitative abnormalities have been implicated in the pathogenesis of hypercoagulability in ET and PV patients. Increased expression of P-selectin, thrombospondin, and the activated fibrinogen receptor GPIIb/IIIa by platelets has been found to correlate with thrombosis.[26-27] The formation of platelet-leukocyte aggregates, platelet activation and microparticles shedding are also implicated in the pathogenesis of thrombosis in these patients.[28]

The current management of MPN patients is highly dependent on patient's thrombotic risk. Age, previous thrombotic event and cardiovascular risk factors (hypertension, smoking, hypercholesterolaemia and diabetes mellitus) are well established predictors of arterial and venous thrombosis. In this regard treatment is tailored individually based on patients' vascular risk (Table 1)[29].

Table 1. Risk based treatment algorithm in ET and PV patients.

\begin{tabular}{|c|c|c|c|}
\hline Risk category & Risk factors & ET Treatment & PV Treatment \\
\hline Low risk & $\begin{array}{c}\text { Age }<60 \text { and no his- } \\
\text { tory of thrombosis* }\end{array}$ & Low dose aspirin & Low dose aspirin + phlebotomy \\
\hline High risk & $\begin{array}{c}\text { Age } \geq 60 \text { and/or a } \\
\text { positive history of } \\
\text { thrombosis* }\end{array}$ & $\begin{array}{c}\text { Low dose aspirin } \\
\text { + hydroxyurea }\end{array}$ & $\begin{array}{c}\text { Low dose aspirin + phlebotomy } \\
\text { + hydroxyurea }\end{array}$ \\
\hline
\end{tabular}

${ }^{*}$ Arterial and/or venous thrombosis.

\section{Platelets and cancer}

Studies from recent years provided increasing evidence for a much wider role of platelets, beyond maintaining hemostasis. Despite representing the smallest anucleated hematopoietic blood cells formed from megakaryocytes' cytoplasm, platelets are as active and biologically influential as the other blood cells. Experimental studies indicate that platelets have an important connecting function between coagulation and cancer progression.[30-31]

The platelet membrane, rich in phospholipids, also contains glycoproteins and integrins essential for platelet mediated hemostasis.[32] In addition, these molecules have been implicated in platelet-tumor cell adhesion and activation. Indeed, agents inhibiting platelet glycoprotein IIb-IIIa, fibronectin and von Willebrand factor, remarkably inhibited adhesion of tumor cells to platelets and consequently experimental hematogenous metastasis. [33] Platelets contain several types of secretory granules, such as alfa granules, dense granules and lysosomal granules that store and secrete proteins that in addition to coagulation can regulate other processes such as angiogenesis and cancer metastasis. Platelets 
can be activated directly by the tumor cells or indirectly by tumor secreted activators.[34] Once activated, platelets increasingly interact through specific adhesion molecules with other cells such as leukocytes, endothelial cells as well as the circulating tumor cells.[35] Platelets binding to tumor cells promote the malignant process by protecting circulating tumor cells from lysis by natural killer cells.[36] Upon activation, platelets release various angiogenesisregulating factors (i.e vascular endothelial growth factor (VEGF), platelet derived growth factor, insulin-like growth factor, CD40 etc.). Some studies suggest that platelets are the major source of VEGF in the serum, known as essential factor in tumor growth and development.[37]

Another important molecule recently appreciated for the process of tumor metastasis is P-selectin, an adhesion molecule stored in the alfa granules. Pselectin facilitates direct binding of platelets to tumor cells and augments tumor metastasis. In addition, P-selectin binding to P-selectin glycoligand-1 (PSGL-1) mediates the release of procoagulant microparticles from platelets and leukocytes, shown to accumulate in the developing thrombi.[38] Recent experimental evidence suggests that specific inhibition of $\mathrm{P}$-selectin represents a potential treatment target in thrombosis, cancer metastasis and inflammation. [39]

\section{Thrombin generation and cancer}

Tumor cells cause thrombin generation via several pathways, such as directly activating the hemostatic system (production of procoagulant proteins, microparticles and fibrinolytic inhibitors), or indirectly by engaging procoagulant and proadhesive properties of the host vascular cells (i.e. platelets, leukocytes, endothelial cells.)[40] On the other hand, thrombin is the key coagulation enzyme that promotes angiogenesis and contributes significantly to a more malignant tumor phenotype. As shown in Figure 2, thrombin has been linked to several steps of tumor progression, i.e. it stimulates tumor-platelet adhesion, adhesion to endothelium, tumor implantation, tumor cell proliferation and metastasis. Thrombin is one of the most potent physiological activators of platelets, via the platelet protease-activated thrombin receptors (PAR-1 and PAR-4), leading to overexpression of glycoprotein IIb/IIIa, von Willebrand factor, Pselectin and fibronectin, found important in tumor cell-platelet interactions. Thrombin pre-treated platelets enhance tumor cell-platelet adhesion, inhibitable by agents known to interfere with the platelet glycoprotein IIb/IIIa integrin, von Willebrand factor and fibronectin.[33] The Karpatkin laboratory has also demonstrated enhanced adhesion of thrombin-treated melanoma cells to endothelial cells and subendothelial matrix, the first barrier to tumor invasion and metastasis.[41] Thrombin's mitogenic effect was first demonstrated in the 1970's on chick embryo fibroblasts.[42] Since then, many investigators demonstrated thrombin's mitogenic potential on fibroblasts, endothelial cells and smooth muscle cells. [43-45] Many studies have clearly showed that thrombin is a growth factor for different tumor cells, evidenced by in vitro and in vivo experiments. Ogiichi et al. showed that human glioma cells can generate thrombin 
and this thrombin generation induces glioma cell proliferation in vitro. [46] Furthermore, a recent study evidenced that osteosarcomas cells are capable to generate thrombin resulting in direct activation of cellular proliferation and thrombus formation in the microenvironment. Treatment with low molecular weight heparin reduced in vitro osteosarcoma proliferation and procoagulant activity as well as tumor growth in vivo.[47] The role of thrombin in tumor cell invasion has been demonstrated after incubation of thrombin and U2-OS osteosarcoma cells that resulted in migration of malignant cells through a Matrigel barrier.[48] Finally, the role of thrombin in tumor metastasis has been demonstrated in vivo when thrombin pre-treated colon carcinoma and melanoma cell lines showed dramatic increase in pulmonary metastasis. [49-50]

Figure 2. Thrombin-mediated tumor progression.
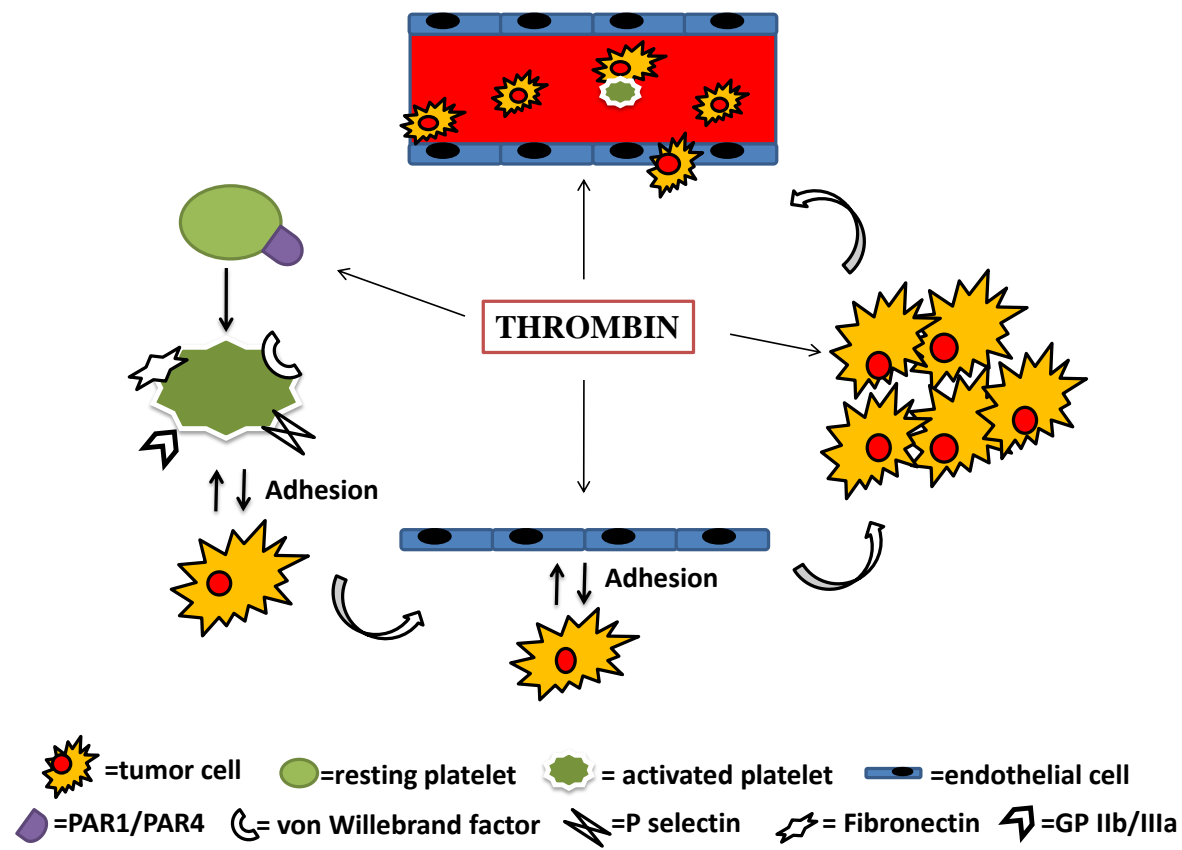

Activation of PARs, found on the surface of many tumor cell lines, by thrombin, is an important molecular mechanism linked to angiogenesis and tumor progression. Thrombin activation of PARs leads to upregulation of many angiogenesis-related genes, including VEGF, VEGF receptors, tissue factor, bFGF and metalloproteinase-2. A recent study showed that thrombin stimulates prostate tumor growth after PAR-1 activation.[51] Activation of PAR-1 was also shown to increase pulmonary metastasis in melanoma and colon carcinoma cell lines, to promote cell growth in NIH3T3 cells and cell invasion in breast cancer experimental model.[52-54] 
Knowledge gained from in vitro studies and in vivo animal models suggests that targeting thrombin could lead to a potential therapeutic benefit in cancer patients.

\section{Outline of the thesis}

Chapter 1 is the General Introduction to the work described in this thesis. It provides the background of the thrombotic complications associated to cancer, particularly to patients with ET and PV. These patients are at high risk for thrombosis affecting patients' mortality, morbidity and quality of life. The pathogenesis of this hemostatic imbalance is mostly related to both quantitative and qualitative abnormalities of circulating blood cells, specifically the increased leukocyte count, formation of platelet-leukocyte aggregates, platelet activation and microparticles shedding. The role of platelets in the pathogenesis of thrombosis in MPN patients is still under investigation. While a high platelet count is no major determinant of the risk of thrombosis, platelet qualitative abnormalities have been increasingly recognized as important contributors to hypercoagulability in these patients. Recently, the role of platelets beyond hemostasis has been implicated in cancer related processes like inflammation, angiogenesis and tumor growth and dissemination.

Tumor cells generate thrombin, the most potent physiological activator of platelets. Activated platelets generate thrombin on their surface, engage in platelet-tumor and platelet-tumor- endothelial cell interactions thus promoting the malignant process.

On the basis of this background it follows that identification of platelet prothrombotic potential, by measuring the platelet- associated thrombin generation, in MPN patients, can be considered an important determinant of a risk of thrombosis as well as a pathophysiologically relevant factor in the progression of malignant disease.

\section{Part one}

Chapter 2 is a review summarizing the prothrombotic mechanisms of tumor cells and their role in both coagulation and tumor progression. In particular, this chapter focuses on the capacity of tumor cells to promote activation of the coagulation system, and on the mechanisms by which clotting proteins may promote tumor growth and metastasis.

Chapter 3 is a review of the current recommendations for prevention and treatment of VTE in cancer patients. In addition, this review provides an insight into the new anticoagulant drugs potentially suitable for use in oncology. 


\section{Part two}

Chapter 4 is a study investigating the influence of in-vitro contact activation on in-vitro measurement of thrombin generation at low tissue factor concentrations using the new calibrated automated thrombinoscopy.

\section{Part three}

Chapter 5 presents the results of the first study demonstrating plateletdependent hypercoagulability in MPN patients, characterized by increased thrombin generation and tissue factor levels, particularly in those patients positive for the JAK2V617F mutation.

Chapter 6 Increased levels of circulating immature platelets have been associated with MPN, and other conditions at increased risk for thrombosis (i.e. acute coronary syndrome, cardioembolic stroke). We measured the immature platelet parameters using a new automated hematology analyser in a group of ET and PV patients and correlated the results to JAK2 V617F mutation and myelosuppressive treatment with hydroxyurea.

Chapter 7 Antiplatelet therapy with aspirin is now a standard regimen for prevention of thrombosis in low and high risk MPN patients. We performed a study in a group of ET and PV patients to monitor the effects of aspirin on plateletmediated hemostatic and procoagulant activity by measuring platelet adhesive and procoagulant function using platelet function analyser -100 and thrombin generation assay, respectively.

Chapter 8 Since platelet adhesion and aggregation in vivo is influenced by a number of different agonists that act on pathways that are not all blocked by thromboxane inhibition, in this study we investigated adenosine diphosphate induced platelet aggregation and platelet associated thrombin generation in a group of ET and PV patients.

Chapter 9 Cytoreductive therapy with hydroxyurea is a recommended approach in high risk ET and PV patients in order to minimize their risk of thrombosis. In this study we evaluated the effect of hydroxyurea therapy on plasma levels of nitric oxide derivatives and soluble selectins of platelet, endothelial cell and leukocyte origin in a group of ET and PV patients.

Finally, in Chapter 10 the principal findings of this thesis and relevance into understanding the pathogenesis of thrombotic complications in ET and PV are discussed in relation to literature. 


\section{References}

1 Yach D, Hawkes C, Gould CL, Hofman KJ. The global burden of chronic diseases: overcoming impediments to prevention and control. Jama. 2004; 291: 2616-22. 10.1001/jama.291.21.2616 291/21/2616 [pii].

2 Sorensen HT, Mellemkjaer L, Olsen JH, Baron JA. Prognosis of cancers associated with venous thromboembolism. The New England journal of medicine. 2000; 343: 1846-50.

3 Khorana AA, Francis CW, Culakova E, Kuderer NM, Lyman GH. Thromboembolism is a leading cause of death in cancer patients receiving outpatient chemotherapy. J Thromb Haemost. 2007; 5: 632-4. JTH2374 [pii]

10.1111/j.1538-7836.2007.02374.x.

4 Blom JW, Doggen CJ, Osanto S, Rosendaal FR. Malignancies, prothrombotic mutations, and the risk of venous thrombosis. Jama. 2005; 293: 715-22.

5 Buller HR, van Doormaal FF, van Sluis GL, Kamphuisen PW. Cancer and thrombosis: from molecular mechanisms to clinical presentations. J Thromb Haemost. 2007; 5 Suppl 1: 246-54.

6 Murchison JT, Wylie L, Stockton DL. Excess risk of cancer in patients with primary venous thromboembolism: a national, population-based cohort study. Br J Cancer. 2004; 91: 92-5. 10.1038/sj.bjc.6601964 6601964 [pii].

$7 \quad$ Sorensen HT, Mellemkjaer L, Steffensen FH, Olsen JH, Nielsen GL. The risk of a diagnosis of cancer after primary deep venous thrombosis or pulmonary embolism. The New England journal of medicine. 1998; 338: 1169-73. 10.1056/NEJM199804233381701.

8 Khorana AA, Francis CW, Culakova E, Kuderer NM, Lyman GH. Frequency, risk factors, and trends for venous thromboembolism among hospitalized cancer patients. Cancer. 2007; 110: 2339-46.

9 Khorana AA, Francis CW, Culakova E, Fisher RI, Kuderer NM, Lyman GH. Thromboembolism in hospitalized neutropenic cancer patients. J Clin Oncol. 2006; 24: 484-90. 24/3/484 [pii] 10.1200/JCO.2005.03.8877.

10 Blom JW, Vanderschoot JP, Oostindier MJ, Osanto S, van der Meer FJ, Rosendaal FR. Incidence of venous thrombosis in a large cohort of 66,329 cancer patients: results of a record linkage study. J Thromb Haemost. 2006; 4: 529-35.

11 Falanga A. The incidence and risk of venous thromboembolism associated with cancer and nonsurgical cancer treatment. Cancer investigation. 2009; 27: 105-15.

12 Khorana AA, Kuderer NM, Culakova E, Lyman GH, Francis CW. Development and validation of a predictive model for chemotherapy-associated thrombosis. Blood, 2008, 4902-7.

13 Lyman GH, Khorana AA, Falanga A, Clarke-Pearson D, Flowers C, Jahanzeb M, Kakkar A, Kuderer NM, Levine MN, Liebman H, Mendelson D, Raskob G, Somerfield MR, Thodiyil P, Trent D, Francis CW. American Society of Clinical Oncology guideline: recommendations for venous thromboembolism prophylaxis and treatment in patients with cancer. J Clin Oncol. 2007; 25: 5490505 .

14 Panova-Noeva M, Falanga A. Treatment of thromboembolism in cancer patients. Expert Opin Pharmacother. 2010; 11: 2049-58. 10.1517/14656566.2010.494181.

15 Levine RL, Gilliland DG. Myeloproliferative disorders. Blood. 2008; 112: 2190-8. $112 / 6 / 2190$ [pii]

10.1182/blood-2008-03-077966.

16 Tefferi A, Thiele J, Orazi A, Kvasnicka HM, Barbui T, Hanson CA, Barosi G, Verstovsek S, Birgegard G, Mesa R, Reilly JT, Gisslinger H, Vannucchi AM, Cervantes F, Finazzi G, Hoffman R, Gilliland DG, Bloomfield CD, Vardiman JW. Proposals and rationale for revision of the World Health Organization diagnostic criteria for polycythemia vera, essential thrombocythemia, and primary myelofibrosis: recommendations from an ad hoc international expert panel. Blood. 2007; 110: 1092-7.

17 Marchioli R, Finazzi G, Landolfi R, Kutti J, Gisslinger H, Patrono C, Marilus R, Villegas A, Tognoni G, Barbui T. Vascular and neoplastic risk in a large cohort of patients with polycythemia vera. J Clin Oncol. 2005; 23: 2224-32. JC0.2005.07.062 [pii] 10.1200/JC0.2005.07.062. 
18 Elliott MA, Tefferi A. Thrombosis and haemorrhage in polycythaemia vera and essential thrombocythaemia. British journal of haematology. 2005; 128: 275-90.

19 Kiladjian JJ, Cervantes F, Leebeek FW, Marzac C, Cassinat B, Chevret S, Cazals-Hatem D, Plessier A, Garcia-Pagan JC, Darwish Murad S, Raffa S, Janssen HL, Gardin C, Cereja S, Tonetti C, Giraudier S, Condat B, Casadevall N, Fenaux P, Valla DC. The impact of JAK2 and MPL mutations on diagnosis and prognosis of splanchnic vein thrombosis: a report on 241 cases. Blood. 2008; 111: 4922-9. blood-2007-11-125328 [pii]

10.1182/blood-2007-11-125328.

20 Perea G, Remacha A, Besses C, Jimenez M, Florensa L, Cervantes F. Is polycythemia vera a serious disease in young adults? Haematologica. 2001; 86: 543-4.

21 Michiels JJ, Berneman Z, Schroyens W, Koudstaal PJ, Lindemans J, van Vliet HH. Plateletmediated thrombotic complications in patients with ET: Reversal by aspirin, platelet reduction, and not by coumadin. Blood cells, molecules \& diseases. 2006; 36: 199-205. S1079-9796(06)00027-1 [pii] 10.1016/j.bcmd.2005.12.021.

22 Carobbio A, Finazzi G, Guerini V, Spinelli O, Delaini F, Marchioli R, Borrelli G, Rambaldi A, Barbui T. Leukocytosis is a risk factor for thrombosis in essential thrombocythemia: interaction with treatment, standard risk factors, and Jak2 mutation status. Blood. 2007; 109: 2310-3.

23 Landolfi R, Di Gennaro L, Barbui T, De Stefano V, Finazzi G, Marfisi R, Tognoni G, Marchioli R. Leukocytosis as a major thrombotic risk factor in patients with polycythemia vera. Blood. 2007; 109: 2446-52.

24 Austin SK, Lambert JR. The JAK2 V617F mutation and thrombosis. British journal of haematology. 2008; 143: 307-20.

25 Carobbio A, Thiele J, Passamonti F, Rumi E, Ruggeri M, Rodeghiero F, Randi ML, Bertozzi I, Vannucchi AM, Antonioli E, Gisslinger H, Buxhofer-Ausch V, Finazzi G, Gangat N, Tefferi A, Barbui T. Risk factors for arterial and venous thrombosis in WHO-defined essential thrombocythemia: an international study of 891 patients. Blood. 2011. blood-2011-02-339002 [pii] 10.1182/blood-2011-02-339002.

26 Griesshammer M, Beneke H, Nussbaumer B, Grunewald M, Bangerter M, Bergmann L. Increased platelet surface expression of P-selectin and thrombospondin as markers of platelet activation in essential thrombocythaemia. Thrombosis research. 1999; 96: 191-6. S00493848(99)00095-X [pii].

27 Jensen MK, de Nully Brown P, Lund BV, Nielsen OJ, Hasselbalch HC. Increased platelet activation and abnormal membrane glycoprotein content and redistribution in myeloproliferative disorders. British journal of haematology. 2000; 110: 116-24. bjh2030 [pii].

28 Villmow T, Kemkes-Matthes B, Matzdorff AC. Markers of platelet activation and plateletleukocyte interaction in patients with myeloproliferative syndromes. Thrombosis research. 2002; 108: 139-45. S0049384802003547 [pii].

29 Tefferi A. Annual Clinical Updates in Hematological Malignancies: A Continuing Medical Education Series: Polycythemia vera and essential thrombocythemia: 2011 update on diagnosis, risk-stratification, and management. American journal of hematology. 2011; 86: 292-301. 10.1002/ajh.21946.

30 Karpatkin S, Pearlstein E, Ambrogio C, Coller BS. Role of adhesive proteins in platelet tumor interaction in vitro and metastasis formation in vivo. The Journal of clinical investigation. 1988; 81: 1012-9. 10.1172/JCI113411.

31 Borsig L, Wong R, Feramisco J, Nadeau DR, Varki NM, Varki A. Heparin and cancer revisited: mechanistic connections involving platelets, P-selectin, carcinoma mucins, and tumor metastasis. Proceedings of the National Academy of Sciences of the United States of America. 2001; 98: 3352-7. 10.1073/pnas.061615598

98/6/3352 [pii].

32 Heemskerk JW, Bevers EM, Lindhout T. Platelet activation and blood coagulation. Thrombosis and haemostasis. 2002; 88: 186-93.

33 Nierodzik ML, Klepfish A, Karpatkin S. Role of platelets, thrombin, integrin IIb-IIIa, fibronectin and von Willebrand factor on tumor adhesion in vitro and metastasis in vivo. Thrombosis and haemostasis. 1995; 74: 282-90.

$34 \quad$ Wojtukiewicz MZ, Sierko E, Rak J. Contribution of the hemostatic system to angiogenesis in cancer. Seminars in thrombosis and hemostasis. 2004; 30: 5-20. 10.1055/s-2004-822967.

35 Felding-Habermann B. Tumor cell-platelet interaction in metastatic disease. Haemostasis. 2001; 31 Suppl 1: 55-8. 


\section{CHAPTER I}

36 Nieswandt B, Hafner M, Echtenacher B, Mannel DN. Lysis of tumor cells by natural killer cells in mice is impeded by platelets. Cancer research. 1999; 59: 1295-300.

37 Mohle R, Green D, Moore MA, Nachman RL, Rafii S. Constitutive production and thrombin-induced release of vascular endothelial growth factor by human megakaryocytes and platelets. Proceedings of the National Academy of Sciences of the United States of America. 1997; 94: 663-8.

38 Falati S, Liu Q, Gross P, Merrill-Skoloff G, Chou J, Vandendries E, Celi A, Croce K, Furie BC, Furie B. Accumulation of tissue factor into developing thrombi in vivo is dependent upon microparticle P-selectin glycoprotein ligand 1 and platelet P-selectin. The Journal of experimental medicine. 2003; 197: 1585-98. 10.1084/jem.20021868

jem.20021868 [pii].

39 Kozlowski EO, Pavao MS, Borsig L. Ascidian dermatan sulfates attenuate metastasis, inflammation and thrombosis by inhibition of P-selectin. J Thromb Haemost. 2011; 9: 1807-15. 10.1111/j.1538-7836.2011.04401.x.

40 Rickles FR, Falanga A. Molecular basis for the relationship between thrombosis and cancer. Thrombosis research. 2001; 102: V215-24. S0049-3848(01)00285-7 [pii].

41 Klepfish A, Greco MA, Karpatkin S. Thrombin stimulates melanoma tumor-cell binding to endothelial cells and subendothelial matrix. Int J Cancer. 1993; 53: 978-82.

42 Chen LB, Buchanan JM. Mitogenic activity of blood components. I. Thrombin and prothrombin. Proceedings of the National Academy of Sciences of the United States of America. 1975; 72: $131-5$.

43 Glenn KC, Carney DH, Fenton JW, 2nd, Cunningham DD. Thrombin active site regions required for fibroblast receptor binding and initiation of cell division. The Journal of biological chemistry. 1980; 255: 6609-16.

44 Gospodarowicz D, Brown KD, Birdwell CR, Zetter BR. Control of proliferation of human vascular endothelial cells. Characterization of the response of human umbilical vein endothelial cells to fibroblast growth factor, epidermal growth factor, and thrombin. J Cell Biol. 1978; 77: 77488.

45 Morris DL, Ward JB, Jr., Nechay P, Whorton EB, Jr., Fenton JW, 2nd, Carney DH. Highly purified human alpha-thrombin promotes morphological transformation of BALB/c 3T3 cells. Carcinogenesis. 1992; 13: 1-7.

46 Ogiichi T, Hirashima Y, Nakamura S, Endo S, Kurimoto M, Takaku A. Tissue factor and cancer procoagulant expressed by glioma cells participate in their thrombin-mediated proliferation. J Neurooncol. 2000; 46: 1-9.

47 Ichikawa J, Cole HA, Magnussen RA, Mignemi NA, Butler M, Holt GE, O'Rear L, Yuasa M, Pabla B, Haro H, Cates JM, Hamm HE, Schwartz HS, Schoenecker JG. Thrombin induces osteosarcoma growth, a function inhibited by low molecular weight heparin in vitro and in vivo: Procoagulant nature of osteosarcoma. Cancer. 2011.10.1002/cncr.26518.

48 Radjabi AR, Sawada K, Jagadeeswaran S, Eichbichler A, Kenny HA, Montag A, Bruno K, Lengyel E. Thrombin induces tumor invasion through the induction and association of matrix metalloproteinase- 9 and beta1-integrin on the cell surface. The Journal of biological chemistry. 2008; 283: 2822-34. M704855200 [pii]

10.1074/jbc.M704855200.

49 Nierodzik ML, Plotkin A, Kajumo F, Karpatkin S. Thrombin stimulates tumor-platelet adhesion in vitro and metastasis in vivo. The Journal of clinical investigation. 1991; 87: 229-36. 10.1172/JCI114976.

50 Nierodzik ML, Kajumo F, Karpatkin S. Effect of thrombin treatment of tumor cells on adhesion of tumor cells to platelets in vitro and tumor metastasis in vivo. Cancer research. 1992; 52: 3267-72.

51 Hu L, Ibrahim S, Liu C, Skaar J, Pagano M, Karpatkin S. Thrombin induces tumor cell cycle activation and spontaneous growth by down-regulation of p27Kip1, in association with the upregulation of Skp2 and MiR-222. Cancer research. 2009; 69: 3374-81. 0008-5472.CAN-08-4290 [pii] 10.1158/0008-5472.CAN-08-4290.

52 Nierodzik ML, Bain RM, Liu LX, Shivji M, Takeshita K, Karpatkin S. Presence of the seven transmembrane thrombin receptor on human tumour cells: effect of activation on tumour adhesion to platelets and tumor tyrosine phosphorylation. British journal of haematology. 1996; 92: 452-7. 
53 Martin CB, Mahon GM, Klinger MB, Kay RJ, Symons M, Der CJ, Whitehead IP. The thrombin receptor, PAR-1, causes transformation by activation of Rho-mediated signaling pathways. Oncogene. 2001; 20: 1953-63. 10.1038/sj.onc.1204281.

$54 \quad$ Even-Ram SC, Maoz M, Pokroy E, Reich R, Katz BZ, Gutwein P, Altevogt P, Bar-Shavit R. Tumor cell invasion is promoted by activation of protease activated receptor-1 in cooperation with the alpha vbeta 5 integrin. The Journal of biological chemistry. 2001; 276: 10952-62. $10.1074 /$ jbc.M007027200

M007027200 [pii]. 


\section{CHAPTER 2}

\section{Procoagulant mechanisms in tumour cells}

Anna Falanga, Marina Panova-Noeva, Laura Russo

Best Practice \& Research Clinical Haematology. 2009;22(1):49-60. Review. 


\section{Abstract}

Pathogenesis of the prothrombotic state of cancer patients is due, at least in part, to the ability of cancer cells to activate the coagulation system. Several complex and not fully recognized interactions between the malignant cell and the clotting system promote a shift in the haemostatic balance compared with a procoagulant state. Tumour cells possess the capacity to interact with the haemostatic system in multiple ways. The principal mechanisms include the expression of haemostatic proteins by tumour cells, the production of inflammatory cytokines by tumour and/or host cells, and the direct adhesion of tumour cells to normal cells, including platelets, endothelial cells and monocytes. This chapter will summarize the prothrombotic mechanisms of tumour cells and their role in both coagulation and tumour progression. In particular, this chapter will focus on the capacity of tumour cells to promote activation of the coagulation system, and on the mechanisms by which clotting proteins may promote tumour growth and metastasis. 


\section{Introduction}

Patients with malignancy have an acquired thrombophilic condition and are at high risk of venous thromboembolism (VTE) [1]. The prothrombotic state of these patients is due to complex and not fully recognized interactions between cancer and the haemostatic system that promote a shift in the balance of procoagulant activities over anticoagulant activities. Recent advances in biochemistry, cell biology and molecular biology have helped to provide a better understanding of these interactions [2]. As shown in Fig. 1, the principal prothrombotic mechanisms associated with cancer cells are: the expression of haemostatic proteins, including procoagulant, and antifibrinolytic activities; the production of inflammatory cytokines by tumour and/or host cells with subsequent activation of vascular cells; and the direct adhesion of tumour cells to normal cells, including platelets, endothelial cells (ECs) and monocytes [1]. On the other hand, tumour growth, neoangiogenesis and tumour dissemination appear to be influenced by tumour-associated coagulation activation and feedback on the coagulation cascade, further enhancing thrombogenesis [3].

The impact of biological factors on the risk of thrombosis in patients with cancer is still largely unknown. Differently the contribution of several clinical risk factors (i.e. surgery, chemotherapy, hormonal therapy and erythropoiesisstimulating agents) is better characterized [4]. Recent data show that the primary site of cancer, prechemotherapy platelet count $>350 \times 10^{9} / \mathrm{L}$, erythropoietin administration, leukocytosis and high body mass index are independent risk factors for VTE [5]. Furthermore, a high level of plasma-soluble P-selectin were also found to be an independent predictive parameter for the development of VTE [6].

Clearly the pathogenesis of thrombosis in cancer is unique in that the tumour tissues per se activate blood coagulation, and mechanisms that are involved in the malignant transformation may also be involved in the regulation of tumour cell procoagulant factors. In human malignancies this appears to be true for the JAK2V617F mutation expression in patients with myeloproliferative disorders [7], and for PML-RAR $\alpha$ hybrid gene expression in patients with acute promyelocytic leukaemia (APL) [8]. In both cases, the genetic lesion is associated with expression of a prothrombotic phenotype. This chapter provides an overview of the prothrombotic properties of tumour cells and their role in coagulation and tumour progression. In particular, the chapter will focus on the capacity of tumour cells to promote activation of the clotting system, and on the mechanisms by which clotting proteins may promote tumour growth and metastasis. Finally, the inhibition of coagulation as a bifunctional tool to control both thrombosis and malignancy will be explored. 
Fig. 1. Tumour cell mechanisms of blood clotting activation. Cancer cells can activate the haemostatic system through the production of haemostatic factors (i.e. procoagulant proteins, microparticles and fibrinolysis inhibitors), the release of inflammatory cytokines and the expression of adhesion molecules.

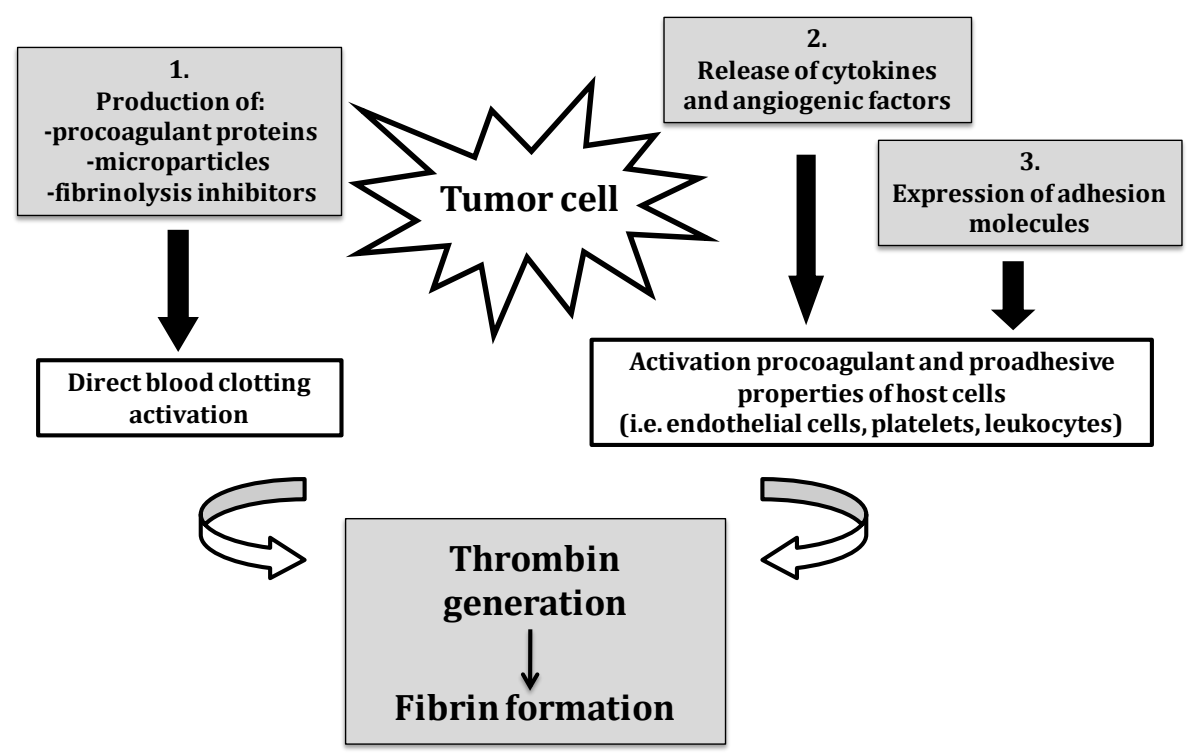

\section{Mechanisms by which tumour cells activate the coagulation system}

The principal mechanisms by which tumour cells activate blood coagulation involve the production of haemostatic factors, the release of inflammatory cytokines and the expression of adhesion receptors (Fig. 1).

\section{Haemostatic factors}

Tumour cells can express haemostatic factors including: procoagulant proteins, such as tissue factor (TF) and cancer procoagulant (CP); microparticles (MPs); and fibrinolysis proteins.

\section{Procoagulant proteins}

$\mathrm{TF}$ is a transmembrane glycoprotein that is the primary initiator of normal blood coagulation. TF forms a complex with factor VIIa (TF/FVIIa) to trigger blood coagulation by proteolytically activating factor IX and factor X. Normal cells, including ECs and monocyte-macrophages, do not express TF unless they are adequately stimulated [9]. In normal conditions, TF is very low in the circulation of normal subjects. However, constitutive TF expression characterizes 
numerous malignant tumour tissues. In addition, TF expression can be induced on tumour-associated macrophages and ECs either by inflammatory endogenous agonists, i.e. tumour necrosis factor alpha (TNF-a) and interleukin (IL)-1b, or by exogenous agonists, i.e. bacterial lipopolysaccharide or tumour-specific antigens. In breast cancer, the expression of $\mathrm{TF}$ in tumour stroma correlates with progression to invasive cancer. Similarly, the expression of TF by glioma cell lines and glioma surgical specimens correlates with the histological grade of malignancy. In some instances, the expression of TF in the primary tumour correlates with circulating $\mathrm{TF}$ antigen, suggesting that $\mathrm{TF}$ released by tumour cells contributes to an increased concentration of circulating TF [10].

$\mathrm{CP}$ is a cysteine protease that activates factor $\mathrm{X}$ directly in the absence of activated factor VII. CP is synthesized by malignant cells, and its activity has been found in extracts of different tumours [11-13]. The presence of CP antigen and CP procoagulant activity (PCA) has been identified in the sera of cancer patients. Although CP is found almost exclusively in malignant cells, its role as a tumour marker or as a factor predictive of clinical thrombosis has not been demonstrated successfully. Of interest, in APL blasts, CP expression parallels the degree of malignant transformation and is lost upon cellular differentiation by therapy with all-trans-retinoic acid (ATRA). In contrast, cells resistant to ATRA maintain their malignant phenotype and CP expression [14]. Similar observations have been reported for breast cancer [15].

\section{Microparticles}

MPs are small membrane vesicles released from cells following activation or apoptosis. MPs released by tumour cells have been associated with the hypercoagulable state of cancer. The first demonstration of tumour-shed vesicles with procoagulant activity was by Dvorak et al in 1981 [16]; they showed that a mouse breast carcinoma cell line and a guinea pig hepatocarcinoma cell linewere able to release PCA in tissue culture and in vivo. This PCAwas associated with small vesicles shed by the tumour cell surface. More recently, circulating MPs have been described in plasma of patients with various tumours such as pancreas and breast adenocarcinoma, giant cell lung carcinoma, colorectal cancer and acute leukaemias [17-19]. MPs seem to contribute to intravascular thrombin generation by exposure of phosphatidilserine and procoagulant proteins such as TF [20], and may explain the increased level of TF in the circulation of cancer patients. As shown recently by Hron et al [21], patients with colorectal cancer had two-fold higher TF-positive MPs compared with controls, and the MP levels correlated positively with the D-dimer level as a marker of clotting activation. In another study, elevated MP-associated TF activity was significantly related to the development of VTE in patients with disseminated mucinous carcinoma [17]. Further research is ongoing to demonstrate that MPs derived from tumour cells may bear active TF and can be considered as a biomarker of increased thrombotic risk [9]. 


\section{Fibrinolysis proteins}

All fibrinolytic system molecules that are important in the maintenance of proper haemostasis are expressed on the surface of tumour cells. They possess both urokinase-type plasminogen activator (u-PA) and tissue-type plasminogen activator, and can also produce plasminogen activator inhibitors 1 and 2 (PAI-1 and PAI-2). There are specific receptors on tumour cells that support the assembly of all the fibrinolytic components (i.e. u-PAR), thus facilitating activation of the fibrinolytic cascade [22]. In patients with leukaemia, the expression of these activities by blast cells may play a role in the pathogenesis of bleeding symptoms. On the other hand, a defect in the generation of normal plasma fibrinolytic activity due to increased production of the fibrinolysis inhibitor PAI1 has been found in patients with solid tumours, and may represent another mechanism for the tendency of these patients to develop VTE [1]. Fibrinolytic proteins are under evaluation as potentially valuable predictors of disease-free interval and long-term survival in malignant disease. Breast cancer patients with low levels of u-PA and PAI-1 have significantly better survival than patients with high levels of either factor, particularly in node-negative breast cancer [23].

Fibrinolysis is also a key component in tumour biology. It is essential for the release of tumour cells from their primary site, and has numerous functions in promoting cell mobility and motility, and facilitating tumour neoangiogenesis [24].

\section{Inflammatory cytokines}

Tumour cells synthesize and release a variety of cytokines including proinflammatory (i.e. TNF-a, IL-1b) and pro-angiogenic factors [i.e. vascular endothelial growth factor (VEGF), basic fibroblast growth factor (bFGF)]. Cytokine overproduction also derives from normal inflammatory tissues as part of the reactive process of the host in response to the tumour insult. Most of these cytokines activate and induce the expression of a procoagulant phenotype by normal monocytes and ECs.

Monocyte activation has been described to occur in malignancy both in vitro and in vivo. Indeed, tumour-associated macrophages harvested from experimental and human tumours express significantly more TF than control cells. In addition, circulating monocytes from patients with different types of cancer express increased TF activity. The generation of PCA by monocytemacrophages in vivo is probably one mechanism for clotting activation in malignancy [1].

Cytokines stimulate ECs to increase production of the fibrinolysis inhibitor PAI1. In addition, they upregulate $\mathrm{EC}$ surface $\mathrm{TF}$ expression and downregulate thrombomodulin (TM) expression $[25,26]$. TM is a membrane receptor of vascular ECs with a potent anticoagulant function [26]. It binds and forms a com- 
plex with thrombin to activate the natural anticoagulant protein C. Upregulation of the procoagulant $\mathrm{TF}$ with downregulation of the anticoagulant $\mathrm{TM} /$ protein $\mathrm{C}$ system converts the normal anticoagulant endothelium into a prothrombotic endothelium.

\section{Adhesion molecules}

The expression of tumour cell surface adhesion molecules and/or their counter receptors permits direct interaction of these cells with host cells, including ECs, platelets and leukocytes. The attachment of tumour cells to vascular ECs is relevant to promote localized clotting activation to the vessel wall and to start thrombus formation. The adhesion can occur directly or via the cooperation of granulocytes. The interaction between tumour cells and ECs is mediated by different pathways of adhesion molecules expressed by different types of tumour [27]. In flow conditions, the interaction involves rolling and firm adhesion, depending on the respective adhesive properties of both ECs and tumour cells. Some tumour cell types roll and adhere using E-selectin molecules, while others adhere without rolling using vascular cell adhesion molecule-1 (VCAM-1) receptors [28]. Thus, various molecules expressed on ECs, including selectins, integrins and immunoglobulins, are necessary for the adhesion of cancer cells and their migration to distant sites to form metastases. P-selectin (CD62P) is an important cell adhesion molecule expressed by stimulated ECs and activated platelets. It mediates heterotypic aggregation of activated platelets to cancer cells, and the adhesion of cancer cells to stimulated ECs. In addition, P-selectin mediates the homotypic aggregation of activated platelets and the transfer of procoagulant MPs between cells, which further contributes to fibrin deposition and microthrombi formation [29].

Tumour cells also induce platelet activation and aggregation by the release of soluble factors, such as ADP and a cysteine proteinase, or by thrombin generated via activation of the coagulation cascade [1]. These phenomena lead to increased exposure of adhesion molecules on the platelet surface, including platelet glycoprotein (GP) IIb/IIIa, fibronectin and von Willebrand factor (vWF), which are required for the adhesion of tumour cells to platelets [30,31]. Thrombin activates and enhances exposure of GPIIb/IIIa on both the platelet membrane and the tumour surface, and stimulates the expression of platelet fibronectin and vWF, which further anchor platelets to tumour cells. Thrombin increases tumour cell/platelet adhesion in vitro and metastasis formation in vivo [32].

In recent years, at least three molecular mechanisms mediating tumour cell/platelet adhesion have been well characterized. The first mechanism is based on the binding of platelet integrin $\alpha \mathrm{IIb} / \beta 3$ to the tumour cell integrin $\alpha \mathrm{V} / \beta 3[33,34]$. Another mechanism involves platelet P-selectin binding to glycoprotein s-Le(x) on mucin-producing carcinomas [35,36], or to sulphatides on the plasma membranes of granulocytes and tumour cells [37]. The third me- 
chanism identifies the central role of the platelet adhesion receptor GPIb $\alpha$ in promoting tumour metastasis [38].

\section{Role of the coagulation system in tumour progression}

Tumour growth and formation of metastases involve a multistep cascade of events by which cancer cells proliferate, detach from the primary site, and migrate to establish new colonies in distant sites. Tumour growth is largely due to the capacity of cancer cells to promote the process of neoangiogenesis by secreting angiogenic factors (i.e. VEGF and bFGF). The formation of new vessels is essential for the provision of nutrients to the malignant tissues [39]. The metastatic process involves adhesion of bloodborne malignant cells to the vascular ECs, degradation of the surrounding extracellular matrix (ECM), extravasation into the blood stream, and finally migration and proliferation to a secondary site.

Procoagulant proteins such as $\mathrm{TF}$, activated factor $\mathrm{X}$ (FXa), thrombin and fibrin have the capacity to support the malignant process by promoting neoangiogenesis and formation of metastases (Fig. 2). Cellular components of haemostasis, i.e. platelets and leukocytes, also contribute to these processes.

Fig. 2. Coagulation protein in tumour biology. Procoagulant proteins induce tumour growth, neoangiogenesis, tumour cell invasionand metastasis.

\begin{tabular}{|l|}
\hline Tissue Factor/FVIIa \\
Factor Xa \\
Thrombin \\
Fibrin \\
\hline
\end{tabular}

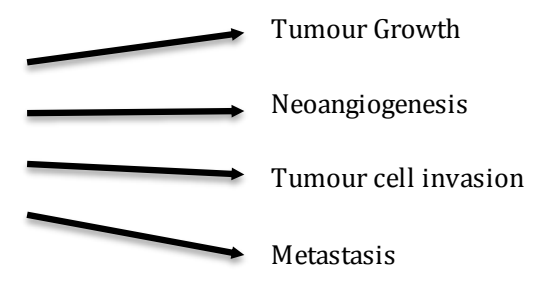

\section{Coagulation and neoangiogenesis}

In addition to their primary role in haemostasis and blood coagulation, haemostatic proteins play several roles in tumour neoangiogenesis.

TF induces angiogenesis via clotting-dependent mechanisms by downstream generation of thrombin and fibrin, and by thrombin-induced platelet activation. In addition, formed fibrin induces upregulation of TF on tumour cells and ECs, and secretion of the pro-angiogenic factor IL-8, thus generating a vicious circle of clot formation and tumour growth [40].

The function of TF in tumour angiogenesis can also be mediated through mechanisms independent of thrombin generation and fibrin deposition. These mechanisms are induced via phosphorylation of the TF cytoplasmic tail and subsequent signal transduction cascades. In the protease-receptor pathway, the TF/FVIIa complex activates one or more protease-activated receptors (PARs), 
which couple to $\mathrm{G}$ proteins to impact multiple signalling pathways. Recent research provided evidence that TF/VIIa targets PAR-2 to support angiogenesis in vivo [41]. TF can also promote increased expression of the angiogenic factor VEGF and decreased expression of the anti-angiogenic peptide thrombospondin.

FXa also exerts cell-signal-inducing effects independent of downstream activated coagulation proteases. Most of these signals originate via a number of different receptors, including effector protease receptor-1 (EPR-1). The binding of FXa to EPR-1 results in the proteolytic cleavage of PAR-2 and subsequent intracellular calcium signalling. PAR-1 has also been identified as a candidate receptor for the cellular effects of FXa. Both FXa and thrombin can induce expression of the angiogenesis promoting gene Cyr61 and connective tissue growth factor (CTGF). Cyr61 and CTGF are immediate early response genes and belong to a novel class of the cysteine rich secreted protein family involved in a wide array of important biological processes including angiogenesis, wound healing, fibrosis and atherosclerosis [42].

Thrombin is an effective activator of angiogenesis via clotting-dependent mechanisms involving platelet activation and fibrin deposition. Furthermore, thrombin induces angiogenesis through clotting- independent mechanisms mediated by PAR activation and resulting signal transduction cascades (Fig. 3). Thrombin activation of PARs leads to upregulation of many angiogenesisrelated genes, including VEGF, vascular endothelial growth factor receptors (VEGFR), TF, bFGF and metalloproteinase-2. In addition, thrombin stimulates the release of VEGF and angiopoietin from platelets, which induce tube formation from ECs.

Finally, fibrin formation plays an important role in thrombogenesis as well as in tumour progression. Fibrin deposited within the vascular endothelium of new tumour vessels, or attached around inflammatory cells or tumour cells, is suggested to facilitate angiogenesis. Local deposition of fibrin can stabilize the adhesion of tumour cells or tumour-cell-associated emboli to the endothelium, particularly in a high shear stress environment. In addition, the fibrin matrix provides an excellent scaffold for the formation of new vessels [43]. Fibrin also induces EC expression of TF and the pro-angiogenic cytokine IL-8. The fibrin matrix protects the pro-angiogenic growth factors bFGF, VEGF and insulin-like growth factor-1 from proteolytic degradation [3]. Of note, fibrin degradation products also contribute to tumour progression by expressing angiogenic, chemo-attractant and immunomodulatory properties [43]. Finally, activated platelets support the angiogenic process by releasing VEGF and platelet-derived growth factor [44]. Activated platelets can also release phospholipids, which enhance the chemoattractant activity and pro-angiogenic features of ECs, thus providing another link between haemostasis and angiogenesis [45]. 
Figure 3. Thrombin is an effective activator of angiogenesis and tumour invasion and metastasis via both clotting-dependent (involving platelet activation and fibrin deposition) and clotting independent mechanisms [mediated by protease activated receptor (PAR) activation and upregulation of angiogenesis-related genes]. EC, endothelial cell.

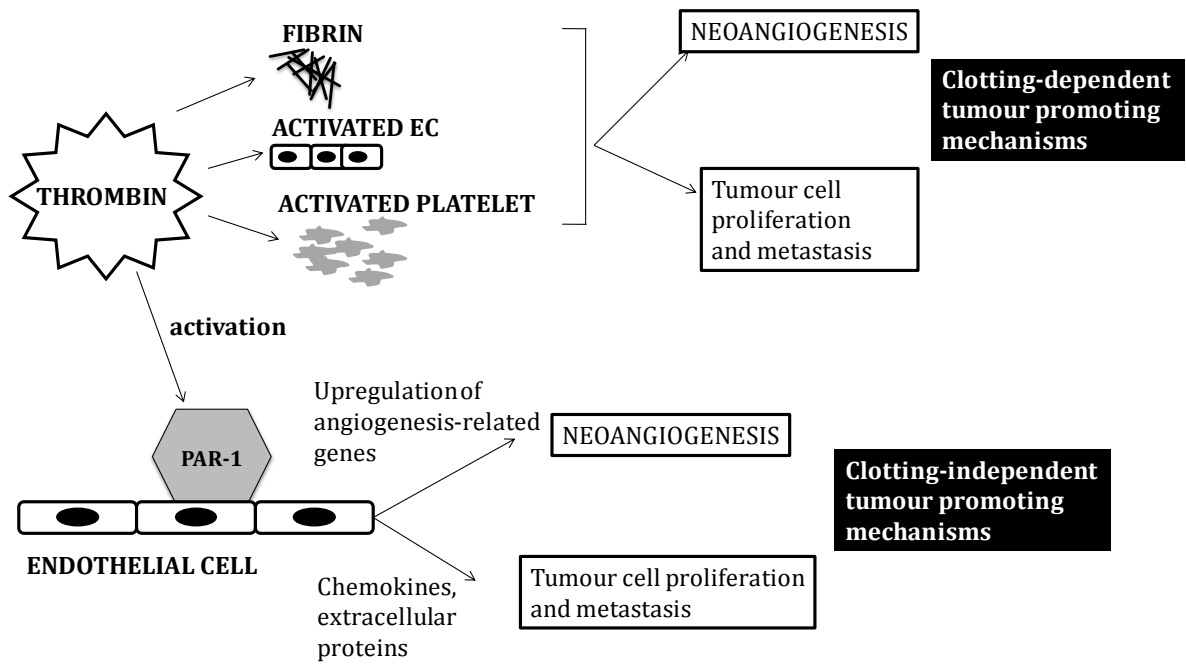

\section{Coagulation and tumour invasion and metastasis}

There is substantial evidence for the role of procoagulant proteins (i.e. TF and thrombin), and circulating platelets and leukocytes in tumour invasion and metastasis.

Mechanisms associated with TF include: the capacity of the TF/VIIa-Xa complex to promote local thrombin generation with subsequent proteolytic activation of platelet and endothelial PARs and fibrin deposition; the capacity of the tumourassociated TF/VIIa-Xa to activate PAR-1 and PAR-2 signaling pathways directly; and the capacity of the TF/FVIIa complex to cooperate with TF pathway inhibitor expressed by tumour vessels in inducing cell adhesion and migration by a thrombin-independent circle. However, the finding that genetic defects in platelets and fibrinogen, as key thrombin targets, significantly reduce the metastatic potential of TF-expressing cells, suggests that the TF-related metastatic potential is mainly directed through thrombin generation and thrombin-mediated proteolysis [46].

Thrombin contributes significantly to a more malignant phenotype by inducing platelet/tumour aggregation, tumour adhesion to ECs and the ECM, and tumour cell proliferation and metastases. Important in this setting is the capacity of thrombin to trigger the release of growth factors, chemokines and extracellular proteins that promote the proliferation and migration of tumour cells (Fig. 3). The prometastatic activity of thrombin is demonstrated by experimental pul- 
monary metastasis models, in which lung metastasis is increased by thrombintreated tumour cells compared with untreated tumour cells [47-49]. Activation of PAR-1 by thrombin stimulates chemokines of melanoma and prostate tumour cells [50]. Additionally, overexpression of PAR-1 in B16 malignant melanoma cells leads to a five-fold increase in experimental pulmonary metastasis [32]. A strong correlation also exists between elevated PAR expression and invasive potential in a model of breast cancer cells [51]. PAR-1 expression confers invasive properties to non-invasive cancer cells, and, conversely, knockdown of PAR-1 blunts invasive properties of aggressive cell lines [51,52]. Furthermore, thrombin-mediated activation of PAR-1 produces direct or indirect activities that stimulate cellular proliferation [3].

An important role in the steps of tumour invasion and metastasis is played by cellular components such as platelets and leukocytes.

The role of thrombin-activated platelets is shown by murine models, in which the elimination of circulating platelets results in a significant reduction in the formation of tumour metastases. Indeed, activated platelets facilitate the adhesion of tumour cells to EC and favour their migration through the vessel wall by the release of heparanase. Additionally, tumour-cell-associated platelets may support metastasis formation by preventing interactions between tumour cells and innate immune cells, as shown by immunodepletion studies in vivo [53].

Leukocytes, particularly polymorphonuclear cells (PMNCs), promote tumour growth and metastases [54-57], as the interaction of tumour cells with PMNCs or ECs represents a crucial step in the early phase of extravasation and formation of new metastatic lesions [58]. In fact, PMNCs may adhere to tumour cells, facilitating their migration across the endothelial barrier. In addition, PMNCs release numerous metalloproteinases that hydrolyse ECM components and favour cancer cell dissemination. Circulating PMNCs are activated in cancer patients by locally generated mediators (i.e. TNF- $\alpha$ ) or by direct cell-to-cell interactions leading to expression of surface adhesion molecules, including the $\beta 2$ integrin CD11b/CD18. Increased PMNC CD11b/CD18 expression significantly enhances cancer cell/PMNC adhesion [59]. Furthermore, the selectins, including L-, E- and P-selectin, mediate the initial interactions between circulating PMNCs, activated ECs and tumour cells. During haematogeneous metastasis, tumour cells carrying selectin ligands enter the circulation and may encounter vascular selectins, thus supporting cancer progression, as shown by different studies using mouse models and carcinoma cell lines [58].

\section{Anticoagulant therapies to improve cancer outcome}

The hypothesis that inhibition of clotting mechanisms may limit cancer disease has attracted many researchers since the early experimental evidence of a possible involvement of the haemostatic system in tumour progression. Clinical trials with anticoagulant drugs were started in the early 1980s to test the effects of anticoagulation on the survival of cancer patients. The first randomized con- 
trolled trial found an improvement in overall survival among small cell lung cancer patients receiving warfarin in addition to chemotherapy [60]. Since then, different studies with warfarin or heparin, first unfractioned heparin (UFH) and subsequently low-molecular-weight heparin (LMWH), have been conducted with the endpoint of mortality in patients with cancer without thrombosis.

The efficacy and safety of anticoagulants as antineoplastic therapy were evaluated by a recent meta-analysis of clinical studies involving both warfarin and heparin. The study shows a significant reduction of $13.3 \%$ in cancer mortality associated with the use of LMWH, and a non-significant reduction of 5.8\% associated with the use of warfarin. Bleeding complications were increased significantly in anticoagulant-treated patients [61]. In another meta-analysis involving only clinical trials of LMWH, the use of LMWH in addition to standard cancer treatment improved the survival of patients with solid tumours, with a mortality risk reduction of $13 \%$ in the first year and $10 \%$ in the second year, without increasing the bleeding risk [62]. The biological rationale for using anticoagulant drugs (i.e. heparin and vitamin $\mathrm{K}$ antagonist) in cancer patients relies on their capacity to block the clotting cascade activation. However, these drugs, particularly LMWH, show several clotting-independent activities against cancer [63].

A better understanding of the molecular interactions between the haemostatic system and the tumour may provide appropriate targets for the production of bifunctional drugs; agents that will reverse the coagulopathy and attack the malignant process. A recent series of experimental and clinical studies with well-defined types of cancer cells reveal how oncogenic events may deregulate the haemostatic system. Activated oncogenes (K-ras, EGFR, PML-RARa and $M E T$ ) or inactivated tumour suppressors (i.e. p53 or PTEN) increase TF levels and activity, which is postulated to promote not only hypercoagulability but also tumour aggressiveness and angiogenesis [64-66]. In human glioma cells, inactivation of PTEN tumour suppressor gene resulted in upregulation of TF, especially under hypoxic conditions. Some oncogenes also upregulate fibrinolytic proteins such as PAI-1 [66]. As shown in the study by Boccaccio et al, using a mouse model, hepatoma induced by MET oncogene transcription is associated with, apparently independent of TF, a lethal and symptomatic thrombohaemorragic event [64]. This event was associated with upregulation of PAI-1 and cyclo-oxygenase -2 (COX-2) genes.

Concerning human tumours, two possible examples come from haematological malignancies where activation of blood coagulation may result from genetriggered signalling pathways. In APL cells, the t15-17 translocation, which results in fusion of the nuclear retinoic acid receptor $(R A R \alpha)$ gene on chromosome 17 with part of the $P M L$ gene on chromosome 15, induces hyperexpression of TF in the leukaemic cell, linking the primary oncogenic event with induction of hypercoagulability [67]. Treatment of APL with ATRA blocks the actions of the $P M L-R A R \alpha$ oncoprotein and leads to lower TF expression by leukaemic cells [68]. Another example is from patients with essential thrombocy- 
thaemia (ET), where the molecular abnormality, the $J A K 2 V 617 F$ gain of function mutation, translates into increased clotting activation. In particular, ET patients carrying the mutation have an increase in platelet surface TF expression, platelet/PMNC aggregates and plasma thrombotic markers [7]. On the other hand, cytoreductive treatment with hydroxyurea of patients with ET downregulates TF expression by PMNCs and decreases circulating platelet/PMNC aggregates [69].

As the molecular basis for activation of clotting in malignancies becomes better elucidated, the development of new drugs that will target both the malignant process and the resultant prothrombotic diathesis can be predicted.

\section{Summary and conclusions}

Tumour-induced procoagulant mechanisms are multiple and complex. The twoway relationship with cancer on one side and haemostasis on the other promotes a hypercoagulable state in patients, and enhances thromboembolic complications. Cancer cells exhibit a procoagulant phenotype, but the oncogenic events leading to the malignant transformation can deregulate the haemostatic system. The abnormal coagulation, in turn, modulates tumour growth and enhances tumour dissemination. Consequently, a vicious cycle is formed where tumour growth leads to increased clotting, and increased clotting accelerates tumour growth. New therapeutic approaches to test the use of anticoagulants as adjuvant therapy for cancer are under investigation. New agents capable of targeting specific pathways of clotting proteins and blocking cancer represent important future perspectives.

\section{Practice points}

- haemostatic proteins support the malignant phenotype by promoting neoangiogenesis and metastasis formation

- TF expression characterizes many malignant tumours, and some studies suggest that tumour related $\mathrm{TF}$ contributes to circulating $\mathrm{TF}$

- $\quad$ in APL blasts, CP expression correlates with the degree of malignant phenotype

- tumour-derived cytokines activate the endothelial surface to express a procoagulant and proadhesive phenotype

- the use of anticoagulant drugs (i.e. LMWH) in addition to standard antineoplastic treatment may improve the survival of cancer patients

- $\quad$ in patients with APL, treatment with ATRA has a bifunctional role to block both the malignant process and the hypercoagulable state

- the JAK2V617F mutation expressed in a high proportion of patients with essential thrombocythaemia and polycythaemia vera increases the expression of procoagulant proteins by platelets and leukocytes, and increases thrombotic risk. 


\section{Research agenda}

- tumour-derived MPs as a probable biomarker for increased thrombotic risk

- fibrinolytic proteins as possible predictors of long-term survival in malignant diseases

- development of new drugs that will target the malignant process and the specific pathways of the clotting proteins

\section{Conflict of interest statement}

None.

Acknowledgements

This work was supported by Grant no. 29/07 'Oncological Research' from the Italian Ministry of Health and by the Annadal Foundation, Maastricht, The Netherlands. 


\section{References:}

1 Rickles FR, Falanga A. Molecular basis for the relationship between thrombosis and cancer. Thrombosis research. 2001; 102: V215-24.

2 Lee AY. Cancer and thromboembolic disease: pathogenic mechanisms. Cancer treatment reviews. 2002; 28: 137-40.

3 Rickles FR, Patierno S, Fernandez PM. Tissue factor, thrombin, and cancer. Chest. 2003; 124: 58S-68S.

$4 \quad$ Heit JA, Silverstein MD, Mohr DN, Petterson TM, O'Fallon WM, Melton LJ, 3rd. Risk factors for deep vein thrombosis and pulmonary embolism: a population-based case-control study. Archives of internal medicine. 2000; 160: 809-15.

5 Khorana AA, Kuderer NM, Culakova E, Lyman GH, Francis CW. Development and validation of a predictive model for chemotherapy-associated thrombosis. Blood. 2008; 111: 4902-7. 6 Ay C, Simanek R, Vormittag R, Dunkler D, Alguel G, Koder S, Kornek G, Marosi C, Wagner O, Zielinski C, Pabinger I. High plasma levels of soluble P-selectin are predictive of venous thromboembolism in cancer patients - results from the Vienna Cancer and Thrombosis Study (CATS). Blood. 2008.

7 Falanga A, Marchetti M, Vignoli A, Balducci D, Russo L, Guerini V, Barbui T. V617F JAK-2 mutation in patients with essential thrombocythemia: relation to platelet, granulocyte, and plasma hemostatic and inflammatory molecules. Experimental hematology. 2007; 35: 702-11.

8 Falanga A, Rickles FR. Pathogenesis and management of the bleeding diathesis in acute promyelocytic leukaemia. Best practice \& research. 2003; 16: 463-82.

9 Furie B, Furie BC. Mechanisms of thrombus formation. The New England journal of medicine. 2008; 359: 938-49.

10 Rak J, Milsom C, May L, Klement P, Yu J. Tissue factor in cancer and angiogenesis: the molecular link between genetic tumor progression, tumor neovascularization, and cancer coagulopathy. Seminars in thrombosis and hemostasis. 2006; 32: 54-70.

11 Falanga A, Gordon SG. Isolation and characterization of cancer procoagulant: a cysteine proteinase from malignant tissue. Biochemistry. 1985; 24: 5558-67.

12 Donati MB, Gambacorti-Passerini C, Casali B, Falanga A, Vannotti P, Fossati G, Semeraro N, Gordon SG. Cancer procoagulant in human tumor cells: evidence from melanoma patients. Cancer research. 1986; 46: 6471-4.

13 Mielicki W, Serwa J, Kurzawinski T, Wierzbicki R. Procoagulant activity of human stomach and colon cancers. Oncology. 1990; 47: 299-302.

14 Falanga A, Consonni R, Marchetti M, Locatelli G, Garattini E, Passerini CG, Gordon SG, Barbui T. Cancer procoagulant and tissue factor are differently modulated by all-trans-retinoic acid in acute promyelocytic leukemia cells. Blood. 1998; 92: 143-51.

15 Falanga A, Toma S, Marchetti M, Palumbo R, Raffo P, Consonni R, Marziali S, Dastoli G, Barbui T. Effect of all-trans-retinoic acid on the hypercoagulable state of patients with breast cancer. American journal of hematology. 2002; 70: 9-15.

16 Dvorak HF, Quay SC, Orenstein NS, Dvorak AM, Hahn P, Bitzer AM, Carvalho AC. Tumor shedding and coagulation. Science (New York, NY. 1981; 212: 923-4.

17 Tesselaar ME, Romijn FP, Van Der Linden IK, Prins FA, Bertina RM, Osanto S. Microparticle-associated tissue factor activity: a link between cancer and thrombosis? J Thromb Haemost. 2007; 5: 520-7.

18 Del Conde I, Bharwani LD, Dietzen DJ, Pendurthi U, Thiagarajan P, Lopez JA. Microvesicleassociated tissue factor and Trousseau's syndrome. J Thromb Haemost. 2007; 5: 70-4.

19 Carr JM, Dvorak AM, Dvorak HF. Circulating membrane vesicles in leukemic blood. Cancer research. 1985; 45: 5944-51.

20 Hugel B, Martinez MC, Kunzelmann C, Freyssinet JM. Membrane microparticles: two sides of the coin. Physiology (Bethesda, Md. 2005; 20: 22-7.

21 Hron G, Kollars M, Weber H, Sagaster V, Quehenberger P, Eichinger S, Kyrle PA, Weltermann A. Tissue factor-positive microparticles: cellular origin and association with coagulation activation in patients with colorectal cancer. Thrombosis and haemostasis. 2007; 97: 119-23.

22 Hajjar KA. Cellular receptors in the regulation of plasmin generation. Thrombosis and haemostasis. 1995; 74: 294-301. 
23 Annecke K, Schmitt M, Euler U, Zerm M, Paepke D, Paepke S, von Minckwitz G, Thomssen C, Harbeck N. uPA and PAI-1 in breast cancer: review of their clinical utility and current validation in the prospective NNBC-3 trial. Advances in clinical chemistry. 2008; 45: 31-45.

24 McMahon GA, Petitclerc E, Stefansson S, Smith E, Wong MK, Westrick RJ, Ginsburg D, Brooks PC, Lawrence DA. Plasminogen activator inhibitor-1 regulates tumor growth and angiogenesis. The Journal of biological chemistry. 2001; 276: 33964-8.

25 van Hinsbergh VW, Bauer KA, Kooistra T, Kluft C, Dooijewaard G, Sherman ML, Nieuwenhuizen W. Progress of fibrinolysis during tumor necrosis factor infusions in humans. Concomitant increase in tissue-type plasminogen activator, plasminogen activator inhibitor type-1, and fibrin(ogen) degradation products. Blood. 1990; 76: 2284-9.

26 Van de Wouwer M, Collen D, Conway EM. Thrombomodulin-protein C-EPCR system: integrated to regulate coagulation and inflammation. Arteriosclerosis, thrombosis, and vascular biology. 2004; 24: 1374-83.

27 Rice GE, Bevilacqua MP. An inducible endothelial cell surface glycoprotein mediates melanoma adhesion. Science (New York, NY. 1989; 246: 1303-6.

28 Giavazzi R, Foppolo M, Dossi R, Remuzzi A. Rolling and adhesion of human tumor cells on vascular endothelium under physiological flow conditions. The Journal of clinical investigation. 1993; 92: 3038-44.

29 Chen M, Geng JG. P-selectin mediates adhesion of leukocytes, platelets, and cancer cells in inflammation, thrombosis, and cancer growth and metastasis. Archivum immunologiae et therapiae experimentalis. 2006.

30 Karpatkin S, Pearlstein E, Ambrogio C, Coller BS. Role of adhesive proteins in platelet tumor interaction in vitro and metastasis formation in vivo. The Journal of clinical investigation. 1988; 81: 1012-9.

31 Biggerstaff JP, Seth N, Amirkhosravi A, Amaya M, Fogarty S, Meyer TV, Siddiqui F, Francis JL. Soluble fibrin augments platelet/tumor cell adherence in vitro and in vivo, and enhances experimental metastasis. Clinical \& experimental metastasis. 1999; 17: 723-30.

32 Nierodzik ML, Karpatkin S. Thrombin induces tumor growth, metastasis, and angiogenesis: Evidence for a thrombin-regulated dormant tumor phenotype. Cancer cell. 2006; 10: 355-62.

33 Felding-Habermann B, O'Toole TE, Smith JW, Fransvea E, Ruggeri ZM, Ginsberg MH, Hughes PE, Pampori N, Shattil SJ, Saven A, Mueller BM. Integrin activation controls metastasis in human breast cancer. Proceedings of the National Academy of Sciences of the United States of America. 2001; 98: 1853-8.

34 Felding-Habermann B. Targeting tumor cell-platelet interaction in breast cancer metastasis. Pathophysiology of haemostasis and thrombosis. 2003; 33 Suppl 1: 56-8.

35 Borsig L, Wong R, Feramisco J, Nadeau DR, Varki NM, Varki A. Heparin and cancer revisited: mechanistic connections involving platelets, P-selectin, carcinoma mucins, and tumor metastasis. Proceedings of the National Academy of Sciences of the United States of America. 2001; 98: 3352-7.

36 Borsig L. Non-anticoagulant effects of heparin in carcinoma metastasis and Trousseau's syndrome. Pathophysiology of haemostasis and thrombosis. 2003; 33 Suppl 1: 64-6.

37 Merten M, Beythien C, Gutensohn K, Kuhnl P, Meinertz T, Thiagarajan P. Sulfatides activate platelets through P-selectin and enhance platelet and platelet-leukocyte aggregation. Arteriosclerosis, thrombosis, and vascular biology. 2005; 25: 258-63.

38 Jain S, Zuka M, Liu J, Russell S, Dent J, Guerrero JA, Forsyth J, Maruszak B, Gartner TK, Felding-Habermann B, Ware J. Platelet glycoprotein Ib alpha supports experimental lung metastasis. Proceedings of the National Academy of Sciences of the United States of America. 2007; 104: 9024-8.

39 Yano S, Nishioka Y, Goto H, Sone S. Molecular mechanisms of angiogenesis in non-small cell lung cancer, and therapeutics targeting related molecules. Cancer science. 2003; 94: 479-85.

40 Rickles FR. Mechanisms of cancer-induced thrombosis in cancer. Pathophysiology of haemostasis and thrombosis. 2006; 35: 103-10.

41 Uusitalo-Jarvinen H, Kurokawa T, Mueller BM, Andrade-Gordon P, Friedlander M, Ruf W. Role of protease activated receptor 1 and 2 signaling in hypoxia-induced angiogenesis. Arteriosclerosis, thrombosis, and vascular biology. 2007; 27: 1456-62.

$42 \quad$ Ruf W. Tissue factor and PAR signaling in tumor progression. Thrombosis research. 2007; 120: S7-S12. 
43 Palumbo JS, Kombrinck KW, Drew AF, Grimes TS, Kiser JH, Degen JL, Bugge TH. Fibrinogen is an important determinant of the metastatic potential of circulating tumor cells. Blood. 2000; 96: 3302-9.

44 Pinedo HM, Verheul HM, D'Amato RJ, Folkman J. Involvement of platelets in tumour angiogenesis? Lancet. 1998; 352: 1775-7.

45 English D, Garcia JG, Brindley DN. Platelet-released phospholipids link haemostasis and angiogenesis. Cardiovascular research. 2001; 49: 588-99.

46 Palumbo JS, Talmage KE, Massari JV, La Jeunesse CM, Flick MJ, Kombrinck KW, Hu Z, Barney KA, Degen JL. Tumor cell-associated tissue factor and circulating hemostatic factors cooperate to increase metastatic potential through natural killer cell-dependent and-independent mechanisms. Blood. 2007; 110: 133-41.

47 Wojtukiewicz MZ, Tang DG, Ciarelli JJ, Nelson KK, Walz DA, Diglio CA, Mammen EF, Honn KV. Thrombin increases the metastatic potential of tumor cells. International journal of cancer. 1993; 54: 793-806.

48 Nierodzik ML, Plotkin A, Kajumo F, Karpatkin S. Thrombin stimulates tumor-platelet adhesion in vitro and metastasis in vivo. The Journal of clinical investigation. 1991; 87: 229-36.

49 Nierodzik ML, Kajumo F, Karpatkin S. Effect of thrombin treatment of tumor cells on adhesion of tumor cells to platelets in vitro and tumor metastasis in vivo. Cancer research. 1992; 52: 3267-72.

50 Shi X, Gangadharan B, Brass LF, Ruf W, Mueller BM. Protease-activated receptors (PAR1 and PAR2) contribute to tumor cell motility and metastasis. Mol Cancer Res. 2004; 2: 395-402.

51 Even-Ram S, Uziely B, Cohen P, Grisaru-Granovsky S, Maoz M, Ginzburg Y, Reich R, Vlodavsky I, Bar-Shavit R. Thrombin receptor overexpression in malignant and physiological invasion processes. Nature medicine. 1998; 4: 909-14.

52 Boire A, Covic L, Agarwal A, Jacques S, Sherifi S, Kuliopulos A. PAR1 is a matrix metalloprotease-1 receptor that promotes invasion and tumorigenesis of breast cancer cells. Cell. 2005; 120: 303-13.

53 Palumbo JS, Talmage KE, Massari JV, La Jeunesse CM, Flick MJ, Kombrinck KW, Jirouskova M, Degen JL. Platelets and fibrin(ogen) increase metastatic potential by impeding natural killer cellmediated elimination of tumor cells. Blood. 2005; 105: 178-85.

54 Aeed PA, Nakajima M, Welch DR. The role of polymorphonuclear leukocytes (PMN) on the growth and metastatic potential of $13762 \mathrm{NF}$ mammary adenocarcinoma cells. International journal of cancer. 1988; 42: 748-59.

55 Starkey JR, Liggitt HD, Jones W, Hosick HL. Influence of migratory blood cells on the attachment of tumor cells to vascular endothelium. International journal of cancer. 1984; 34: 53543.

56 Welch DR, Schissel DJ, Howrey RP, Aeed PA. Tumor-elicited polymorphonuclear cells, in contrast to "normal" circulating polymorphonuclear cells, stimulate invasive and metastatic potentials of rat mammary adenocarcinoma cells. Proceedings of the National Academy of Sciences of the United States of America. 1989; 86: 5859-63.

57 Wu QD, Wang JH, Condron C, Bouchier-Hayes D, Redmond HP. Human neutrophils facilitate tumor cell transendothelial migration. American journal of physiology. 2001; 280: C814-22. 58 Borsig L. Selectins facilitate carcinoma metastasis and heparin can prevent them. News Physiol Sci. 2004; 19: 16-21.

59 Klink M, Jastrzembska K, Nowak M, Bednarska K, Szpakowski M, Szyllo K, Sulowska Z. Ovarian cancer cells modulate human blood neutrophils response to activation in vitro. Scandinavian journal of immunology. 2008; 68: 328-36.

60 Zacharski LR, Henderson WG, Rickles FR, Forman WB, Cornell CJ, Jr., Forcier RJ, Edwards RL, Headley E, Kim SH, O'Donnell JF, et al. Effect of warfarin anticoagulation on survival in carcinoma of the lung, colon, head and neck, and prostate. Final report of VA Cooperative Study \#75. Cancer. 1984; 53: 2046-52.

61 Kuderer NM, Khorana AA, Lyman GH, Francis CW. A meta-analysis and systematic review of the efficacy and safety of anticoagulants as cancer treatment: impact on survival and bleeding complications. Cancer. 2007; 110: 1149-61.

62 Lazo-Langner A, Goss GD, Spaans JN, Rodger MA. The effect of low-molecular-weight heparin on cancer survival. A systematic review and meta-analysis of randomized trials. J Thromb Haemost. 2007; 5: 729-37. 
63 Falanga A, Piccioli A. Effect of anticoagulant drugs in cancer. Current opinion in pulmonary medicine. 2005; 11: 403-7.

64 Boccaccio C, Sabatino G, Medico E, Girolami F, Follenzi A, Reato G, Sottile A, Naldini L, Comoglio PM. The MET oncogene drives a genetic programme linking cancer to haemostasis. Nature. 2005; 434: 396-400.

65 Rak J, Yu JL, Luyendyk J, Mackman N. Oncogenes, trousseau syndrome, and cancerrelated changes in the coagulome of mice and humans. Cancer research. 2006; 66: 10643-6.

66 Rong Y, Post DE, Pieper RO, Durden DL, Van Meir EG, Brat DJ. PTEN and hypoxia regulate tissue factor expression and plasma coagulation by glioblastoma. Cancer research. 2005; 65: 140613.

67 Falanga A, Rickles FR. Management of Thrombohemorrhagic Syndromes (THS) in Hematologic Malignancies. Hematology / the Education Program of the American Society of Hematology American Society of Hematology. 2007; 2007: 165-71.

68 Falanga A, Barbui T, Rickles F. Hypercoagulability and tissue factor gene upregulation in hematologic malignancies. Seminars in thrombosis and hemostasis. 2008; 34: 204-10.

69 Maugeri N, Giordano G, Petrilli MP, Fraticelli V, de Gaetano G, Cerletti C, Storti S, Donati MB. Inhibition of tissue factor expression by hydroxyurea in polymorphonuclear leukocytes from patients with myeloproliferative disorders: a new effect for an old drug? J Thromb Haemost. 2006; 4: 2593-8. 


\section{CHAPTER 3}

\section{Treatment of thromboembolism in cancer patients}

Marina Panova-Noeva, Anna Falanga

Expert Opinion on Pharmacotherapy 2010;11(12):2049-58. 


\section{Abstract}

Importance of the field: Cancer patients are at increased risk for developing venous thromboembolism (VTE). The occurrence of VTE predicts worse prognosis in cancer patients, and while the 1 year survival in cancer patients free of thrombosis is $36 \%$, differently in patients with diagnosed VTE is $12 \%$. The management of VTE in cancer patients is challenging, because the anticoagulant treatment in these patients can be less effective and carry considerable morbidity.

Areas covered in this review: This review covers the treatment strategies for cancer patients with VTE and highlights the new anticoagulant agents and their potential use in oncology. In writing this review, a literature search was performed using the PUB MED database with the following subject headings: cancer, venous thromboembolism and anticoagulant treatment.

What the reader will gain: The readers of this article will gain a comprehensive overview of the current recommendations for prevention and treatment of VTE in cancer patients. In addition, this review provides an insight into the new anticoagulant drugs potentially suitable for use in oncology, in particular idraparinux, apixaban, rivaroxaban and dabigatran etexilate.

Take home message: Low-molecular-weight heparin remains the best treatment option for initial and long term treatment of VTE in cancer patients. 


\section{Introduction}

Cancer patients are at increased risk for developing venous thromboembolism (VTE), either as deep vein thrombosis (DVT) or pulmonary embolism (PE) or both. Many studies have shown that VTE occurs commonly and is associated with decreased survival in these patients [1-3]. Patients with active cancer have a 6 to 7 times increased risk of developing symptomatic VTE compared to noncancer patients [4-5]. In addition, VTE can be the first symptom of an occult cancer. A large population based study shows that $18 \%$ of all VTE in the community is associated with an underlying cancer [6]. The first report that thrombosis is associated with an underlying cancer was published in 1865 by the French internist Armand Trousseau [7]. Patients who present with unprovoked or idiopathic VTE or PE have a 2 to 3 fold increased risk of having an occult cancer compared to patients with secondary VTE [8-10].

The risk of developing VTE varies according to the type of malignancy, being highest in patients with malignant brain tumors, haematological malignancies, and tumors of the pancreas, uterus, ovary, stomach, lung and kidney [2, 4, 1112]. VTE incidence rates can also vary according to the histology and as shown in the study by Blom et al., lung cancer patients with adenocarcinoma have higher VTE incidence compared to squamous cell carcinoma [13]. In addition, patients diagnosed with metastatic disease have much higher VTE incidence compared to patients diagnosed with local stage cancer. The incidence of VTE is the highest in the initial period after the cancer diagnosis. One possible explanation for this observation might be the cancer aggressiveness. The study by Alcalay et al. with colon cancer patients and the later study by Rodriguez et al., with ovarian cancer patients, have shown that faster-growing cancers are associated with a higher rate of VTE [14-15]. Aside the common risk factors for thrombosis, such as advanced age, female sex, race, previous history of thrombosis, prothrombotic mutations and immobility, the anticancer treatmentrelated factors further increase the risk of thrombosis in cancer patients [2,1617]. Non surgical treatments such as chemotherapy, hormonal therapy, antiangiogenic agents and supportive therapy, all have a prothrombotic effect in cancer patients. Conventional cytotoxic chemotherapy is a well defined independent risk factor for VTE with an incidence rate between 10 and $20 \%$ per year [5, 18]. The new agents used in treatment of multiple myeloma, thalidomide and lenalidomide, have been associated with 20 - 40\% increased risk for VTE, particularly when used in combination with dexamethasone or doxorubicin [1920]. A systematic review for the use of tamoxifen in early stage breast cancer women showed an increased risk of VTE by 2 to 7 fold compared to placebo. This risk increased to 20 fold when chemotherapy and tamoxifen were used in combination. The risk of VTE in users of tamoxifen was found to increase with age, particularly in women above 60 years of age [21]. Therefore chemotherapy and hormone therapy should be viewed as independent risk factors for VTE. Anastrozole, a new aromatase inhibitors used as adjuvant therapy in early breast cancer women, showed lower risk for VTE compared to tamoxifen, yet 
the incidence of VTE with these new agents was higher than that expected in the general population [22]. Increased thrombotic events were also observed in patients with haematological malignancy treated with protocols containing Lasparaginase. According to a meta-analysis of 17 studies, the rate of thrombotic/haemorrhagic events and DVT in children with acute lymphoblastic leukemia (ALL) is 5.2\% and the majority of the events occur during induction therapy with L-asparaginase [23]. Adults with ALL who receive asparaginase therapy have a reported incidence of VTE between 4.2 and 9.6\% [24-25]. Erythropoiesis stimulating agents (ESAs) and white blood cell growth factors have been introduced as important tools for the treatment of cancer patients with anaemia and neutropenia. These treatments alleviates fatigue syndrome and improves patients' quality of life when compared to placebo or transfusion therapy [26]. However, the use of ESAs and other hematopoietic growth factors have been shown as independent risk factors for VTE in cancer patients on chemotherapy [27]. Furthermore, the use of central venous catheters (CVCs) for chemotherapy administration is associated independently with an increased risk of thrombosis. The trauma of the vessel wall, directly or indirectly due to high drug concentration, the type, position or duration of catheterization, all may influence the risk of thrombosis [28].

The occurrence of VTE predicts worse prognosis in cancer patients, and while the 1 year survival in cancer patients free of thrombosis was 36\%, differently in patients with diagnosed VTE was $12 \%$ [1]. In addition, treatment of VTE in cancer patients is challenging because the anticoagulant treatment in cancer patients can be less effective and carry considerable morbidity [29].

From all the reasons discussed above, it appears that preventing VTE in the cancer patients is a very important issue. Equally important is the search for more effective and safe treatments for overt VTE in this condition. Several national and international scientific societies have recently published guidelines for VTE prevention and management in cancer patients, including the American College of Chest Physicians (ACCP), the National Comprehensive Cancer Network (NCCN), the American Society of Clinical Oncology (ASCO), the European Society of Medical Oncology (ESMO), the International Union of Angiology, the Italian Association of Medical Oncology (AIOM), and the French national guidelines (FNCLCC) [30-36]. All these guidelines provide recommendations on how to appropriately target antithrombotic prophylaxis and treatment of VTE in cancer patients. This review focuses only on the treatment strategies for cancer patients with VTE and highlights the new antithrombotic agents and their potential use in oncology.

\section{Management of manifest VTE}

The standard therapy of a first acute VTE episode in patients without cancer consists of an initial phase, in which intravenous adjusted dose UFH (APTT range $=1.5-2.5$ ), or subcutaneous weight-adjusted doses of low-molecular- 
weight-heparin (LMWH) or fondaparinux are administered, followed by a prolonged phase in which Vitamin $\mathrm{K}$ antagonists (VKA) at International Ratio (INR) 2-3 (range) are given for at least three months. VKA are started within the first 24 hours of heparin (or fondaparinux) therapy. When INR values reach the level $>2$, heparins are stopped (usually after 5-7 days) and only VKA is continued [35]. LMWH are equally effective and safe for treatment of DVT or PE or both [37]. Due to their effectiveness they are the first choice in the initial phase of VTE treatment. Fondaparinux is also effective and safe in the initial phase of VTE treatment.

\section{VTE initial treatment}

The initial treatment of an acute VTE episode in cancer patients is not different from the recommended initial treatment for patients without cancer. UFH and LMWH have shown similar efficacy and safety in the meta-analysis of several trials comparing the two drugs for the initial treatment of patients with acute VTE [37]. About $20 \%$ of patients enrolled in each of these trials had cancer. The Matisse-PE randomized trial including 2213 patients with symptomatic pulmonary embolism (PE), compared the efficacy and safety of fondaparinux to UFH. In addition, the Matisse-DVT clinical trial compared the efficacy and safety of fondaparinux to enoxaparin in 2205 patients with symptomatic deep vein thrombosis (DVT). Both studies conclude that fondaparinux is not inferior and is safe as UFH or enoxaparin for the initial treatment of symptomatic PE or DVT, respectively [38-39]. A recent subgroup analysis of the Matisse clinical trials including 240 cancer patients with PE and 237 cancer patients with DVT was published. Regarding overall survival and bleeding, fondaparinux was found comparable to enoxaparin and UFH in cancer patients. The recurrence rates of VTE were not significantly different between the fondaparinux arm and LMWH or UFH arms [40].

\section{VTE long-term treatment}

The current recommendations for the long-term treatment of VTE in patients with cancer differ from the standard treatment in patients without cancer (Figure 1). Indeed, while in patients with VTE without cancer, VKA therapy is started within 24 hours of the start of heparin treatment and continued longterm, in patients with cancer the continual parenteral administration of LMWH is the first recommended approach. In patients with cancer, VKA therapy is shown to be less effective than LMWH in preventing VTE recurrences and has increased toxicity. In addition, there are other problems for a correct anticoagulation with VKA, due to the difficulties to maintain a tight therapeutic control (for anorexia, vomiting, and drug interactions), the possibility of frequent interruptions for thrombocytopenia and invasive procedures, and difficulties to find venous access for INR monitoring. A randomized controlled trial (CLOT study) compared the efficacy and safety of LMWH (dalteparin) versus VKA therapy, administered for a total 6 months, in preventing VTE recurrences in 672 cancer 
patients who had acute symptomatic DVT or PE or both. Patients were randomly assigned to standard treatment, i.e. dalteparin administered at a dose of $200 \mathrm{IU} / \mathrm{kg}$ daily for 5 to 7 days followed by VKA for 6 months (target INR=2.5) or to the experimental arm, i.e. dalteparin given as monotherapy at $200 \mathrm{IU} / \mathrm{kg}$ daily for the first month, followed by $75 \%$ of the initial dose for 5 more months. The results showed that the patients randomized to the experimental arm had significantly lower VTE recurrences (27 of 336) compared to the standard longterm VKA group (53 of 336). The hazard ratio for recurrent VTE in the longterm dalteparin group compared to the VKA group was 0.48 (95\% confidence interval $=0.3-0.77, \mathrm{p}=0.002$ ). No significant differences were observed for any bleeding events or death between the two groups [41].

Figure 1. Treatment of thromboembolism in cancer patients. Currently recommended treatment of idiopatic venous thromboembolism in patients without (A) and with (B) cancer.

A.

Non-cancer patients with acute DVT or PE

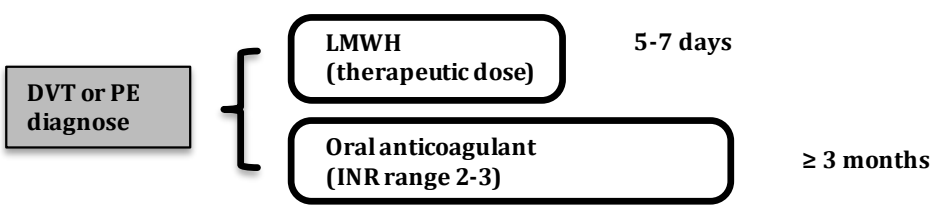

B.

Cancer patients with acute DVT or PE

1 month

DVT or PE

diagnose
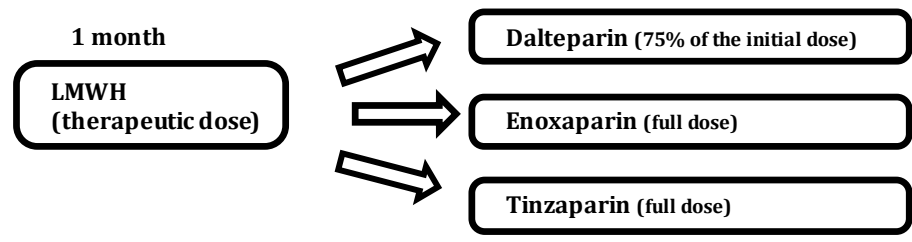

An open-label trial randomized patients with and without cancer with symptomatic proximal DVT of the lower limbs to receive, for 6 months, either LMWH (tinzaparin) or VKA (acenocoumarol). Whereas LMWH showed no advantage in the efficacy and safety over VKA in patients without cancer, in patients with cancer LMWH was found superior to VKA [42]. Another study compared long term VKA to long term enoxaparin given for 3 months in 146 patients with cancer and VTE. The results of this randomized controlled study showed that enoxaparin is more safe and effective compared to VKA ( $\mathrm{p}=0.04$ by the long rank test), based on a cumulative end-point of hemorrhages and thrombosis [43]. A recent meta-analysis of all randomized controlled trials testing the efficacy and safety of long-term LMWH versus VKA included 1158 adult patients with cancer-associated thrombosis. The analysis showed that 6 months treatment with LMWH have a significant superiority over VKA (relative risk 
$(R R)=0.52, p=0.002)$, without increasing bleeding complications [44]. A Cochrane systematic review, including the results of 8 randomized controlled trials, showed similar statistically significant benefit of LMWH over VKA $(R R=0.53$; $95 \% \mathrm{CI}=0.35-0.80$ ) for reduction of recurrent VTE [45]. To date all guidelines agree on that LMWH is the preferred agent for long-term treatment of cancer associated thrombosis. It shows superior efficacy over warfarin without increasing bleeding, has no interaction with cancer treatment, and is more convenient.

\section{Duration of anticoagulation}

Since malignancy is "per se" an important risk factor for thrombosis and cancer patients are at increased risk of recurrent VTE, the anticoagulant treatment for a first episode of VTE should be continued as long as the cancer is active, unless a severe bleeding risk outweights the risk of VTE recurrence [34]. The ACCP guidelines suggest continuing with either LMWH or VKA after 6 months [35]. However, no clinical trials demonstrate an optimal duration of anticoagulation. In addition, the natural history of recurrent thrombosis after stopping anticoagulants is not well studied in cancer patients.

\section{Treatments of VTE recurrences during anticoagulation for a first VTE episode.}

Recurrences of VTE are an important therapeutic challenge in cancer patients. In addition to an increased risk of developing VTE compared to the general population, cancer patients also have 3 -fold increased risk of recurrent VTE while receiving anticoagulant therapy compared to non-cancer patients [29, 46]. A prospective observational study by Hansson et al, showed that, in patients with previous VTE, the presence of malignancy is an independent risk factor for a recurrent VTE with a RR of 1,97 (95\% CI, 1.20-3.23; P<0.001) [47]. Figure 2 shows the suggested therapeutic options in case of recurrent VTE during anticoagulant treatment. These experience-based recommendations suggest: 1. switching to LMWH for "warfarin failures", and 2. increasing LMWH dose for "LMWH" failures. The efficacy of a LMWH dose increase for patients who develop a recurrent VTE while treated with therapeutic doses of LMWH was demonstrated by a recent retrospective cohort study evaluating the management of recurrent VTE and outcome in 70 cancer patients. Patients receiving a therapeutic dose LMWH at the time of recurrent VTE received 20\% higher LMWH dose for 4 weeks, whereas patients on maintenance LMWH received a therapeutic LMWH dose for 6-12 weeks. Patients on low dose LMWH and patients on VKA switched to therapeutic dose of LMWH for 1 month, followed by a maintenance dose. During the 3 month follow-up period only 6 patients $(8.6 \%)$ had a second VTE. All these patients continued with an escalated LMWH dose and none had any further recurrent thrombotic event in the next 3 month follow up [48]. 


\section{Vena cava filters:}

There is limited data on the use, safety and the long term outcome of vena cava filters. The results of the few observational studies showed that $4-32 \%$ of the patients might still develop recurrent thrombosis. No studies have demonstrated a benefit of their use in reducing the patients' mortality [49]. The use of vena cava filters may affect the risk of PE but not the risk of DVT [50]. Therefore, the use of vena cava filters have been considered as an alternative to prevent PE only in patients having a contraindication to anticoagulation (i.e. active bleeding, active cerebrovascular hemorrhage, severe, uncontrolled or malignant hypertension, pericarditis, profound and prolonged thrombocytopenia, severe head trauma) or patients with recurrent VTE despite adequate treatment.

Figure 2. Treatment of VTE recurrences.

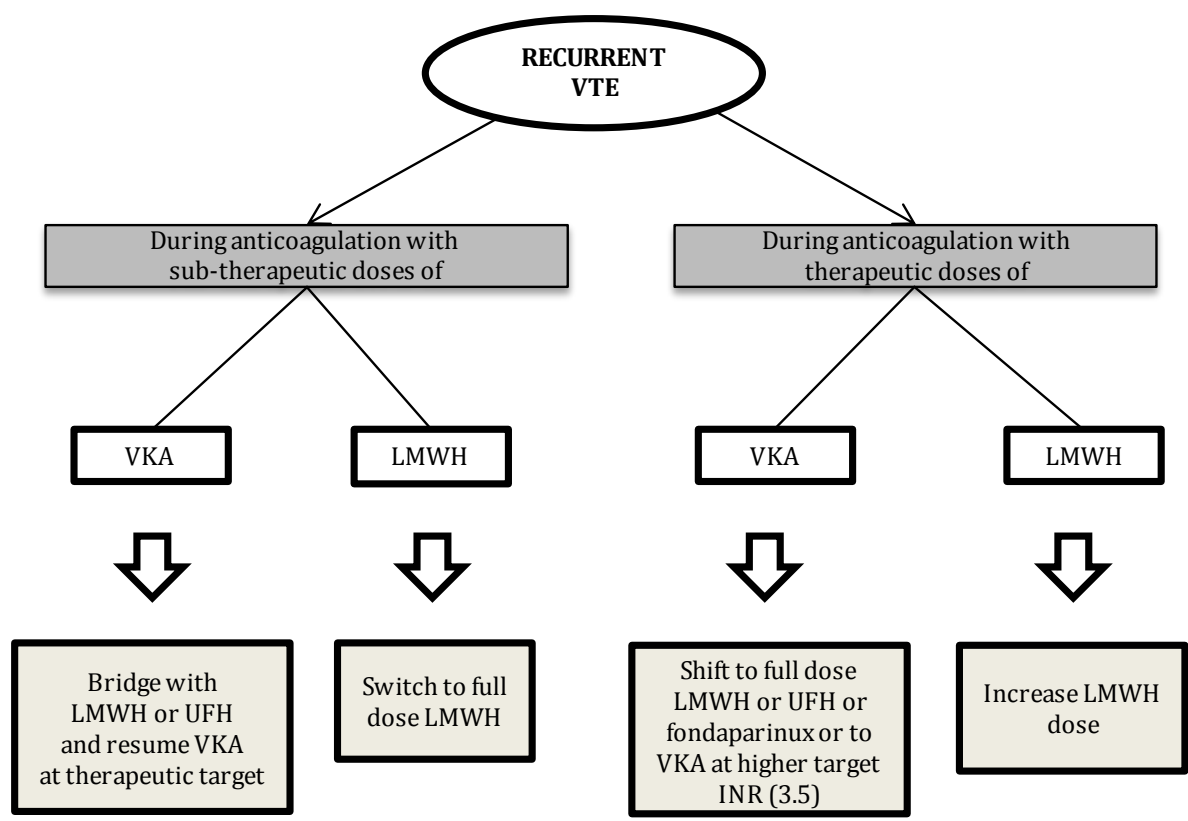

\section{Treatment of VTE in paediatric cancer patients}

Like adults, children with cancer are at increased risk for VTE. The most common cancer in children associated with VTE is the ALL. L-asparaginase and corticosteroid treatment have been identified as the main risk factors for VTE in these patients [51]. The prevalence of VTE in children with ALL ranges from $1.1-11 \%$ when VTE is diagnosed on the basis of clinical symptomsand from 37.5 to $40 \%$ when $x$-ray screening is used [52-53]. Due to the lack of evidence for the benefit and the increased risk of bleeding, antithrombotic prophylaxis is not 
recommended in the routine practice of children with cancer. Differently, LMWH is the preferred choice for VTE treatment in children with cancer with duration of 3 months or until the VTE risk factor persists, such as asparaginase treatment [54].

\section{New antithrombotic drugs}

Despite the prompt treatment of VTE in cancer patients, 9-17\% of patients still experience recurrent VTE while on treatment with LMWH or warfarin. The importance for regular monitoring and the long term need for daily treatment with parenteral drugs (i.e. LMWH) add an additional burden to cancer patients. The need for safer and more effective anticoagulant drug for VTE treatment in cancer patients therefore remains a challenge. Several new antithrombotic drugs have been developed and are at different stages of clinical testing. Some of these drugs might have an impact in the prevention and treatment of VTE in cancer patients.

The new anticoagulants under development interfere with either the initial or the propagation phase of the coagulation cascade, or with fibrin generation. Figure 3 shows the new antithrombotic drugs at stage III of the clinical testing in the setting of VTE treatment and their mode of action on the coagulation cascade. This review focuses on data for drugs that, potentially, are suitable for use in oncology, such as idraparinux, apixaban, rivaroxaban and dabigatran etexilate.

\section{$\underline{\text { 1. Indirect FXa inhibitor }}$}

Idraparinux is a synthetic pentasaccharide and an indirect Factor Xa (FXa) inhibitor. It binds antithrombin with very high affinity and has plasma half-life of 80 hours. It is therefore suitable for subcutaneous administration once a week in a fixed dose. In a phase II, dose-finding trial including 659 patients with proximal DVT, a dose of $2.5 \mathrm{mg}$ idraparinux was chosen for further investigation in phase III clinical trials [55]. The phase III clinical trials demonstrated that, athough effective in preventing thrombosis, idraparinux administration is associated with increased risk of bleeding [56-58]. The focus for further investigation has therefore shifted to a biotinylated form of idraparinux SSR12517E, or idrabiotaparinux. Compared to idraparinux, the new drug has an antidote, the avidin, that administered intravenously can completely neutralize the action of idrabiotaparinux [59]. The EQUINOX study, which includes patients with DVT of the lower limbs, demonstrated similar efficacies between idraparinux and idrabiotaparinux and a trend to less bleeding with idrabiotaparinux. Currently, a phase III clinical trial is on-going in patients with symptomatic PE with or without signs of DVT. After a treatment of at least 5 days with LMWH or heparin, patients are randomized to receive either idrabiotaparinux or VKA [60]. The BOREALIS-AF study was designed to evaluate the efficacy and safety of idrabiotaparinux administered once-a-week subcutaneously compared to 
INR adjusted-dose warfarin in patients with atrial fibrillation. The trial was prematurely discontinued in December 2009 because idrabiotaparinux could not show significant improvement in the care of these patients.

Figure 3. New anticoagulant drugs' mode of action on coagulation cascade.

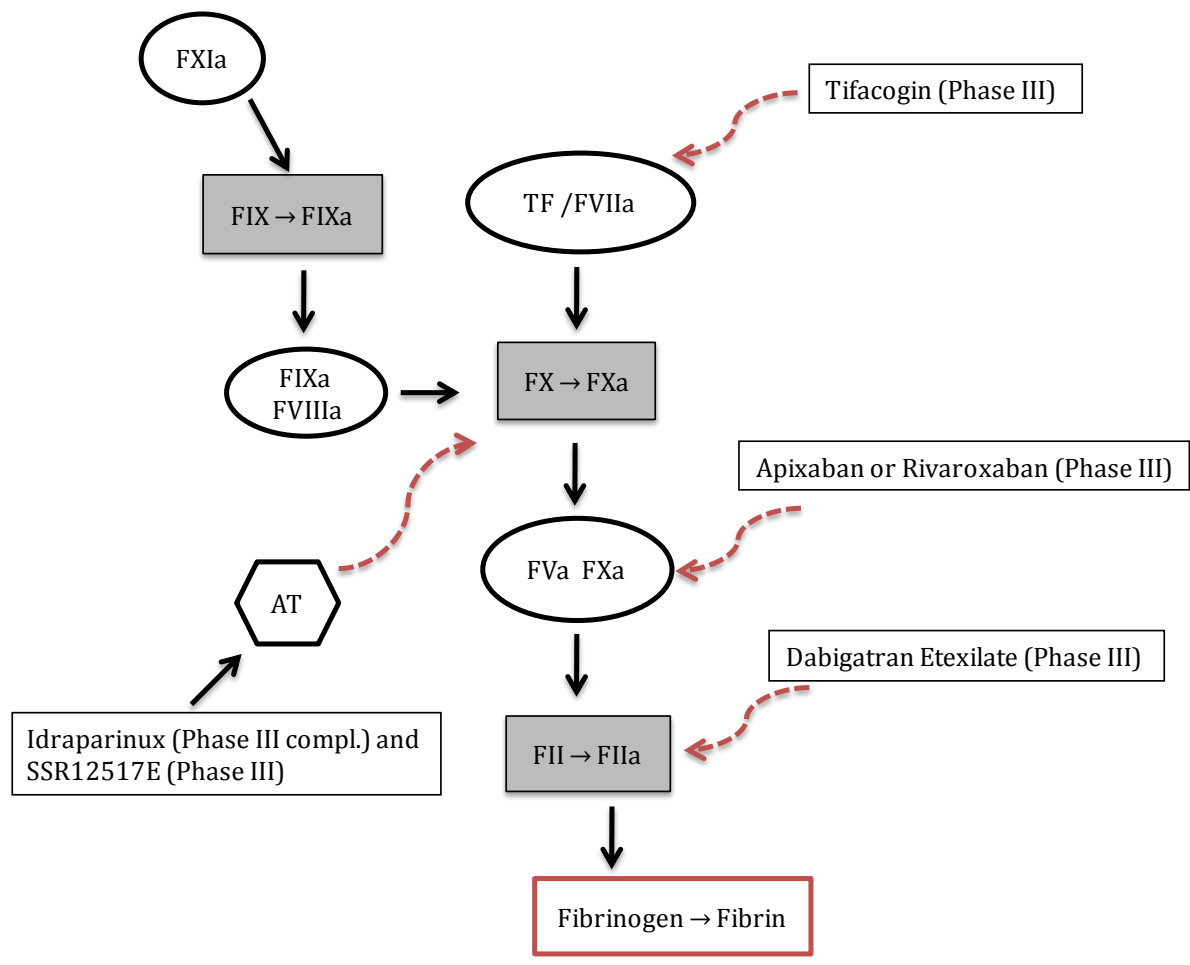

\section{Direct oral Factor Xa inhibitors}

Other important drugs that can find its role in VTE management in cancer patients are the direct FXa inhibitors apixaban and rivaroxaban. Both have an advantage to be administered orally and have a maximum plasma concentration in 3-4 hours after ingestion. Apixaban has a combined hepatic and renal elimination, while rivaroxaban in $66 \%$ is eliminated by the kidneys and therefore is contraindicated in patients with creatinine clearance less than $30 \mathrm{ml} / \mathrm{min}$. The results of the phase III apixaban study, ADVANCE-1, in which patients undergoing knee replacement were randomly assigned to start either apixaban (2.5 $\mathrm{mg}$ ) or enoxaparin (30 mg) twice daily after surgery, showed no difference in the primary efficacy outcome between the two arms $(8.99 \%$ vs $8.85 \%$ respectively). However, the rates of major bleeding were less in the apixaban arm $(0.69 \%)$ than in the enoxaparin arm $(1.39 \%)$, suggesting that apixaban is an effective oral anticoagulant [61]. The results of the ADVANCE-2 study in which 
patients with total knee replacement surgery were randomized to receive either apixaban (2.5 mg) twice daily or enoxaparin (40 mg) once daily were presented at the International Society of Thrombosis and Haemostasis congress held in July 2009 in Boston, Massachusetts. Patients in the apixaban arm had significantly lower $(\mathrm{p}<0.001)$ VTE events $(15.1 \%)$ than patients in the enoxaparin arm (24.4\%). The clinically relevant bleeding was less in the apixaban arm (3.5\%) but not significantly different from enoxaparin arm $(4.8 \%, p=0.09)$. Apixaban is being studied in patients with symptomatic VTE (AMPLIFY, phase III) comparing apixaban (10 mg twice daily for 7 days followed by $5 \mathrm{mg}$ twice daily for 6 months) to standard strategy with enoxaparin followed by VKA. Trials including patients with acute coronary syndrome (APPRAISE study) and atrial fibrillation (ARISTOTLE study) are ongoing. A phase II trial tested apixaban $(5,10$ or $20 \mathrm{mg}$ once daily for 12 weeks) versus placebo for prevention of VTE in patients with advanced or metastatic cancer undergoing chemotherapy. The study enrolled 125 patients and ended January 2009. The results showed that 12 weeks of apixaban is well tolerated in patients with advanced cancer on chemotherapy. Major bleeding and drug associated side events were very low in the apixaban arms. No thrombotic events were registered in the apixaban arms, but 3 patients (10.3\%) on placebo developed VTE [62].

Rivaroxaban has already been approved in postoperative orthopaedic prophylaxis for the prevention of VTE on base of 4 phase III clinical trials. The results of these clinical trials (RECORD 1-4) suggest that $10 \mathrm{mg}$ once daily of oral Rivaroxaban is superior as postoperative prophylaxis in patients undergoing knee and hip arthroplasty to standard treatment with LMWH. Major bleeding was rare in all 4 studies and not significantly different between the two arms [63-66]. A dosage of $10 \mathrm{mg}$ daily for prevention of thrombosis and $20 \mathrm{mg}$ daily for treatment of established thrombosis are evaluated in the on-going phase III studies. In patients with atrial fibrillation, $10 \mathrm{mg}$ of rivaroxaban once daily is compared to standard warfarin therapy in prevention of stroke and systemic embolism. The same dosage of $10 \mathrm{mg}$ daily rivaroxaban for 35 days has been evaluated for prevention of thrombosis in acutely ill medical patients compared to enoxaparin $40 \mathrm{mg}$ once daily for 10 days. This large, randomized, doubleblind multicenter study (MAGELLAN) also included patients with active cancer who had been hospitalized for chemotherapy or treatment of the complications of the active cancer. Study enrolment closed in April 2010.

\section{Direct oral thrombin inhibitors}

Dabigatran etexilate is an oral direct thrombin inhibitor that reaches its plasma peak after $2 \mathrm{~h}$ and has a half-life of approximately 14-17 h. It is primarily eliminated via the kidneys and therefore is contraindicated in patients with renal failure. In phase III clinical trials (RE-MODEL, RE-NOVATE and RE- MOBILIZE), two different dosages of dabigatran etexilate $(150 \mathrm{mg}$ and $220 \mathrm{mg}$ ) were compared to enoxaparin in patients undergoing orthopaedic surgery. The results showed that dabigatran etexilate is not significantly different in preventing VTE in patients undergoing knee or hip surgery compared to the standard treatment 
with enoxaparin. In addition, no differences in bleeding events were found between the three arms [67-69]. The phase III RELY study randomized 18,113 patients with non-valvular atrial fibrillation to receive either 110 or $150 \mathrm{mg}$ twice daily dabigatran etexilate, or standard treatment with warfarin (target INR 2-3). The results of the study, recently published, show that $110 \mathrm{mg}$ dabigatran etexilate twice daily is not inferior to warfarin in preventing stroke/systemic embolism and has significantly lower bleeding events (2.71 vs $3.36 \%$ ). The patients receiving higher dosage of $150 \mathrm{mg}$ twice daily dabigatran etexilate had significantly lower rate of stroke/systemic embolism (1.11 vs $1.69 \%$ per year) and similar risk of major bleeding compared to patients on warfarin. Both doses of dabigatran etexilate used in this study showed similar net clinical benefit outcome due to the lower risk of ischemia in $150 \mathrm{mg}$ arm and lower risk of bleeding in $110 \mathrm{mg}$ arm [70]. Recently, the results of the RECOVER randomized, double-blind study were published showing that dabigatran etexilate at a fixed dose of $150 \mathrm{mg}$ twice daily is as effective and similarly safe as VKA in the long term treatment of an acute VTE [71].

\section{Conclusion}

The published guidelines provide specific recommendations for the use of anticoagulants in the prevention and treatments of VTE in cancer patients. However, the available data are limited and new research is needed, by well designed randomized clinical trials. In addition, the available clinical trials cannot recommend anticoagulation to improve cancer patients' survival and new clinical trials designed specifically for this reason are needed to improve the current guidelines. Alternatively, new anticoagulants, such as direct FXa and thrombin inhibitors, have the potential to substitute for the current LMWH prevention and long term treatment in cancer patients. The preliminary data are suggestive of a potential clinical benefit from several of these agents. However, many questions remain and it is therefore important to evaluate the effectiveness and safety of the new anticoagulants in cancer setting.

\section{Expert opinion}

Cancer-associated thrombosis is a common cause of morbidity and mortality in patients with malignancy. Due to the introduction of new more thrombogenic chemotherapeutic regimens, improved oncology outcomes and an aging population, the incidence of thrombosis in cancer is continuously increasing. In this setting, thrombosis interferes with cancer treatment, prolongs patient hospitalization, increases the use of healthcare resourses and finally increases patients' emotional and economic burden. Treatment of thrombosis in cancer is critical, as the current treatments strategies still do not meet patient needs; even treated cancer patients experience recurrent thrombosis.

On the basis of the increasing concern about VTE risk in cancer patients, the prevention of VTE has become an important issue. The new oral anticoagulants could have a potential for the primary prevention of thrombosis, especially in 
those patients receiving anticancer treatments. Generally, clinical studies of the new anticoagulants begin with patients in need of short term prevention of VTE. These are typically patients undergoing hip or knee elective surgery. In this setting the efficacy and the safety of the drug profile is being examined and the eventual adverse events from the drug administration are recognized. The next phase of the drug clinical development is evaluating the anticoagulant effect in patients with a disease such as DVT or PE. Finally, antithrombotic drugs are evaluated in patients in need of long term prevention, such as patients with atrial fibrillation at risk of stroke or systemic embolism.

Cancer is a high risk situation for thrombosis. Except for one small phase II trial of apixaban in patients with metastatic cancer, no trial has been designed to evaluate the effect of the new antithrombotic drugs in cancer patients. It is therefore difficult to draw conclusion for this setting based on the results of the trials designed for different indications. In addition, even with the risk of thrombosis, these patients are also at increased risk of bleeding. Although the task is challenging, finding an adequate substitute drug for the current therapeutic management of VTE in cancer is important.

It is particularly important to understand the two-way relationship between cancer and haemostasis that promotes a hypercoagulable state and enhances thromboembolic complications. Whereas the tumour cells demonstrate a procoagulant phenotype, the thrombosis modulates cancer growth and enhances cancer dissemination [72]. Hypercoagulation can be detected in the early stages of malignant diseases as low grade intravascular coagulation [73]. The principal mechanism by which tumour cells activate blood coagulation is by the production of haemostatic factors (i.e. the tissue factor and the cancer procoagulant), the release of pro-inflammatory and pro-angiogenic factors and the expression of adhesion molecules [72]. A number of preclinical studies suggest the potential anticancer properties of the heparin and LMWH [74-75]. It has been demonstrated that, as well as blocking the coagulation cascade, LMWH also has clotting independent activities against cancer [76]. Therefore, the use of anticoagulant drugs is seen not only to restore the hypercoagulable state but also to block tumour growth and tumour dissemination. In this sense it is important to evaluate the effect of the new antithrombotic drugs on tumour progression and cancer survival. New studies are needed to evaluate whether the new agents will retain the same anti-inflamatory, immunomodulatory and antiangiogenic properties as LMWH in the cancer setting. The results of clinical trials and meta-analysis indicate that LMWH has an influence beyond its effects in coagulation. The available data suggest that LMWH has a direct antitumor effect and influence on cancer patients' survival. However, these studies have several limitations, such as heterogeneity in the cancer population, anticoagulant used, dosage and duration. Future prospective trials are therefore needed to clarify which LMWH is most effective, at what dosage and duration, and which cancer population would benefit the most. 


\section{Article highlights}

- Cancer patients are at increased risk for developing thrombosis either as DVT or PE.

- Cancer-associated thrombosis predicts worse prognosis in patients with malignancy.

- Current guidelines recommend the use of antithrombotic prophylaxis only in hospitalized cancer patients in absence of contraindications.

- LMWH is preferred as monotherapy at least 3 months in patients with VTE and cancer followed by LMWH or warfarin as long as the cancer is active.

- In case of recurrent VTE switch to LMWH in "warfarin failures" or increase LMWH dosage in "LMWH failures".

- Thrombin and Factor Xa inhibitors are potentially suitable for use in oncology due to their advantageous mode of oral administration without need for regular laboratory monitoring.

- New clinical trails are needed to evaluate the effectiveness and the safety profile of the new antithrombotic drugs in cancer patients. 


\section{References:}

1 Sorensen HT, Mellemkjaer L, Olsen JH, Baron JA. Prognosis of cancers associated with venous thromboembolism. The New England journal of medicine. 2000; 343: 1846-50.

2 Khorana AA, Francis CW, Culakova E, Kuderer NM, Lyman GH. Frequency, risk factors, and trends for venous thromboembolism among hospitalized cancer patients. Cancer. 2007; 110: 2339-46.

3 Chew HK, Wun T, Harvey D, Zhou H, White RH. Incidence of venous thromboembolism and its effect on survival among patients with common cancers. Archives of internal medicine. 2006; 166: 458-64.

4 Blom JW, Doggen CJ, Osanto S, Rosendaal FR. Malignancies, prothrombotic mutations, and the risk of venous thrombosis. Jama. 2005; 293: 715-22.

5 Buller HR, van Doormaal FF, van Sluis GL, Kamphuisen PW. Cancer and thrombosis: from molecular mechanisms to clinical presentations. J Thromb Haemost. 2007; 5 Suppl 1: 246-54.

6 Heit JA, O'Fallon WM, Petterson TM, Lohse CM, Silverstein MD, Mohr DN, Melton LJ, 3rd. Relative impact of risk factors for deep vein thrombosis and pulmonary embolism: a populationbased study. Archives of internal medicine. 2002; 162: 1245-8.

7 Donati MB. Thrombosis and cancer: Trousseau syndrome revisited. Best practice \& research. 2009; 22: 3-8.

$8 \quad$ Prins MH, Hettiarachchi RJ, Lensing AW, Hirsh J. Newly diagnosed malignancy in patients with venous thromboembolism. Search or wait and see? Thrombosis and haemostasis. 1997; 78: 121-5.

9 Monreal M, Fernandez-Llamazares J, Perandreu J, Urrutia A, Sahuquillo JC, Contel E. Occult cancer in patients with venous thromboembolism: which patients, which cancers. Thrombosis and haemostasis. 1997; 78: 1316-8.

10 Iodice S, Gandini S, Lohr M, Lowenfels AB, Maisonneuve P. Venous thromboembolic events and organ-specific occult cancers: a review and meta-analysis. J Thromb Haemost. 2008; 6: 781-8.

11 Khorana AA, Francis CW, Culakova E, Fisher RI, Kuderer NM, Lyman GH. Thromboembolism in hospitalized neutropenic cancer patients. J Clin Oncol. 2006; 24: 484-90.

12 Blom JW, Vanderschoot JP, Oostindier MJ, Osanto S, van der Meer FJ, Rosendaal FR. Incidence of venous thrombosis in a large cohort of 66,329 cancer patients: results of a record linkage study. J Thromb Haemost. 2006; 4: 529-35.

13 Blom JW, Osanto S, Rosendaal FR. The risk of a venous thrombotic event in lung cancer patients: higher risk for adenocarcinoma than squamous cell carcinoma. J Thromb Haemost. 2004; 2: $1760-5$.

14 Alcalay A, Wun T, Khatri V, Chew HK, Harvey D, Zhou H, White RH. Venous thromboembolism in patients with colorectal cancer: incidence and effect on survival. J Clin Oncol. 2006; 24: 1112-8.

15 Rodriguez AO, Wun T, Chew H, Zhou H, Harvey D, White RH. Venous thromboembolism in ovarian cancer. Gynecologic oncology. 2007; 105: 784-90.

16 Heit JA, Silverstein MD, Mohr DN, Petterson TM, O'Fallon WM, Melton LJ, 3rd. Risk factors for deep vein thrombosis and pulmonary embolism: a population-based case-control study. Archives of internal medicine. 2000; 160: 809-15.

17 Agnelli G, Bolis G, Capussotti L, Scarpa RM, Tonelli F, Bonizzoni E, Moia M, Parazzini F, Rossi R, Sonaglia F, Valarani B, Bianchini C, Gussoni G. A clinical outcome-based prospective study on venous thromboembolism after cancer surgery: the @RISTOS project. Annals of surgery. 2006; 243: 89-95.

18 Falanga A. The incidence and risk of venous thromboembolism associated with cancer and nonsurgical cancer treatment. Cancer investigation. 2009; 27: 105-15.

19 Alkindi S, Dennison D, Pathare A. Arterial and venous thrombotic complications with thalidomide in multiple myeloma. Archives of medical research. 2008; 39: 257-8. 
20 Palumbo A, Rajkumar SV, Dimopoulos MA, Richardson PG, San Miguel J, Barlogie B, Harousseau J, Zonder JA, Cavo M, Zangari M, Attal M, Belch A, Knop S, Joshua D, Sezer O, Ludwig H, Vesole D, Blade J, Kyle R, Westin J, Weber D, Bringhen S, Niesvizky R, Waage A, von Lilienfeld-Toal M, Lonial S, Morgan GJ, Orlowski RZ, Shimizu K, Anderson KC, Boccadoro M, Durie BG, Sonneveld P, Hussein MA. Prevention of thalidomide- and lenalidomide-associated thrombosis in myeloma. Leukemia. 2008; 22: 414-23.

21 Deitcher SR, Gomes MP. The risk of venous thromboembolic disease associated with adjuvant hormone therapy for breast carcinoma: a systematic review. Cancer. 2004; 101: 439-49.

22 Lycette JL, Luoh SW, Beer TM, Deloughery TG. Acute bilateral pulmonary emboli occurring while on adjuvant aromatase inhibitor therapy with anastrozole: Case report and review of the literature. Breast cancer research and treatment. 2006; 99: 249-55.

23 Caruso V, Iacoviello L, Di Castelnuovo A, Storti S, Mariani G, de Gaetano G, Donati MB. Thrombotic complications in childhood acute lymphoblastic leukemia: a meta-analysis of 17 prospective studies comprising 1752 pediatric patients. Blood. 2006; 108: 2216-22.

24 Gugliotta L, Mazzucconi MG, Leone G, Mattioli-Belmonte M, Defazio D, Annino L, Tura S, Mandelli F. Incidence of thrombotic complications in adult patients with acute lymphoblastic leukaemia receiving $\mathrm{L}$-asparaginase during induction therapy: a retrospective study. The GIMEMA Group. European journal of haematology. 1992; 49: 63-6.

25 Melillo L, Grandone E, Colaizzo D, Cappucci F, Valvano MR, Cascavilla N. Symptomatic venous thromboembolism and thrombophilic status in adult acute leukemia: a single-center experience of 114 patients at diagnosis. Acta haematologica. 2007; 117: 215-20.

26 Littlewood TJ, Bajetta E, Nortier JW, Vercammen E, Rapoport B. Effects of epoetin alfa on hematologic parameters and quality of life in cancer patients receiving nonplatinum chemotherapy: results of a randomized, double-blind, placebo-controlled trial. J Clin Oncol. 2001; 19: 2865-74.

27 Khorana AA, Francis CW, Culakova E, Lyman GH. Risk factors for chemotherapyassociated venous thromboembolism in a prospective observational study. Cancer. 2005; 104: 2822-9.

28 Kuter DJ. Thrombotic complications of central venous catheters in cancer patients. The oncologist. 2004; 9: 207-16.

29 Prandoni P, Lensing AW, Piccioli A, Bernardi E, Simioni P, Girolami B, Marchiori A, Sabbion P, Prins MH, Noventa F, Girolami A. Recurrent venous thromboembolism and bleeding complications during anticoagulant treatment in patients with cancer and venous thrombosis. Blood. 2002; 100: 3484-8.

30 Mandala M, Falanga A, Piccioli A, Prandoni P, Pogliani EM, Labianca R, Barni S. Venous thromboembolism and cancer: guidelines of the Italian Association of Medical Oncology (AIOM). Critical reviews in oncology/hematology. 2006; 59: 194-204.

31 Mandala M, Falanga A, Roila F. Management of venous thromboembolism in cancer patients: ESMO clinical recommendations. Ann Oncol. 2008; 19 Suppl 2: ii126-7.

32 Farge D, Bosquet L, Kassab-Chahmi D, Mismetti P, Elalamy I, Meyer G, Cajfinger F, Desmurs-Clavel H, Elias A, Grange C, Hocini H, Legal G, Mahe I, Quere I, Levesque H, Debourdeau P. 2008 french national guidelines for the treatment of venous thromboembolism in patients with cancer: Report from the working group. Critical reviews in oncology/hematology. 2009.

33 Wagman LD, Baird MF, Bennett CL, Bockenstedt PL, Cataland SR, Fanikos J, Fogarty PF, Goldhaber SZ, Grover TS, Haire W, Hassoun H, Jahanzeb M, Leung LL, Linenberger ML, Millenson MM, Ortel TL, Salem R, Smith JL, Streiff MB. Venous thromboembolic disease. Clinical practice guidelines in oncology. J Natl Compr Canc Netw. 2006; 4: 838-69.

34 Lyman GH, Khorana AA, Falanga A, Clarke-Pearson D, Flowers C, Jahanzeb M, Kakkar A, Kuderer NM, Levine MN, Liebman H, Mendelson D, Raskob G, Somerfield MR, Thodiyil P, Trent D, Francis CW. American Society of Clinical Oncology guideline: recommendations for venous thromboembolism prophylaxis and treatment in patients with cancer. J Clin Oncol. 2007; 25: 5490505 .

35 Kearon C, Kahn SR, Agnelli G, Goldhaber S, Raskob GE, Comerota AJ. Antithrombotic therapy for venous thromboembolic disease: American College of Chest Physicians Evidence-Based Clinical Practice Guidelines (8th Edition). Chest. 2008; 133: 454S-545S.

36 Prevention and treatment of venous thromboembolism. International Consensus Statement (guidelines according to scientific evidence). Int Angiol. 2006; 25: 101-61. 
37 Gould MK, Dembitzer AD, Doyle RL, Hastie TJ, Garber AM. Low-molecular-weight heparins compared with unfractionated heparin for treatment of acute deep venous thrombosis. A meta-analysis of randomized, controlled trials. Annals of internal medicine. 1999; 130: 800-9.

38 Buller HR, Davidson BL, Decousus H, Gallus A, Gent M, Piovella F, Prins MH, Raskob G, van den Berg-Segers AE, Cariou R, Leeuwenkamp O, Lensing AW. Subcutaneous fondaparinux versus intravenous unfractionated heparin in the initial treatment of pulmonary embolism. The New England journal of medicine. 2003; 349: 1695-702.

39 Buller HR, Davidson BL, Decousus H, Gallus A, Gent M, Piovella F, Prins MH, Raskob G, Segers AE, Cariou R, Leeuwenkamp O, Lensing AW. Fondaparinux or enoxaparin for the initial treatment of symptomatic deep venous thrombosis: a randomized trial. Annals of internal medicine. 2004; 140: 867-73.

40 van Doormaal FF, Raskob GE, Davidson BL, Decousus H, Gallus A, Lensing AW, Piovella F, Prins MH, Buller HR. Treatment of venous thromboembolism in patients with cancer: subgroup analysis of the Matisse clinical trials. Thrombosis and haemostasis. 2009; 101: 762-9.

41 Lee AY, Levine MN, Baker RI, Bowden C, Kakkar AK, Prins M, Rickles FR, Julian JA, Haley S, Kovacs MJ, Gent M. Low-molecular-weight heparin versus a coumarin for the prevention of recurrent venous thromboembolism in patients with cancer. The New England journal of medicine. 2003; 349: 146-53.

42 Romera A, Cairols MA, Vila-Coll R, Marti X, Colome E, Bonell A, Lapiedra O. A randomised open-label trial comparing long-term sub-cutaneous low-molecular-weight heparin compared with oral-anticoagulant therapy in the treatment of deep venous thrombosis. Eur J Vasc Endovasc Surg. 2009; 37: 349-56.

43 Meyer G, Marjanovic Z, Valcke J, Lorcerie B, Gruel Y, Solal-Celigny P, Le Maignan C, Extra JM, Cottu P, Farge D. Comparison of low-molecular-weight heparin and warfarin for the secondary prevention of venous thromboembolism in patients with cancer: a randomized controlled study. Archives of internal medicine. 2002; 162: 1729-35.

44 Louzada ML, Majeed H, Wells PS. Efficacy of low- molecular- weight- heparin versus vitamin $\mathrm{K}$ antagonists for long term treatment of cancer-associated venous thromboembolism in adults: a systematic review of randomized controlled trials. Thrombosis research. 2009; 123: 837-44. 45 Akl EA, Barba M, Rohilla S, Terrenato I, Sperati F, Muti P, Schunemann HJ. Anticoagulation for the long term treatment of venous thromboembolism in patients with cancer. Cochrane database of systematic reviews (Online). 2008: CD006650.

46 Hutten BA, Prins MH, Gent M, Ginsberg J, Tijssen JG, Buller HR. Incidence of recurrent thromboembolic and bleeding complications among patients with venous thromboembolism in relation to both malignancy and achieved international normalized ratio: a retrospective analysis. $J$ Clin Oncol. 2000; 18: 3078-83.

47 Hansson PO, Sorbo J, Eriksson H. Recurrent venous thromboembolism after deep vein thrombosis: incidence and risk factors. Archives of internal medicine. 2000; 160: 769-74.

48 Carrier M, Le Gal G, Cho R, Tierney S, Rodger M, Lee AY. Dose escalation of low molecular weight heparin to manage recurrent venous thromboembolic events despite systemic anticoagulation in cancer patients. J Thromb Haemost. 2009; 7: 760-5.

49 Schunn C, Schunn GB, Hobbs G, Vona-Davis LC, Waheed U. Inferior vena cava filter placement in late-stage cancer. Vascular and endovascular surgery. 2006; 40: 287-94.

50 Wallace MJ, Jean JL, Gupta S, Eapen GA, Johnson MM, Ahrar K, Madoff DC, Morello FA, Murthy R, Hicks ME. Use of inferior vena caval filters and survival in patients with malignancy. Cancer. 2004; 101: 1902-7.

51 Athale UH, Chan AK. Thrombosis in children with acute lymphoblastic leukemia. Part II. Pathogenesis of thrombosis in children with acute lymphoblastic leukemia: effects of the disease and therapy. Thrombosis research. 2003; 111: 199-212.

$52 \quad$ Athale UH, Chan AK. Thrombosis in children with acute lymphoblastic leukemia: part I. Epidemiology of thrombosis in children with acute lymphoblastic leukemia. Thrombosis research. 2003; 111: 125-31.

53 Giordano P, Del Vecchio GC, Saracco P, Zecca M, Molinari AC, De Mattia D. A practical approach to diagnosis and treatment of symptomatic thromboembolic events in children with acute lymphoblastic leukemia: recommendations of the "Coagulation Defects" AIEOP Working Group. Recent patents on cardiovascular drug discovery. 2007; 2: 53-62.

54 Yang J, Paredes N, Chan AK. Antithrombotic therapy in children with venous thromboembolism. Hamostaseologie. 2009; 29: 80-7. 
55 A novel long-acting synthetic factor Xa inhibitor (SanOrg34006) to replace warfarin for secondary prevention in deep vein thrombosis. A Phase II evaluation. J Thromb Haemost. 2004; 2: 47-53.

56 Buller HR, Cohen AT, Davidson B, Decousus H, Gallus AS, Gent M, Pillion G, Piovella F, Prins MH, Raskob GE. Idraparinux versus standard therapy for venous thromboembolic disease. The New England journal of medicine. 2007; 357: 1094-104.

57 Buller HR, Cohen AT, Davidson B, Decousus H, Gallus AS, Gent M, Pillion G, Piovella F, Prins MH, Raskob GE. Extended prophylaxis of venous thromboembolism with idraparinux. The New England journal of medicine. 2007; 357: 1105-12.

58 Bousser MG, Bouthier J, Buller HR, Cohen AT, Crijns H, Davidson BL, Halperin J, Hankey G, Levy S, Pengo V, Prandoni P, Prins MH, Tomkowski W, Torp-Pedersen C, Wyse DG. Comparison of idraparinux with vitamin $\mathrm{K}$ antagonists for prevention of thromboembolism in patients with atrial fibrillation: a randomised, open-label, non-inferiority trial. Lancet. 2008; 371: 315-21.

59 Savi P, Herault JP, Duchaussoy P, Millet L, Schaeffer P, Petitou M, Bono F, Herbert JM. Reversible biotinylated oligosaccharides: a new approach for a better management of anticoagulant therapy. J Thromb Haemost. 2008; 6: 1697-706.

60 Weitz JI, Hirsh J, Samama MM. New antithrombotic drugs: American College of Chest Physicians Evidence-Based Clinical Practice Guidelines (8th Edition). Chest. 2008; 133: 234S-56S.

61 Lassen MR, Raskob GE, Gallus A, Pineo G, Chen D, Portman RJ. Apixaban or enoxaparin for thromboprophylaxis after knee replacement. The New England journal of medicine. 2009; 361: 594604.

62 M.N. Levine HAL, C.P. Esclanate, J.A. Julian, D. Deitchman, M.C. O'Brien and L.M. Ramirez. Randomized phase II trial of an oral factor Xa inhibitor in patients with metastatic cancer on chemotherapy Thrombosis research. 2010; 125: S161-S2.

63 Eriksson BI, Borris LC, Friedman RJ, Haas S, Huisman MV, Kakkar AK, Bandel TJ, Beckmann H, Muehlhofer E, Misselwitz F, Geerts W. Rivaroxaban versus enoxaparin for thromboprophylaxis after hip arthroplasty. The New England journal of medicine. 2008; 358: 276575.

64 Kakkar AK, Brenner B, Dahl OE, Eriksson BI, Mouret P, Muntz J, Soglian AG, Pap AF, Misselwitz F, Haas S. Extended duration rivaroxaban versus short-term enoxaparin for the prevention of venous thromboembolism after total hip arthroplasty: a double-blind, randomised controlled trial. Lancet. 2008; 372: 31-9.

65 Lassen MR, Ageno W, Borris LC, Lieberman JR, Rosencher N, Bandel TJ, Misselwitz F, Turpie AG. Rivaroxaban versus enoxaparin for thromboprophylaxis after total knee arthroplasty. The New England journal of medicine. 2008; 358: 2776-86.

66 Turpie AG, Lassen MR, Davidson BL, Bauer KA, Gent M, Kwong LM, Cushner FD, Lotke PA, Berkowitz SD, Bandel TJ, Benson A, Misselwitz F, Fisher WD. Rivaroxaban versus enoxaparin for thromboprophylaxis after total knee arthroplasty (RECORD4): a randomised trial. Lancet. 2009; 373: 1673-80.

67 Eriksson BI, Dahl OE, Rosencher N, Kurth AA, van Dijk CN, Frostick SP, Kalebo P, Christiansen AV, Hantel S, Hettiarachchi R, Schnee J, Buller HR. Oral dabigatran etexilate vs. subcutaneous enoxaparin for the prevention of venous thromboembolism after total knee replacement: the RE-MODEL randomized trial. J Thromb Haemost. 2007; 5: 2178-85.

68 Eriksson BI, Dahl OE, Rosencher N, Kurth AA, van Dijk CN, Frostick SP, Prins MH, Hettiarachchi R, Hantel S, Schnee J, Buller HR. Dabigatran etexilate versus enoxaparin for prevention of venous thromboembolism after total hip replacement: a randomised, double-blind, non-inferiority trial. Lancet. 2007; 370: 949-56.

69 Ginsberg JS, Davidson BL, Comp PC, Francis CW, Friedman RJ, Huo MH, Lieberman JR, Muntz JE, Raskob GE, Clements ML, Hantel S, Schnee JM, Caprini JA. Oral thrombin inhibitor dabigatran etexilate vs North American enoxaparin regimen for prevention of venous thromboembolism after knee arthroplasty surgery. The Journal of arthroplasty. 2009; 24: 1-9.

70 Connolly SJ, Ezekowitz MD, Yusuf S, Eikelboom J, Oldgren J, Parekh A, Pogue J, Reilly PA, Themeles E, Varrone J, Wang S, Alings M, Xavier D, Zhu J, Diaz R, Lewis BS, Darius H, Diener HC, Joyner CD, Wallentin L. Dabigatran versus warfarin in patients with atrial fibrillation. The New England journal of medicine. 2009; 361: 1139-51.

71 Schulman S, Kearon C, Kakkar AK, Mismetti P, Schellong S, Eriksson H, Baanstra D, Schnee J, Goldhaber SZ. Dabigatran versus warfarin in the treatment of acute venous thromboembolism. The New England journal of medicine. 2009; 361: 2342-52. 
72 Falanga A, Panova-Noeva M, Russo L. Procoagulant mechanisms in tumour cells. Best practice \& research. 2009; 22: 49-60.

73 Falanga A, Barbui T, Rickles FR, Levine MN. Guidelines for clotting studies in cancer patients. For the Scientific and Standardization Committee of the Subcommittee on Haemostasis and Malignancy International Society of Thrombosis and Haemostasis. Thrombosis and haemostasis. 1993; 70: 540-2.

74 Smorenburg SM, Vink R, Otten HM, Swaneveld F, Buller HR. The effects of vitamin Kantagonists on survival of patients with malignancy: a systematic analysis. Thrombosis and haemostasis. 2001; 86: 1586-7.

75 Niers TM, Klerk CP, DiNisio M, Van Noorden CJ, Buller HR, Reitsma PH, Richel DJ. Mechanisms of heparin induced anti-cancer activity in experimental cancer models. Critical reviews in oncology/hematology. 2007; 61: 195-207.

76 Falanga A, Piccioli A. Effect of anticoagulant drugs in cancer. Current opinion in pulmonary medicine. 2005; 11: 403-7. 


\section{CHAPTER 4}

Monitoring thrombin generation: is addition of corn trypsin inhibitor needed?

Henri M.H. Spronk, Arne W.J.H. Dielis, Marina Panova-Noeva, René van Oerle, José W.P. Govers-Riemslag, Karly Hamulyák, Anna Falanga, Hugo Ten Cate

Thrombosis and Haemostasis. 2009;101(6):1156-62. 


\section{Summary}

Thrombin generation monitoring has the potential to be used as a clinical diagnostic tool in the near future. However, robust pre-analytical conditions may be required and one factor that has been reported is in-vitro contact activation that might influence in-vitro measurements of thrombin generation and thereby act as an unpredictable pre-analytical variable. The aim of the current study was to investigate the influence of contact activation and the necessity of corn trypsin inhibitor (CTI) to abolish contact activation in thrombin generation measurements at low tissue factor (TF) concentrations. Thrombin generation was performed using the Calibrated Automated Thrombinoscopy (CAT), thereby determining the endogenous thrombin potential (ETP), peak height, and the lag time, in plasma obtained from healthy volunteers. Addition of CTI after plasma preparation had no significant influence on thrombin generation triggered with $0.5 \mathrm{pM}$ TF or higher, as demonstrated by unaltered ETP and lag time values between analyses with and without CTI. Addition of CTI before blood collection reduced thrombin generation triggered with $0.5 \mathrm{pM}$ TF: both the ETP and peak height were significantly reduced compared to no CTI addition. In contrast, thrombin generation remained unaltered at a $1 \mathrm{pM}$ TF trigger or above. This study demonstrates that addition of CTI after plasma separation is not necessary when triggering with TF concentrations of $0.5 \mathrm{pM}$ and higher. Furthermore, it was demonstrated that it is not needed to pre-fill blood collecting tubes with CTI when measuring thrombin generation at TF concentrations of $\geq 1 \mathrm{pM}$. 


\section{Introduction}

Thrombin is an essential enzyme in the coagulation cascade [1] and changes in thrombin production may be associated with thrombotic as well as haemorrhagic conditions in patients [2-9]. One of the more commonly used methods to assess thrombin generation in plasma is the Calibrated Automated Thrombogram (CAT, Thrombinoscope BV, Maastricht, The Netherlands). This method uses a low affinity fluorogenic substrate (Z-Gly-Gly-Arg-AMC), which is converted into a fluorescent signal by thrombin. The activity of thrombin is thus continuously registered over time, resulting in a characteristic thrombin generation curve. Over the past years this method was validated for pre-analytical conditions [10-12] and shown to exert good reproducibility and stability. One problem, however, might be the activation of factor (F)XII during blood drawing and/or during analysis. Recently, van Veen and Dargaud demonstrated the contribution of contact activation to thrombin generation analysis, especially at low concentrations of TF $[10,12]$, thereby introducing an unpredictable preanalytical variable which increased inaccuracy and imprecision [13]. The use of the specific FXIIa inhibitor corn trypsin inhibitor (CTI) attenuated the effects of contact activation observed during thrombin generation. The consequences of contact activation for clinical practice are considerable: addition of CTI to blood collection tubes increases the costs and requires an additional tube besides the commonly used vacutainer. Since contact activation can occur during venipuncture or in the thrombin generation analysis itself, we hypothesized that the blood collection procedure and the used reagents for thrombin generation are key determinants in in-vitro activation of FXII. In order to verify the previous results of Van Veen and Dargaud, as well as to determine the effects of blood collection and used reagents, we analyzed thrombin generation under well defined conditions with and without CTI.

\section{Methods}

\section{Experimental design}

1. Effects of blood collection method.

Venous blood from four healthy volunteers was simultaneously collected using a standard 21-gauge needle (BD, Plymouth, UK) for the right arm and a Winged Infusion Set or "butterfly"-needle equipped with a $30 \mathrm{~cm}$ long tubing (Push Button Blood Collection Set, BD) for the left arm.

\section{Effects of CTI-addition to plasma.}

Venous blood from twelve healthy volunteers was collected in $3.2 \%(\mathrm{w} / \mathrm{v})$ citrate using a 21-gauge needle and plasma was prepared as described below. Just before thrombin generation analysis CTI was added to the plasmas to obtain a final concentration of 25 or $50 \mu \mathrm{g} / \mathrm{ml}$. Thrombin generation was analyzed using $0.5,1,2$, or $5 \mathrm{pM}$ TF as trigger. 
3. Effects of CTI-addition to venous blood.

Venous blood from twelve healthy volunteers (the same subjects as above) was collected in $3.2 \%(\mathrm{w} / \mathrm{v}$ ) citrate containing CTI (final concentration of $40 \mu \mathrm{g} / \mathrm{ml}$ in plasma) using a 21-gauge needle. Thrombin generation was analyzed using $0.5,1,2$, or $5 \mathrm{pM}$ TF as trigger.

\section{Blood collection and plasma preparation}

Venous blood from the left and from the right arm of four healthy volunteers was collected in $3.2 \%(\mathrm{w} / \mathrm{v})$ citrate using a 21 -gauge needle (BD) or a Winged Infusion Set (BD) through venipuncture. The first $10 \mathrm{~mL}$ of venous blood were discarded. Platelet-poor plasma (PPP) was prepared by two centrifugation steps: the first at 2,000 x g for 15 minutes (min) and the second at 11,000 x g for $10 \mathrm{~min}$. Plasma aliquots were snap-frozen in liquid nitrogen and stored at $80{ }^{\circ} \mathrm{C}$ until use. All samples were thawed at $37^{\circ} \mathrm{C}$ for $15 \mathrm{~min}$ before analysis and analyzed batch-wise. CTI was obtained from Haematologic Technologies, Inc. (Essex Junction, VT) and added to the $3.2 \%(\mathrm{w} / \mathrm{v})$ citrate collection tubes to obtain a final concentration of $40 \mu \mathrm{g} / \mathrm{ml}$ in plasma. To study the effect of CTI addition during thrombin generation, CTI was added to plasma before analysis to obtain final concentrations of 25 or $50 \mu \mathrm{g} / \mathrm{ml}$. Kaolin was added to $3.2 \%$ $(\mathrm{w} / \mathrm{v})$ citrate tubes to obtain a final concentration of $1 \mathrm{mg} / \mathrm{ml}$ after plasma collection.

\section{Normal pool plasma and FXII-deficient plasmas}

Normal pooled plasma was prepared at the departments of Haematology and Clinical Chemistry of the Maastricht University Medical Center, The Netherlands, by pooling plasma from 85 healthy volunteers not using any medication. FXII-deficient plasma was either obtained from the Maastricht University Medical Center (indicated as FXII-deficient plasma [1]) or George King Bio-Medical Inc. (Overland Park, KS, USA; indicated as FXII-deficient plasma [2]) and were both from patients with a congenital FXII-deficiency. FXI-deficient plasma was obtained from George King Bio-Medical Inc.

\section{Thrombin generation}

Thrombin generation in tissue factor (TF)-triggered platelet poor plasma was measured by means of the CAT method (Thrombinoscope BV) as described previously [14], which makes use of a low affinity fluorogenic substrate for thrombin (Z-Gly-Gly-Arg-AMC) to continuously monitor thrombin activity in clotting plasma. In order to correct for inner-filter effects and substrate consumption, each thrombin generation measurement was calibrated against the fluorescence curve obtained in the same plasma with a fixed amount of thrombin- $\alpha 2$-macroglobulin complex (Thrombin Calibrator, Thrombinoscope BV), as recommended by the manufacturer. Fluorescence was read in an Ascent Reader (Thermolabsystems OY, Helsinki, Finland) equipped with a 390/460 filter set, 
and thrombin generation curves were calculated with the Thrombinoscope software (Thrombinoscope BV).

Unless stated otherwise, thrombin generation was determined under several experimental conditions (final plasma concentrations): $0.5,1,2$, or $5 \mathrm{pM}$ TF and $4 \mu \mathrm{M}$ phospholipids. The TF triggers and phospholipids were obtained from Thrombinoscope BV. Three parameters were derived from the thrombin generation curves: lag time, peak height and endogenous thrombin potential (ETP, area under the curve).

\section{FXIIa-C1-esterase inhibitor complex measurement}

Complexes of FXIIa and FXIa with their natural inhibitor C1 esterase inhibitor, respectively, were measured with enzyme-linked immunosorbent assays (ELISAs), using monoclonal antibodies ( $\mathrm{mAb}$ ) and as described previously [15]. In brief, mAb F3 was used to recognize FXII, mAb XI-5 to FXI, and mAb KOK 12 specific for complexed C1 esterase inhibitor. Appropriate secondary antibodies were biotinylated using EZLink N-hydroxysuccinimide ester-biotin according to instructions from the manufacturer (Pierce, Rockford, IL, USA). Absorbance was read at $450 \mathrm{~nm}$ on an EL 808 Ultra microplate reader (Bio-tek Instruments Inc., Winooski, VT, USA). Results were expressed as a percentage of activated normal pooled plasma. Normal pooled EDTA plasma was maximally activated at 37 ${ }^{\circ} \mathrm{C}$ by incubation with an equal volume of $0.2 \mathrm{mg} / \mathrm{ml}$ dextran sulfate ( $\mathrm{Mr} 500$ 000; Sigma Chemical Co., St Louis, MO, USA) to obtain reference curves for the FXIIa:C1 esterase inhibitor ELISA, whereas kaolin (final concentration 5 $\mathrm{mg} / \mathrm{ml}$ )-activated EDTA plasma was used for the FXIa:C1 esterase inhibitor ELISA. Activation was stopped by adding three volumes of phosphate-buffered saline (PBS) containing $0.1 \mathrm{mg} / \mathrm{ml}$ soybean trypsin inhibitor (Sigma Chemical Co.) and $0.05 \%(\mathrm{w} / \mathrm{v}$ ) polybrene (Sigma Chemical Co.). Kaolin was removed by centrifuging the reaction mixture for $5 \mathrm{~min}$ at 13,000 x g. No signal was detected in ELISAs performed on activated FXII- or FXI-deficient plasmas.

\section{Statistical analysis}

The data obtained for the thrombin generation experiments are expressed as median with inter quartile range (IQR). Differences in thrombin generation parameters between the groups treated with or without CTI were calculated with a non-parametric paired test (Wilcoxon signed rank test). A two-tailed probability value (p) of $\mathrm{p}<0.05$ was considered statistically significant. Statistical analysis was performed using the Graph Pad Prism 5 software (GraphPad Software, La Jolla, CA, USA).

\section{Results}

\section{Effects of blood collection method}


Inter-laboratory variations in thrombin generation measurements can be the result of differences in equipment (including filter settings and temperature), reagent batches, as well as pre-analytical variables such as the method used for venous blood drawing. Using two different needle systems venous blood was simultaneously obtained from four healthy volunteers. Thrombin generation triggered with $5 \mathrm{pM}$ TF in the prepared PPP was not different between the two collection methods. For the needle system (21-gauge needle) a median ETP of 1,171 nM.min (IQR: 1,158-1,321) was observed whereas for the Winged Infusion Set the ETP was 1,219 nM.min (IQR: 1,179-1,352), differences not significant. Also, the peak height and lag time did not differ between the two systems (data not shown). For the 1 pM TF trigger, however, both the ETP and peak height were significantly increased for plasmas obtained with the Winged Infusion Set compared to the needle system (Figure 1). On average, the ETP increased by almost $15 \%$ or 151 nM.min whereas the peak height gained up to $24 \%$ more thrombin ( $38 \mathrm{nM}$ ) by using a low TF trigger in the thrombin generation assay.

The differences between the two blood drawing systems are most likely due to enhanced contact activation induced by the $30 \mathrm{~cm}$ long tubing in the Winged Infusion Set. In order to find out whether CTI selectively inhibits FXIIa and no other enzymes of the coagulation cascade, 0,25 or $50 \mu \mathrm{g} / \mathrm{ml}$ CTI was added to normal pool plasma and FXII-deficient plasmas. Subsequently, thrombin generation was triggered with 1 or 5 pM TF. No differences in thrombin generation curves were observed for both triggers in the absence or presence of 25 or 50 $\mu \mathrm{g} / \mathrm{mL}$ CTI, suggesting selectivity of CTI for FXIIa. Since no differences were observed between 25 or $50 \mu \mathrm{g} / \mathrm{ml}$ CTI a "safe" concentration of $40 \mu \mathrm{g} / \mathrm{mL}$ CTI (which is two times the concentration previous used [10, 12-13]) was chosen for all further experiments.

Figure 1: Effect of blood collection method on thrombin generation. Venous blood was collected with a 21-gauge needle (Needle) or with a Winged Infusion Set equipped with a $30 \mathrm{~cm}$ long tubing (Butterfly). Thrombin generation was analysed using 1 pM TF as trigger. A) Lag time in min; B) ETP in nM.min thrombin; C) Peak height in nM thrombin. * Denotes $\mathrm{p}<0.05$.
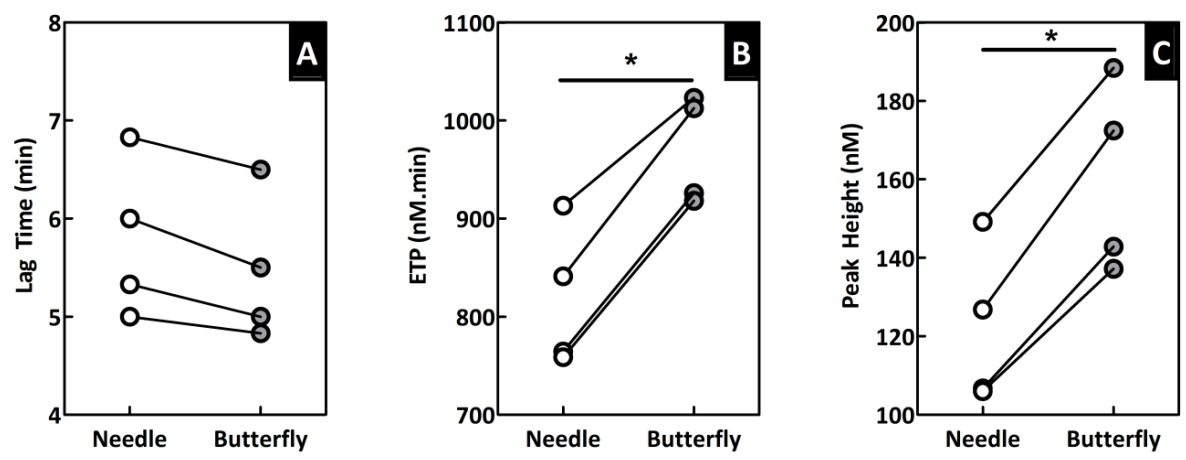


\section{Activation of FXII during blood collection}

To demonstrate activation of FXIIa during collection of blood the contact activation complexes FXIIa-C1 esterase inhibitor and FXIa-C1 esterase inhibitor were analyzed in plasmas obtained from blood collected in $3.2 \%(\mathrm{w} / \mathrm{v})$ citrate blood collection tubes with and without $40 \mu \mathrm{g} / \mathrm{ml}$ CTI. Plasma collected without CTI from twelve healthy volunteers contained $0.16 \%$ (IQR 0.14-0.16) FXIIa-C1 esterase inhibitor complexes and this level was comparable to the concentrations in plasmas collected in the presence of CTI (0.16\% IQR: 0.14-0.18). FXIa-C1 esterase inhibitor complexes, however, were decreased in plasmas containing CTI (0.17\% IRQ: $0.14-0.29$ vs. $0.27 \%$ IRQ: $0.22-0.33$, $\mathrm{p}=0.01$, Figure 2 ).

To show that the presence of CTI in a venous blood collection tube effectively inhibits FXIIa, kaolin ( $1 \mathrm{mg} / \mathrm{ml})$ was added to the tubes in order to activate FXII and thrombin generation was recorded subsequently. Kaolin was found to be a strong initiator of thrombin generation since the lag times shifted from 10.3 min (IQR 8.1-12.2) towards 2.6 min (IQR 2.4-2.9, p<0.01). The ETP and peak height increased as well upon addition of kaolin to venous blood collection tubes. The ETP increased by almost 16\% from 1,386 nM.min (IQR 1,109-1,448) to 1,603 nM.min (IQR 1,386-1,764) upon kaolin addition. The effect was even stronger for the peak height with an increase of 40\% from 297 nM (IQR 226354 ) to $415 \mathrm{nM}$ (IQR 403-442). Combined addition of kaolin and CTI to the blood collection tubes reduced thrombin generation to a level observed for citrated plasma alone. The lag time prolonged to $8.3 \mathrm{~min}(8.0-13.6)$ and both ETP and peak height reduced to 1,490 nM.min (IQR 1,129-1,590, p<0.01 compared to kaolin) and $326 \mathrm{nM}$ (IQR 209-365, p<0.01 compared to kaolin), respectively.

Figure 2: Activation of FXII and FXI during blood drawing. FXIIa- and FXIa-C1 esterase inhibitor complexes were analysed in plasma prepared from blood collected without CTI (-CTI) or with 40 $\mu \mathrm{g} / \mathrm{ml}$ CTI present during drawing (+CTI). The FXIIa-C1 esterase inhibitor complexes are depicted in the left panel, whereas the FXIa-C1 esterase inhibitor complexes are shown in the right panel.
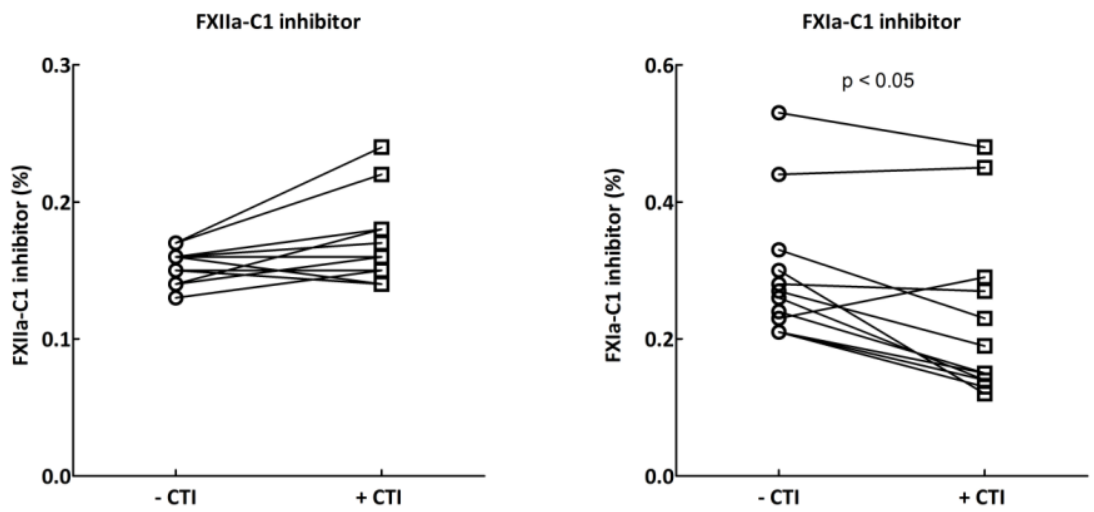


\section{Effects of CTI addition to plasma on thrombin generation}

In order to demonstrate whether CTI addition to plasma influenced thrombin generation under conditions using the standard TF-triggers, CTI was added to plasmas from twelve healthy volunteers and thrombin generation was triggered with $0.5,1,2$, and 5 pM TF. For all TF triggers the measurement with CTI added to plasma was in accordance with the analysis without CTI added. To allow for intra-individual comparison of analyses without and with CTI, an acceptable within individual variability of $10 \%$ was arbitrarily chosen based on inter-assay and inter-individual variations published previously $[11,14]$. Both the ETP and peak height from thrombin generation with CTI were within this $10 \%$ range of the values obtained without CTI (Figure 3). Overall, ETP and peak height on average increased with increasing concentration TF trigger and were not different between analysis with or without CTI. ETP values in the absence of CTI were 1,126 nM.min (IQR 731-1,464), 1,281 nM.min (IQR 904-1,570), 1,369 nM.min (IQR 1,015-1,663), and 1,602 nM.min (IQR 1,214-1,823) for 0.5, 1, 2, and $5 \mathrm{pM} \mathrm{TF}$, respectively (Figure 3A). The corresponding ETP values obtained for analysis with CTI added to plasma were 1,132 nM.min (IQR 739-1,517), 1,358 nM.min (IQR 971-1,646), 1,417 nM.min (IQR 1,093-1,688), and 1,585 nM.min (IQR 1,200-1,821).

Figure 3: Influence of CTI addition to plasma on thrombin generation triggered with $0.5,1,2$, or 5 pM TF (from left to right) for 12 healthy individuals. Upper panel: ETP in nM.min thrombin, lower panel: Peak height in nM thrombin. $\diamond$ Denotes thrombin generation analysis in the absence of CTI and $\otimes$ indicates measurement in the presence of $40 \mu \mathrm{g} / \mathrm{ml}$ CTI added to plasma. Error bars: individual range of $10 \%$.

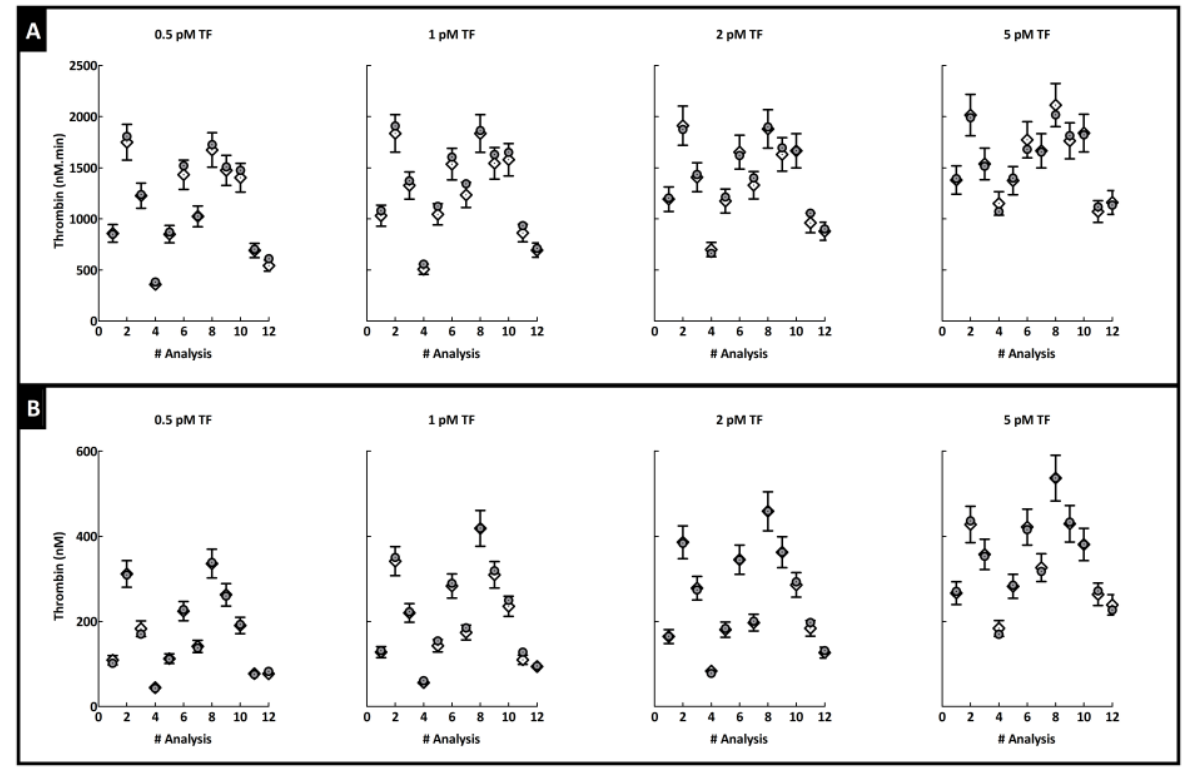


Peak height values obtained in analyses with and without the addition of CTI followed the same pattern as for ETP, with increasing maximum thrombin formation with increasing TF concentrations and no differences between measurements in the absence or presence of CTI (Figure 3B).

\section{Effects of CTI-addition to venous blood on thrombin generation}

Since the presence of CTI during blood collection could efficiently inhibit contact activation, the influences of CTI addition to blood collection tubes was determined through thrombin generation under conditions of the default TF triggers. CTI $(40 \mu \mathrm{g} / \mathrm{ml})$ was added to $3.2 \%(\mathrm{w} / \mathrm{v})$ citrate blood collection tubes and plasma was obtained from twelve healthy volunteers. Thrombin generation was triggered with $0.5,1,2$, or $5 \mathrm{pM}$ TF and compared between plasmas derived from collection tubes with and without CTI (Figure 4).

Figure 4: Influence of CTI addition to $3.2 \%(\mathrm{w} / \mathrm{v})$ citrate blood collection tubes on thrombin generation triggered with $0.5,1,2$, or 5 pM TF (from left to right) for 12 healthy individuals. Upper panel: ETP in nM.min thrombin, lower panel: Peak height in nM thrombin. $\diamond$ Denotes thrombin generation analysis in the absence of CTI and $\otimes$ indicates measurement in the presence of 40 $\mu \mathrm{g} / \mathrm{ml}$ CTI added to $3.2 \%(\mathrm{w} / \mathrm{v})$ citrate blood collection tubes. Error bars: individual range of $10 \%$.

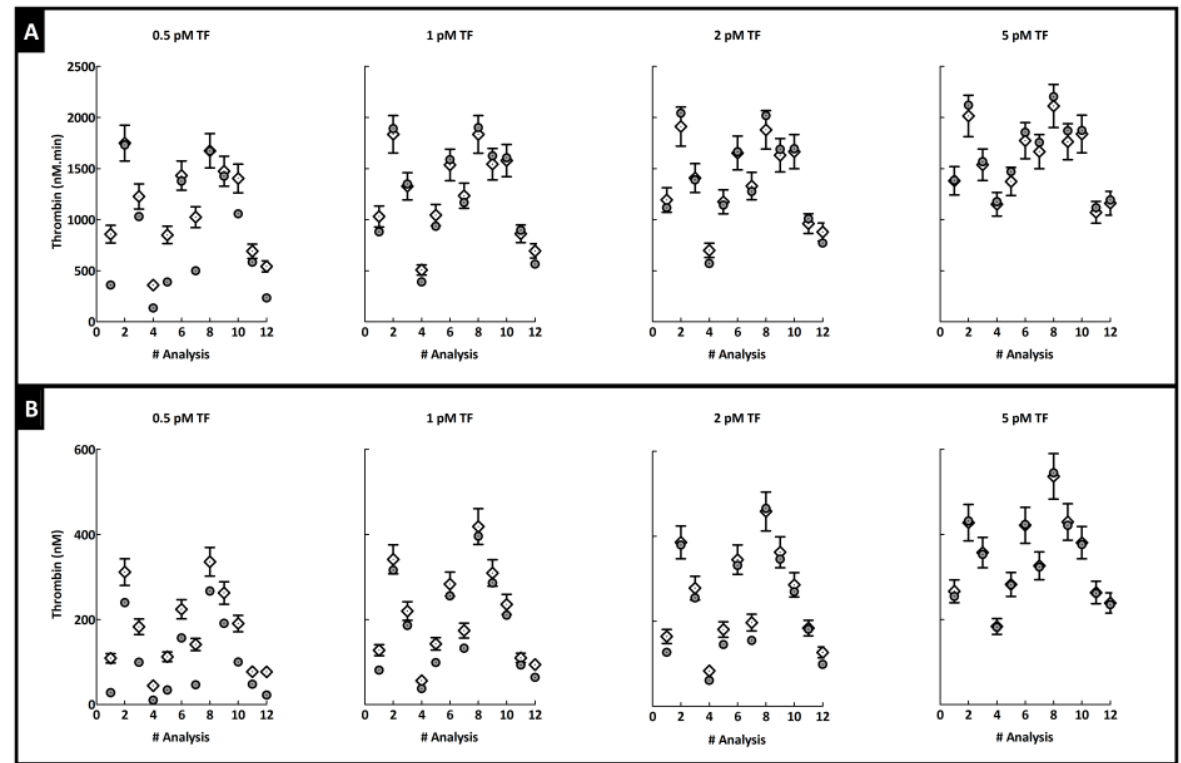

For the higher TF concentrations thrombin generation was comparable between the two collection tubes. ETP values in the absence of CTI were 1,281 nM.min (IQR 904-1,570), 1,369 nM.min (IQR 1,015-1,663), and 1,602 nM.min (IQR 1,214-1,823) for 1, 2, and 5 pM TF, respectively. Addition of CTI to blood collection tubes hardly altered these values: 1,259 nM.min (IQR 885-1,620), 1,333 nM.min (IQR 1,036-1,693), and 1,662 nM.min (IQR 1,241-1,873) for 1, 2, 
and $5 \mathrm{pM}$ TF, respectively. For the $0.5 \mathrm{pM}$ TF analysis, however, eight out of twelve analyses showed a lower ETP and peak height for thrombin generation in plasmas derived from collection tubes containing CTI (Figure 4A). On average the ETP at $0.5 \mathrm{pM}$ TF reduced with $28 \%$ from 1,126 nM.min (IQR 7311,464) to 808 nM.min (IQR 367-1,414) upon addition of CTI to the collection tube. Whereas the peak height for the 1,2 , and 5 pM TF analyses followed the same pattern as the ETP, peak height measured at $0.5 \mathrm{pM}$ TF trigger showed a reduction of 55\% from $162 \mathrm{nM}$ (IQR 85-253) to $74 \mathrm{nM}$ (IQR: 29-182) when CTI was present during blood drawing (Figure 4B).

\section{Discussion}

In recent literature it has been argued that CTI can abrogate the influence of in vitro contact activation on thrombin generation [10, 12-13]. In this study the addition of CTI to a sample after plasma preparation had no influence on thrombin generation, whereas the presence of CTI during blood collection only altered thrombin generation triggered at TF concentrations below $1 \mathrm{pM}$.

In the first part of this study the use of a Winged Infusion Set for blood collection resulted in markedly increased thrombin generation, most likely through contact activation since the presence of CTI in the blood collection tubes reduced the FXIa-C1 esterase inhibitor complexes. This was surprising because this needle system had been previously used assuming that it would provide a rather "atraumatic" sampling condition. Especially thrombin generation conducted at 1 pM TF was altered when blood was collected using the Winged Infusion Set. Due to the presence of a $30 \mathrm{~cm}$ long tubing between the collecting and delivering needle activation of blood coagulation FXII is likely to occur. As reported previously, one of the potential problems with the thrombin generation test in routine clinical practice will be the interference of the contact system [16]. Considering our data, the use of the standard needles used for vacuum blood collection is appears to be satisfactory.

Addition of CTI to plasma has been shown to reduce or overcome the influence of contact activation on thrombin generation [10, 12-13]. Using $5 \mathrm{pM}$ TF as trigger, Luddington and Baglin observed an almost two-fold reduction in ETP upon addition of CTI to the blood collection tube [13]. This effect abolished at a TF concentration of $15 \mathrm{pM}$, suggesting a larger influence of contact activation at lower TF levels. Furthermore, Van Veen and colleagues observed an average reduction in ETP of 343 nM.min upon addition of CTI to plasma and using a TF trigger of 1 pM [12]. Even the use of a higher TF trigger (5 pM) did not completely attenuate the effects of contact activation on thrombin generation. And last, Dargaud and colleagues used the addition of CTI to plasma to reduce the inter laboratory variations in thrombin generation. In their study, addition of CTI to the collection tubes reduced the ETP on average with $178 \mathrm{nM}$.min at a $1.5 \mathrm{pM}$ TF trigger [10]. Again, the use of prefilled CTI/citrate tubes is feasible under research conditions, but major drawbacks exist for application in a hospital laboratory. First of all, currently most hospitals use 3.2 or $3.8 \%$ (w/v) citrate Vacutainer blood collection tubes for coagulation assays. Second, there is a 
significant cost issue. Currently, CTI is sold for a list price of around €100 (app. $\$ 150$ or $£ 70$ ) for $1 \mathrm{mg}$. Pre-filling $4.5 \mathrm{ml}$ tubes to a final plasma concentration of $40 \mu \mathrm{g} / \mathrm{ml}$ (used in this paper) will cost around €15 (app. \$22 or £12) per tube. In conclusion, the use of pre-filled CTI blood collection tubes is not preferred given the major logistic and financial consequences.

In contrast to the described inhibition of contact activation through addition of CTI and the beneficial effects on thrombin generation [10,12-13], no influence on thrombin generation was observed when CTI was added to plasma. Using blood collection tubes pre-filled with CTI, however, thrombin generation triggered with low TF $(0.5 \mathrm{pM})$ was reduced, but this reduction was negligible or absent at higher TF concentrations. These data suggest that the extrinsic pathway can overrule the contact activation pathway in thrombin generation when triggered with 1 pM TF or higher. The differences between our results and the data reported by Van Veen and Dargaud might stem from differences in the used plasma preparations and reagents used for thrombin generation. With regard to the used TF reagents a special note should be made. For all experiments conducted within our laboratory the available CAT-reagents from Thrombinoscope (Maastricht, The Netherlands) were obtained and one batch of reagents was used to avoid differences between batches of reagents. In the absence of an international TF standard, however, it is hard to claim that a given TF concentration is really the absolute concentration. Differences between laboratories might therefore stem from variations in both the TF sources and given concentrations. One striking difference between used protocols is the centrifugation method: in one paper plasma was obtained through double centrifugation at $2000 \mathrm{x}$ g for 10 minutes at room temperature (RT) [12] and in another by double centrifugation at $3000 \mathrm{x}$ g for 15 minutes at RT [10]. Within our laboratory blood is first centrifuged at 2,000 x g for 15 minutes and the obtained plasma is centrifuged a second time at $11,000 \mathrm{x} g$ for 10 minutes (both at RT). The second step at a higher speed appears to be essential to remove remaining micro particles which possibly facilitate activation of FXII (Trappenburg, Onze Lieve Vrouwe Gasthuis, Amsterdam, The Netherlands, personal communication). Secondly, the source of phospholipids and TF to trigger thrombin generation could be major determinants in variations in thrombin generation. We therefore agree with Van Veen and colleagues [12] and with Dargaud and colleagues [10] that there is a lack of standardization among different groups in studies on thrombin generation, which needs to be solved. Standardization without the introduction of pre-filled CTI blood collection tube is preferred since additional tubes will lead towards increasing costs and more complicated logistics in a clinical setting.

Our study showed that there is no significant influence of contact activation on thrombin generation by means of the Calibrated Automated Thrombogram at a TF trigger of $1 \mathrm{pM}$ or above. On the basis of these results and previous data [11], we propose that a standard thrombin generation protocol should include the following: 1: no addition of CTI during or after blood drawing, 2: venipuncture through a 21-gauge needle and blood collection using 3.2\%(w/v) citrate vacutainer (with the first $10 \mathrm{ml}$ of venous blood discarded), 3: uniform plasma 
preparation at high speed centrifugation, 4: uniform reagents, and 5: normalization against an international reference plasma. 


\section{References:}

1 Spronk HM, Govers-Riemslag JW, ten Cate H. The blood coagulation system as a molecular machine. Bioessays. 2003; 25: 1220-8. 10.1002/bies.10360.

2 Ten Cate-Hoek AJ, Dielis AW, Spronk HM, van Oerle R, Hamulyak K, Prins MH, Ten Cate H. Thrombin generation in patients after acute deep-vein thrombosis. Thromb Haemost. 2008; 100: 240-5. 08080240 [pii].

3 Hron G, Kollars M, Binder BR, Eichinger S, Kyrle PA. Identification of patients at low risk for recurrent venous thromboembolism by measuring thrombin generation. JAMA. 2006; 296: 397402. 296/4/397 [pii] 10.1001/jama.296.4.397.

4 Regnault V, Hemker HC, Wahl D, Lecompte T. Phenotyping the haemostatic system by thrombography--potential for the estimation of thrombotic risk. Thromb Res. 2004; 114: 539-45. S004938480400324X [pii] 10.1016/j.thromres.2004.06.017.

5 Dargaud Y, Beguin S, Lienhart A, Al Dieri R, Trzeciak C, Bordet JC, Hemker HC, Negrier C. Evaluation of thrombin generating capacity in plasma from patients with haemophilia A and B. Thromb Haemost. 2005; 93: 475-80. 05030475 [pii] 10.1267/THRO05030475.

6 Dielis AW, Balliel WM, van Oerle R, Hermens WT, Spronk HM, Ten Cate H, Hamulyak K. Thrombomodulin-modified thrombin generation after in vivo recombinant factor VIII treatment in severe hemophilia A. Haematologica. 2008. haematol.13039 [pii] 10.3324/haematol.13039.

7 Siegemund T, Petros S, Siegemund A, Scholz U, Engelmann L. Thrombin generation in severe haemophilia A and B: the endogenous thrombin potential in platelet-rich plasma. Thromb Haemost. 2003; 90: 781-6. 10.1267/THR003050781

03110781 [pii].

8 Besser M, Baglin C, Luddington R, van Hylckama Vlieg A, Baglin T. High rate of unprovoked recurrent venous thrombosis is associated with high thrombin-generating potential in a prospective cohort study. J Thromb Haemost. 2008; 6: 1720-5. JTH3117 [pii]

10.1111/j.1538-7836.2008.03117.x.

9 Eichinger S, Hron G, Kollars M, Kyrle PA. Prediction of recurrent venous thromboembolism by endogenous thrombin potential and D-dimer. Clin Chem. 2008; 54: 2042-8. clinchem.2008.112243 [pii]

10.1373/clinchem.2008.112243.

10 Dargaud Y, Luddington R, Gray E, Negrier C, Lecompte T, Petros S, Hogwood J, Bordet JC, Regnault V, Siegemund A, Baglin T. Effect of standardization and normalization on imprecision of calibrated automated thrombography: an international multicentre study. Br J Haematol. 2007; 139: 303-9. BJH6785 [pii] 10.1111/j.1365-2141.2007.06785.x.

11 Spronk HM, Dielis AW, De Smedt E, van Oerle R, Fens D, Prins MH, Hamulyak K, Ten Cate H. Assessment of thrombin generation II: Validation of the Calibrated Automated Thrombogram in platelet-poor plasma in a clinical laboratory. Thromb Haemost. 2008; 100: 362-4. 08080362 [pii].

12 van Veen JJ, Gatt A, Cooper PC, Kitchen S, Bowyer AE, Makris M. Corn trypsin inhibitor in fluorogenic thrombin-generation measurements is only necessary at low tissue factor concentrations and influences the relationship between factor VIII coagulant activity and thrombogram parameters. Blood Coagul Fibrinolysis. 2008; 19: 183-9. 10.1097/MBC.0b013e3282f4bb47 00001721-200804000-00001 [pii].

13 Luddington R, Baglin T. Clinical measurement of thrombin generation by calibrated automated thrombography requires contact factor inhibition. J Thromb Haemost. 2004; 2: 1954-9. JTH964 [pii] 10.1111/j.1538-7836.2004.00964.x.

14 Dielis AW, Castoldi E, Spronk HM, van Oerle R, Hamulyak K, Ten Cate H, Rosing J. Coagulation factors and the protein $\mathrm{C}$ system as determinants of thrombin generation in a normal population. J Thromb Haemost. 2008; 6: 125-31. JTH2824 [pii] 10.1111/j.1538-7836.2007.02824.x. 
15 Govers-Riemslag JW, Smid M, Cooper JA, Bauer KA, Rosenberg RD, Hack CE, Hamulyak K, Spronk HM, Miller GJ, ten Cate H. The plasma kallikrein-kinin system and risk of cardiovascular disease in men. J Thromb Haemost. 2007; 5: 1896-903. JTH2687 [pii] 10.1111/j.1538-7836.2007.02687.x.

16 Rand MD, Lock JB, van't Veer C, Gaffney DP, Mann KG. Blood clotting in minimally altered whole blood. Blood. 1996; 88: 3432-45. 


\section{CHAPTER 5}

Platelet-induced thrombin generation by the calibrated automated thrombogram assay is increased in patients with essential thrombocythemia and polycythemia vera

Marina Panova-Noeva, Marina Marchetti, Henri M. H. Spronk, Laura Russo, Erika Diani, Guido Finazzi, Silvia Salmoiraghi, Alessandro Rambaldi, Tiziano Barbui, Hugo Ten Cate, Anna Falanga.

American Journal of Hematology. 2011;86(4):337-42. 


\section{Abstract}

The platelet contribution to the thrombophilic state of patients with myeloproliferative neoplasms (MPNs), i.e. Essential Thrombocythemia (ET) and Polycythemia Vera (PV), remains uncertain. In this study we aimed to characterize the thrombin generation (TG) potential expressed by platelets from these subjects, compare it to normal platelets, and identify what factors might be responsible for platelet TG. In a group of $140 \mathrm{MPN}$ patients (80 ET and $60 \mathrm{PV}$ ) and 72 healthy subjects we measured the global procoagulant potential of platelet rich plasma (PRP) utilizing the TG assay by the calibrated automated thrombogram (CAT). To characterize the procoagulant contribution of platelets in PRP, the TG of both isolated platelets and platelet rich plasma was measured, and the platelet surface expression of TF was determined. Finally, the activation status of platelets was assessed by the levels of P-selectin expressed on platelet surface. MPN patients had significantly increased PRP and isolated platelet TG potential compared to controls. This was associated to the occurrence of platelet activation. Patients carriers of the JAK2V617F mutation showed the highest values of TG and platelet surface TF and P-selectin. Platelet TG potential was significantly lower in hydroxyurea (HU) compared to non-HU treated patients and was lowest in HU-treated $J A K 2 V 617 F$ carriers. In subjects not receiving HU, platelet TG significantly increased by $J A K 2 V 617 F$ allele burden increment $(\mathrm{p}<0.05)$. This study demonstrates a platelet-dependent form of hypercoagulability in MPN patients, particularly in those carriers of the JAK2V617F mutation. The cytoreductive therapy with HU significantly affects this prothrombotic phenotype. 


\section{Introduction}

Essential Thrombocythemia (ET) and Polycythemia Vera (PV) are chronic myeloproliferative neoplasms (MPNs) characterised by increased production of mature functional blood cells (i.e. leukocytes, erythrocytes and platelets) and high incidence of thrombo-hemorrhagic complications [1]. Thrombosis is a major cause of morbidity and mortality in these patients and occurs in arterial, venous and microcirculatory sites [2]. Advanced age, prior history of thrombosis and vascular risk factors (smoking, hypercholesterolemia) contribute to the risk of thrombosis in these patients [3]. Recently, a high leukocyte count and the presence of the somatic $\mathrm{V} 617 \mathrm{~F}$ mutation of the Janus 2 tyrosine kinase (JAK2) gene have been associated with an increased thrombotic risk in both ET and PV patients [4-7].

Platelets have been repeatedly involved in the pathogenesis of the hemostatic complications of these diseases. In the past, numerous platelet defects have been identified in ET and PV patients. The majority of these observations were related to a decreased functionality, and included abnormal platelet aggregation, reduced levels of membrane adhesion molecules (i.e. glycoproteins Ib, IIbIIIa, IV and VI), acquired storage pool disease, and defective platelet metabolism (i.e. abnormal arachidonic acid metabolism) [8-10]. To the opposite, more recent studies have shown that platelets from these patients circulate in an activated status, particularly in those carrying the JAK2V617F mutation [11-16], as assessed by the increased expression on their surface of P-selectin and tissue factor (TF). No information, however, are so far available on the procoagulant potential of platelets in these diseases. Platelets actively contribute to thrombin generation (TG) by supplying factors that support prothrombin activation (i.e. platelet factor $\mathrm{V}$ and phosphatidylserine), expressing $\mathrm{TF}$, and providing a procoagulant surface that strongly accelerates tenase and prothrombinase reactions [17-18]. Therefore, in this study, we evaluated in a group of 140 MPN patients, the procoagulant phenotype of platelets, by measuring their TG potential by the Calibrated Automated Thrombogram (CAT) assay [19]. To characterize the procoagulant contribution of platelets in PRP, the TG of isolated platelets and platelet free plasma was also measured, in addition to the determination of platelet surface expression of TF. Finally, the activation status of platelets was assessed as the levels of P-selectin on platelets. The TG parameters of interest (i.e. lag time, peak height and slope) were evaluated in relation to platelet counts, platelet surface TF levels, JAK2V617F mutational status, and patients' therapy. 


\section{Patients and Methods}

\section{Patients}

The study subjects were recruited from the outpatient unit of the Hematology Department of Bergamo Hospital (Italy) in the period from January 2008 to January 2010. The study group consists of 140 consecutive patients, 80 patients with ET and 60 patients with PV diagnosed according to the WHO criteria [20]. Seventy two healthy subjects acted as the control group. Characteristics of the patients and healthy controls are summarized in Table I. The study was approved by the local Ethics Committee (Comitato di Bioetica, Ospedali Riuniti, Bergamo, Italy) and the procedures followed were in accordance with the Helsinki Declaration of 1975 as revised in 2000. All blood samples were obtained with the subject informed consent. None of the patients were taking anticoagulant drugs, oral contraceptives or hormone replacement therapy. None of the healthy controls were taking any anti-platelet or anti-inflammatory drugs in the last 10 days prior blood drawing and none of them had history of thrombosis or other diseases with high risk for thrombosis. In addition none of the female controls were taking oral contraceptives or hormone replacement therapy. Among patients, 72/140 were receiving cytoreductive therapy with hydroxyurea $(\mathrm{HU})$, either alone $(n=10)$ or in combination with aspirin $(n=62), 51 / 140$ were on aspirin alone, and 17/140 were not receiving any cytoreductive or aspirin treatment.

\section{Routine haematological assays}

White blood cell differential count, hematocrit, hemoglobin, red blood cell and platelet counts were determined on a Sysmex-XE 2100 hematology analyzer (Sysmex, Kobe, Japan).

\section{Collection of blood samples}

Blood samples from all patients $(n=140)$ and controls $(n=72)$ were drawn early in the morning before any therapy or food intake. After discarding the first $3 \mathrm{ml}$, the blood was collected into sterile siliconized tubes containing K3ethylenediamine tetraacetic acid (K3-EDTA) for molecular biology studies or trisodium citrate $(0,129 \mathrm{M}, 1: 9 \mathrm{vol}: \mathrm{vol})$ for coagulation and cytofluorimetric studies. 
Table I. Study Subject Characteristics. Data are reported as number or mean (range); ${ }^{*} \mathrm{p}<0.05$ versus controls; ${ }^{* *} \mathrm{p}<0.01$ versus controls.

\begin{tabular}{lccc}
\hline & CONTROLS & ET & PV \\
\hline Number & 72 & 80 & 60 \\
Males/Females & $37 / 35$ & $25 / 55$ & $32 / 28$ \\
Age (years) & $52(26-75)$ & $55(23-80)$ & $60(20-82)$ \\
Platelets (10\%/L) & $243(144-398)$ & $595^{* *}(208-1451)$ & $477^{* *}(93-1278)$ \\
Leukocytes (10\%/L) & $6.7(3.8-9.2)$ & $7.4^{*}(3.6-14.4)$ & $9.2^{* *}(3.1-39.9)$ \\
Hematocrit (\%) & $42.5(35.2-45)$ & $41(35-48.9)$ & $45^{* *}(37.8-50)$ \\
$\begin{array}{l}\text { History of thrombosis (\%) } \\
\text { arterial (\%) } \\
\text { venous (\%) }\end{array}$ & $/$ & $15(19)$ & $12(20)$ \\
Microcirculatory symptoms (\%) & $/$ & $13(87)$ & $9(75)$ \\
\hline
\end{tabular}

\section{Platelet rich plasma, platelet free plasma and washed platelets prepara- tion}

To fully characterize platelet TG, we utilized three different sample preparations, i.e.: 1) platelet rich plasma (PRP), as an overall platelet and plasma containing sample; 2) platelet free plasma (PFP); and 3) isolated washed platelets.

1) Within 30 minutes from the blood draw, PRP was isolated by centrifugation of whole blood for $10 \mathrm{~min}$ at $280 \mathrm{xg}$ at room temperature (RT). To obtain platelet poor plasma (PPP), the rest of the blood sample was centrifuged at 3,500xg for $20 \mathrm{~min}$. PPP was utilised to dilute PRP in order to obtain 150,000 platelets/ $\mu$ l.

2) PFP was isolated by double centrifugation of citrated whole blood at 3,000xg for 15 minutes at RT, aliquoted, snap-frozen in dry ice and stored at $-80 \stackrel{\circ}{\circ}$ until testing.

3) Platelets were further isolated from PRP of a subgroup of 48 subjects (17 ET, 13 PV subjects and 18 controls), according to a published method [21]. Briefly, PRP was diluted in 1:2 ratio with Krebs Ringer buffer ( $4 \mathrm{mM} \mathrm{KCl}, 107 \mathrm{mM} \mathrm{NaCl}, 20 \mathrm{mM} \mathrm{NaHCO}_{3}, 2 \mathrm{mM} \mathrm{Na}_{2} \mathrm{SO}_{4}$, pH 5). After centrifugation at $1,000 \mathrm{xg}$ for $10 \mathrm{~min}$ at $\mathrm{RT}$, the platelet pellet was resuspended in Krebs Ringer buffer supplemented with glucose $(0.9 \mathrm{~g} / \mathrm{L}, \mathrm{pH}$ 6) and centrifuged a second time $(1,000 \mathrm{xg}, 10 \mathrm{~min}, \mathrm{RT})$. This washing procedure was repeated twice, and finally the platelets were resuspended at concentration of 150,000 platelets/ $\mu \mathrm{l}$ in phosphate buffered saline (PBS; 154mM NaCl, $1.4 \mathrm{mM}$ phosphate, $\mathrm{pH} 7.4$ ), snap frozen in 
dry ice, and stored at $-80^{\circ} \mathrm{C}$ until assays. The isolation procedure did not activate platelets as demonstrated by the same levels of P-selectin on platelet surface before and after isolation. On the test day, platelets were thawed in a warm bath at $37^{\circ} \mathrm{C}$ and lysed by 3 cycles of freezing at $-80^{\circ} \mathrm{C}$ and thawing at $37^{\circ} \mathrm{C}$.

\section{CAT assay}

Measurement of TG of PRP and PFP samples and in platelet lysates was performed using the CAT assay. For each experiment, 2 sets of readings in a 96 well micro-plate were used, one from a TG well and another from a thrombin calibrator (TC) well. The TG of PRP was measured in presence and in absence of exogenous TF. Briefly, $20 \mu \mathrm{l}$ of 1pM TF or $20 \mu \mathrm{l}$ of Hepes buffer were added into TG wells and $20 \mu \mathrm{l}$ of calibrator with activity of $600 \mathrm{nM}$ alpha2M-thrombin complex were added to TC well. Eighty $\mu$ l of PRP were added to both wells (TG and TC well). To measure TG of PFP, $20 \mu \mathrm{l}$ of $1 \mathrm{pM}$ TF and $4 \mu \mathrm{M}$ phospholipids were added in TG well and $20 \mu \mathrm{l}$ of calibrator into TC well, followed by $80 \mu \mathrm{l}$ of subject PFP in both wells. To measure TG induced by isolated platelet lysates, $20 \mu \mathrm{l}$ of platelet lysates were added in the TG well and $20 \mu \mathrm{l}$ of calibrator into TC well. Eighty $\mu$ l of normal pooled plasma (NPP) were added to both wells (TG and TC well).

After 10 min prewarming at $37^{\circ} \mathrm{C}$ inside the fluorimeter (Fluoroscan Ascent, Thermo Labsystems, Helsinki, Finland), the reaction was started with $20 \mu$ of a fluorogenic substrate (Z-Gly-Gly-Arg-AMC; Bachem, Bubendorf, Switzerland) $/ \mathrm{CaCl}_{2}$ mixture. The $\mathrm{TG}$ curves were calculated using Thrombinoscope software (Thrombinoscope, Maastricht, The Netherlands) by comparing the signals from the TG and the TC well. TG curves were described in terms of lag time (time when minimum thrombin is formed), peak height (maximum concentration of TG), and slope (speed of TG) calculated using the formula: Slope = peak height / (time to peak - lag time).

\section{Cytofluorimetric analysis of surface platelet TF and P-selectin}

Flowcytometric analysis was used to characterize platelet surface antigens. Citrated whole blood samples were diluted 1:20 with PBS and incubated for 20 min at RT in the dark with the following FITC conjugated monoclonal antibodies: isotype control IgG1 (Beckton Dickinson, San Jose, USA), anti-CD41 (AbD Serotec, Oxford, UK), anti-TF (American Diagnostica, Stamford, USA) and anti-Pselectin (anti-CD62P, Bio Legend, San Diego, USA) as previously described [14]. After incubation, the samples were analysed using the FACS Calibur cytofluori- 
meter (Becton Dickinson, Mountain View, CA, USA). Using the forward and side scatter properties, the platelets were identified in a region that was $100 \%$ positive for CD41 expression (Figure 1). From each sample 5,000 events were collected and the analysis was done using the Cell Quest software (Becton Dickinson). Results are expressed as percentage of positive cells or as mean fluorescence intensity (MFI).

Figure 1. Flow cytometric analysis of platelets. A representative set of scattergrams from a flowcytometric analysis of platelets in a whole blood sample from a control subject. Panel A shows how the forward and side scatter was used to define the platelet gate. Panel B shows the events of platelets marked by the isotype control IgG1. Panel C shows platelets positive for the anti CD-41 antibody.

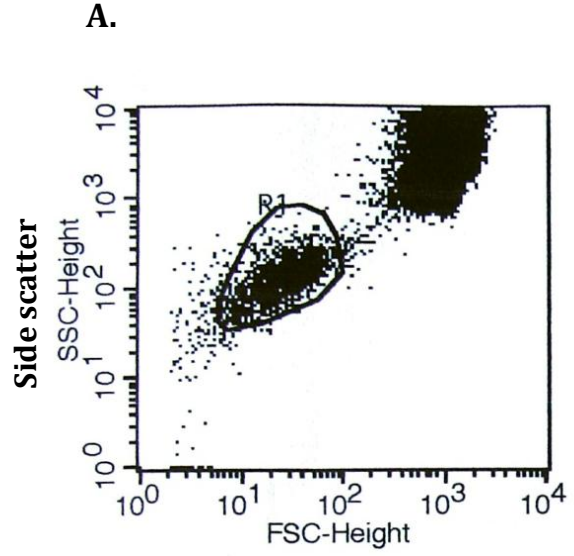

Forward scatter
B.

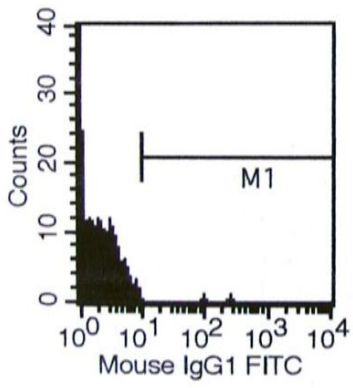

C.

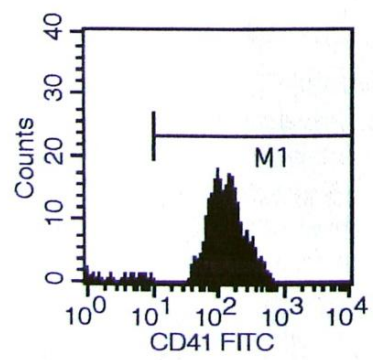

\section{JAK2V617F mutation analysis}

The allele-specific polymerase chain reaction (PCR) was performed as previously described [14]. To analyse the burden of the mutant allele, PCR products were digested with the restriction enzyme-based assay as described by Marchetti et al. [22]. 


\section{Statistical analysis}

Student's t-test or the nonparametric Mann-Whitney-Wilcoxon test were employed to compare the differences between groups, according to the distribution of the test variable. Differences were considered significant at a p-value < 0.05 . Correlation and linear regression analysis was performed using the SPSS 15 statistical package (SPSS, Chicago, IL). Regression coefficients are expressed as $B$, which represents the absolute change of the dependent variable when the independent variable increases by 1 unit.

\section{Results}

\section{Study population characteristics}

A total of 140 consecutive patients, 80 diagnosed with ET and 60 with PV, entered the study. For comparison 72 healthy control subjects were enrolled. The subject characteristics are presented in Table I. The number of males and females were similar among PV and control subjects, whereas among ET patients two-thirds were females. Both ET and PV group had significantly higher platelet, leukocyte and neutrophil mean values compared to the control group. PV group also had significantly higher hematocrit mean value compared to the control group. JAK2V617F mutation was present in 46 ET patients (58\%; all < $50 \%$ allele burden) and 55 PV patients (92\%; 45 with $<50 \%$ and 10 with $>50 \%$ allele burden). The carriers of the JAK2V617F mutation had significantly higher leukocyte, neutrophil and hematocrit values compared to wild type patients $(\mathrm{p}<0.01)$ (data not shown). Three PV patients, wild type for JAK2V617F, were carriers of exon-12 JAK2 mutation.

At the time of enrolment, $46 \%$ of ET and $58 \%$ of PV patients were on cytoreductive treatment with HU. Twenty seven patients (15 ET and 12 PV) had a positive history for at least one major thrombotic event (i.e. acute myocardial infarction, ictus/transient ischemic attack, venous thromboembolism); 22 ET patients (28\%) and 20 PV patients (33\%) experienced microcirculatory symptoms (i.e. headache, paraesthesia, erythromelalgia).

\section{Thrombin Generation of PRP}

Figure 2 shows representative TG curves of PRP from ET and PV patients and healthy controls, triggered in the presence (left panel) and absence (right panel) of exogenous 1pM TF. For all study subjects, the quantity of thrombin generated by PRP in the absence of exogenous TF was lower compared to that triggered by the addition of 1 pM TF. However, in both experimental conditions, 
the TG peak and slope were significantly increased $(\mathrm{p}<0.001)$ in ET and PV patients compared to controls. The TG peak showed low intra-individual coefficient of variation (CV) when repeatedelly measured from 5 controls (5.78\%), 5 ET (6.75\%) and 5 PV (4.02\%) patients in a period of one month.

Figure 2. Representative curves of TG from ET and PV patients. PRP from ETand PV patients generated significantly higher maximum TG concentration compared to control subjects in both conditions, with and without exogenous $1 \mathrm{pM}$ TF. TG in the absence of exogenous $1 \mathrm{pM}$ TF was significantly lower compared to TG induced by 1 pM TF.

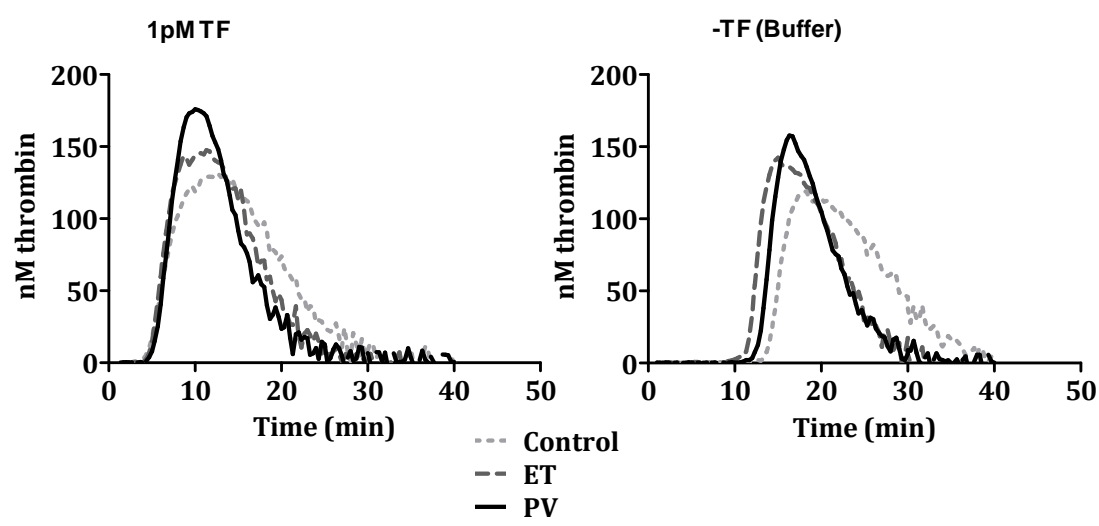

As shown in Table II, PRP from ET and PV patients receiving HU at the time of the study, generated both in the presence and in the absence of exogenous TF less thrombin compared to non-HU treated patients and particularly in those carriers of the JAK2V617F mutation. In addition, TG triggered by exogenous TF in PRP from ET patients on ASA showed lower peak $(155 \pm 33 \mathrm{nM})$ and slope $(29 \pm 12 \mathrm{nM} / \mathrm{min})$ compared to ET patients not taking any treatment (peak: $167 \pm 57 \mathrm{nM}$; slope: $37 \pm 27 \mathrm{nM} / \mathrm{min}$ ), without reaching a statistical significance. Similar results were observed in the absence of exogenous TF (data not shown). To evaluate the contribution of JAK2V617F mutation in determining the TG potential of PRP, the group of patients not on HU therapy at the time of the study were analysed according to JAK2V617F allele burden. These patients, all heterozygous for the mutation, were divided in 3 groups: i.e. negative $(0 \%),<$ $25 \%$ and $25-50 \%$ mutated alleles. The results (Figure 3 ) showed an increase in the TG peak that parallels the increase in the JAK2V617F allele burden. Furthermore, in non-HU treated ET subjects, we observed significantly higher TG in JAK2V617F mutation carriers (peak $=170 \pm 25 \mathrm{nM}$ ) compared to JAK2 wild type (peak $=145 \pm 34, \mathrm{p}<0.05$ ). This association was not observed in HU-treated patients. 
Table II. TG parameters in PRP from MPN patients according to HU Therapy and JAK2V617F mutational status. Data are reported as mean $\pm \mathrm{SEM}$; ${ }^{*} \mathrm{P}<0.05$ versus non- $\mathrm{HU}$; ${ }^{* *} \mathrm{P}<0.01$ versus non-HU JAK2V617F. Three patients carriers for JAK2 exon 12 mutation are not included in the analysis.

\begin{tabular}{|c|c|c|c|c|c|}
\hline & \multirow[b]{2}{*}{$n=$} & \multicolumn{2}{|c|}{$+1 \mathrm{pM} \mathrm{TF}$} & \multicolumn{2}{|c|}{ Buffer } \\
\hline & & Peak & Slope & Peak & Slope \\
\hline non-HU & 65 & $164 \pm 5$ & $34.4 \pm 2$ & $149 \pm 6$ & $41.6 \pm 3$ \\
\hline JAK2 wt & 21 & $156 \pm 9$ & $32 \pm 4$ & $139 \pm 11$ & $38.4 \pm 6$ \\
\hline JAK2V617F & 44 & $171 \pm 6$ & $36.6 \pm 3$ & $157 \pm 7$ & $44.4 \pm 4$ \\
\hline HU & 72 & $148 \pm 5 *$ & $28.4 \pm 2^{*}$ & $130 \pm 5 *$ & $32.4 \pm 2^{*}$ \\
\hline JAK2 wt & 15 & $155 \pm 8$ & $27.5 \pm 2$ & $131 \pm 8$ & $31.3 \pm 3$ \\
\hline JAK2V617F & 57 & $147 \pm 6^{* *}$ & $28.7 \pm 2^{* *}$ & $129 \pm 6 *$ & $32.7 \pm 3^{* *}$ \\
\hline
\end{tabular}

Figure 3. In non-HU-treated patients, JAK2V617F allele burden influence the TG potential of PRP. TG expressed as peak height (nM thrombin) significantly increased in parallel to JAK2V617F allele burden increment. Patients with allele burden $<25 \%$ had significantly $(\mathrm{P}<0.01)$ higher peak compared to control subjects. Patients with $25-50 \%$ allele burden had the highest TG peak, significantly different $(\mathrm{P}<0.001)$ from both control subjects and MPN patients wild type for JAK2 mutation. All patients with $>50 \%$ allele burden were treated with $\mathrm{HU}$.

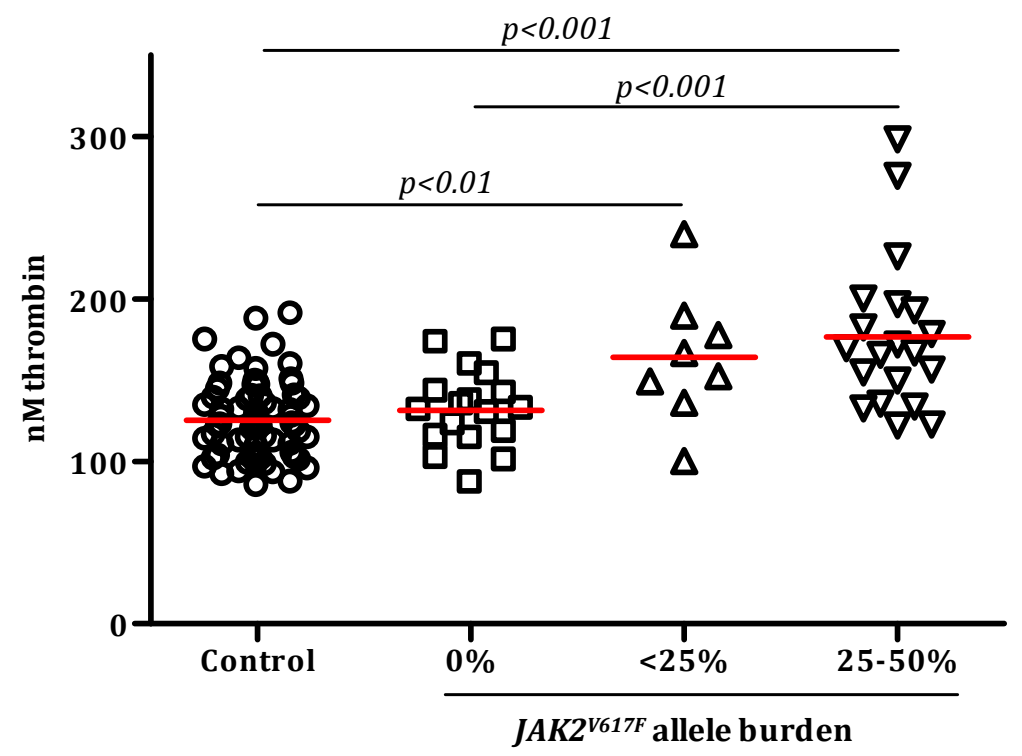




\section{Thrombin Generation of PFP}

To assess whether the increased TG produced by PRP from ET and PV patients was due to the plasma component of the PRP, we measured the TG in PFP of the same subjects. The results showed no significant differences in the different TG parameters between ET and PV patients and healthy controls (data not shown). No statistically significant differences were found when data were analyzed according to the JAK2V617F mutational status and HU therapy.

The intra-assay $\mathrm{CV}$ of thrombin generation triggered with $1 \mathrm{pM}$ TF was $2.1 \%$ measuring the TG in triplicate of 5 control subjects. The inter-assay CV was $3 \%$ estimated by measuring the same PFP triggered by $1 \mathrm{pM}$ TF of 5 control subjects in consecutive 5 days.

\section{Thrombin Generation of isolated platelet lysates}

To further characterize the platelet-bound procoagulant activity, in a subgroup of 48 subjects (17 ET, 13 PV patients and 18 controls), platelets were further isolated from PRP and tested for the capacity to induce TG in NPP (Figure 4). The lag-time of TG was not different between patients (ET: $6.5 \pm 0.4$; PV: $6.0 \pm 0.4$ $\mathrm{min})$ and controls $(6.1 \pm 0.6 \mathrm{~min})$. The peak height $(328 \pm 3.8 \mathrm{nM})$ and the slope $(156 \pm 3.1 \mathrm{nM} / \mathrm{min})$ were significantly increased $(\mathrm{p}<0.05)$ in platelets from ET patients compared to platelets from controls (Peak: $307 \pm 6.3 \mathrm{nM}$; Slope: $142 \pm 5.5 \mathrm{nM} / \mathrm{min})$. Similarly, platelets from PV patients presented with a higher,

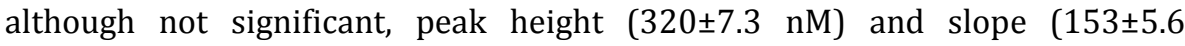
$\mathrm{nM} / \mathrm{min}$ ) compared to controls. These differences became statistically significant in the analysis of data from non-HU-treated PV patients, who had significantly $(\mathrm{p}<0.05)$ higher TG peak $(336 \pm 23 \mathrm{nM})$ and slope $(165 \pm 11 \mathrm{nM} / \mathrm{min}) \mathrm{com}$ pared to both HU-treated patients (peak: $306 \pm 21 \mathrm{nM}$; slope: $143 \pm 20 \mathrm{nM} / \mathrm{min}$ ) and controls.

While, no significant differences were observed between patients with and without a previous history of thrombosis, an increased TG potential was expressed by platelets isolated from MPN patients experiencing symptoms of impaired microcirculation (peak: $335 \pm 6 \mathrm{nM}$; slope: $166 \pm 3.6 \mathrm{nM} / \mathrm{min}$ ) compared to asymptomatic patients (peak: $317 \pm 6.1 \mathrm{nM}, \mathrm{p}=0.07$; slope: $150 \pm 5 \mathrm{nM} / \mathrm{min}$, $\mathrm{p}=0.03)$. 
Figure 4. TG triggered by platelet lysates in patients and controls. Platelets from ET and PV patients induce more TG in normal pooled plasma compared to healthy controls (CTR). Data are mean \pm SEM. $* 5 \mathrm{P}<0.05$ vs. CTR.

Peak height (nM thrombin)

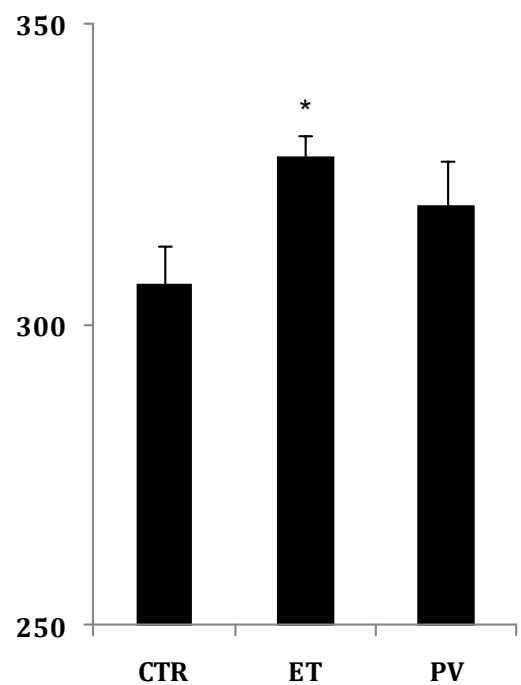

Slope (nM/min)

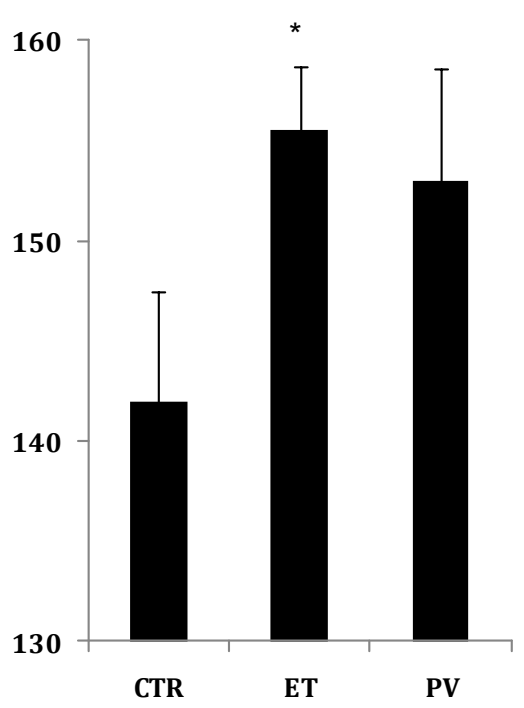

\section{Platelet surface TF and P-selectin}

An analysis of cell membrane antigens was conducted for indentifying and quantifying procoagulant (TF) and activation/adhesive (P-selectin) molecules expressed on platelet surface (Figure 5 ). The $\%$ of platelets positive for TF was significantly $(\mathrm{p}<0.05)$ higher in ET $(37 \pm 2.3 \%)$ and PV $(44 \pm 3 \%)$ patients compared to controls (28 $\pm 2.5 \%$ ) (Figure 5, panel A). MPN patients carriers of the JAK2V617F mutation presented with higher $\%$ of TF-positive platelets $(43 \pm 2.3$ $\%)$ compared to control subjects $(\mathrm{p}=0.001)$ (Figure 5, panel B).

Regarding P-selectin (Figure 5, panel C), significantly increased \% of platelets expressing this activation marker was found $(\mathrm{p}<0.05)$ in both ET $(3.2 \pm 0.4 \%)$ and PV (3.9 $\pm 0.5 \%)$ patients compared to controls $(2.2 \pm 0.2 \%)$. MPN patients carriers of the JAK2V617F mutation presented with higher $\%$ of P-selectin positive platelets $(4.0 \pm 0.4 \%)$ compared to controls $(p=0.001)$ (Figure 5, panel D). The multivariate analysis adjusted for age and sex showed that increased platelet surface TF significantly determines shorter lag-time of the TG induced by platelets isolated from JAK2V617F positive patients $(B=-0.74, p<0.05)$. No in- 
fluences of HU therapy and microcirculatory symptoms were observed on the $\%$ of platelets positive for TF and P-selectin.

Figure 5. Baseline levels of TF and P-selectin on platelet surface. Platelet surface TF (Panel A) and P-selectin (CD62P, Panel C) levels are plotted according to the disease type (i.e., ET or PV) and to JAK2V617F allele burden (Panels B and D). Data are expressed as \% of positive cells and bars represent mean \pm SEM. CTR 5 controls; ${ }^{*} \mathrm{P}<0.05$ versus controls.

A.

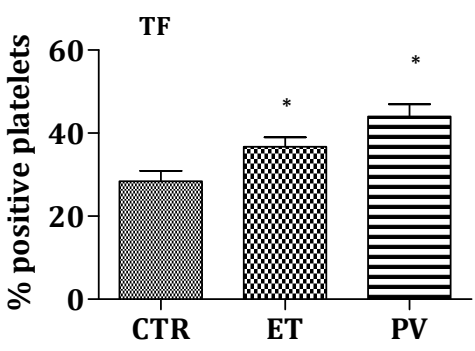

B.

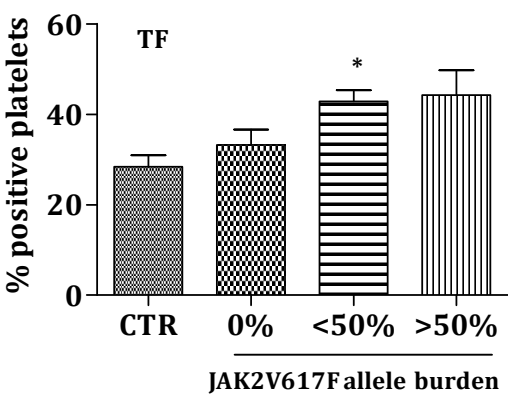

C.

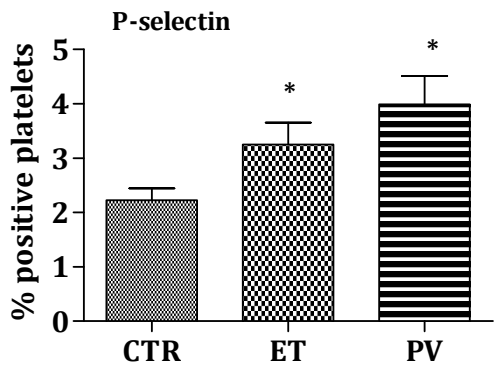

D.

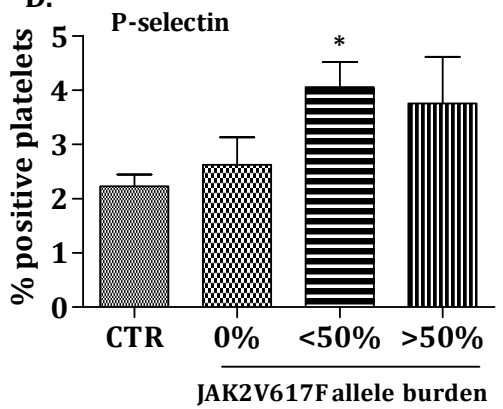

\section{Discussion}

The present study investigated for the first time the TG potential of PRP by the CAT assay in a group of 140 MPN patients (80 ET and $60 \mathrm{PV}$ ). The findings of our study showed an increased TG potential (i.e. higher TG peak height and slope) of fresh PRP and of isolated platelets from ET and PV patients compared to healthy control subjects. Differently, no statistically significant differences were observed in the TG potential of PFP from the same patients compared to controls, as previously observed [22]. These findings suggest that a plateletdependent form of hypercoagulability exists in this group of MPN patients and can be revealed by the TG assay when performed in PRP. A similar observation was reported in a study involving young stroke patients, where an increased TG was observed when the CAT assay was performed in PRP but not in PFP [23]. 
The TG expressed by PRP samples has been useful to assess the procoagulant role of platelets in different clinical conditions, including liver cirrhosis, von Willebrand disease and congenital factor V deficiency [24-26]. The abnormal TG parameters have been associated in several different conditions to an impaired hemostasis, specifically low TG peak with an increased bleeding tendency in patients with von Willebrand disease and high ETP with an increased thrombotic tendency in stroke patients $[23,25]$.

Platelets contribute to TG by providing not only phospholipids but also TF. The results of the cytofluorimetric analysis of platelet surface TF showed, in agreement with previous studies from our [14] and other groups [27], significantly increased \% of platelet positive for TF in both ET and PV patients compared to controls. The highest values were observed in platelets from JAK2V617F mutation carriers, which were also characterized by higher TG potential and higher platelet activation status (i.e. increased platelet P-selectin). Interestingly, in this subgroup of patients, platelet TF expression significantly determined shorter TG lag-time, thus showing an inverse correlation between platelet-associated TF and TG lag-time. This correlation is in line with a recent in vitro study by Ollivier et al. showing that endogenous TF influenced negatively TG lag-time [28].

At the time of the study, about $51 \%$ of the patients were treated with HU on the basis of their clinical risk assessment [29]. Clinical studies supported the hypothesis that cytoreductive therapy with $\mathrm{HU}$ exerts a protective effect against thrombosis by reducing the circulating number of blood cells, including both platelets and leukocytes, and by reducing JAK2V617F allele burden [30-32]. Therefore, in order to evaluate a possible influence of HU on the TG potential of platelets data were analyzed according to patients' therapy. The results of this analysis showed a positive impact of HU therapy on the TG parameters. Particularly, we found that the mean values of TG peak and slope of PRP from HUtreated patients were significantly reduced compared to non-HU treated patients. Similar differences were obtained by measuring the TG potential of isolated platelet, while no significant influence of HU therapy was found in TG potential of PFP. As in the TG assay the number of platelets in PRP and lysates was adjusted to the same fixed concentration for each study subjects, our results suggest that HU may affect not only platelet count, but also some haemostatic properties of platelets. Recently, a study performed in a small group of MPN patients (6 ET and 6 PV patients) showed significantly lower TF expression on neutrophils and less circulating platelet-neutrophil aggregates in the subgroup of patients treated with HU compared to non-HU treated subjects [33]. In addition, in the same study, the in vitro treatment of neutrophils with HU prevented 
both P-selectin-induced TF expression and mixed cell aggregate formation, suggesting an antithrombotic activity of $\mathrm{HU}$ not related to its capacity to merely reduce the cell count. Furthermore, our recent study showed an increased levels of nitric oxide (NO) production in HU treated compared to non-HU treated MPN patients [34]. NO is a potent inhibitor of the platelet activation and represents an important antithrombotic mechanism [35].

We could not show that HU treatment reduced TF expression on platelet surface and studies are needed to investigate the effect of HU on some other platelet prothrombotic characteristics.

It has been observed that JAK2V617F mutation is associated with an increased thrombotic risk in both ET and PV patients [36-38]. Additionally, the presence of the mutation is associated with higher hemoglobin level, higher leukocyte count, lower platelet count and recurrent thrombosis versus patients with wild type JAK2 [39-40]. The analysis based on the JAK2V617F mutational status showed two interesting findings. First, in patients HU naive, the increase in TG of PRP is associated to the increase in JAK2V617F allele burden, thus demonstrating a direct association between JAK2V617F allele burden and increased platelet-associated TG potential. Second, in JAK2V617F positive patients, subjects on HU showed the lowest TG potential. This suggests a more beneficial antithrombotic effect of the drug in this type of patients.

Microvascular circulation disturbances including erythromelalgia, its microvascular ischemic complications, and migraine-like atypical or typical transient ischemic cerebral, ocular, and coronary ischemic attacks are specific clinical manifestations of these diseases. It has been shown that the microvascular disturbances are platelet-mediated processes in vivo which are relieved by treatment with aspirin and by platelet reduction [41]. Interestingly, we found that TG induced by platelets isolated from patients experiencing microcirculatory symptoms was increased compared to patients without symptoms, despite being all treated with HU. Further studies are needed to explore the clinical relevance of this finding.

In conclusion, we have shown that platelets of patients with ET and PV have a higher prothrombotic potential as assessed by the increased TG produced in PRP or induced by isolated platelets. In addition, our data support the hypothesis of an increased hypercoagulable state in subjects carriers of JAK2V617F mutation, which in our study are characterized by the highest TG and TF values. A role of $\mathrm{HU}$ in modulating this phenotype is suggested. Prospective studies are needed to evaluate the contribution of platelet-triggered TG to the occurrence of thrombosis, and the preventive role of HU therapy, in ET and PV patients. 
Support and Financial Disclosure Declaration: This study was partially supported by the MPD-RC NIH grant; a grant from the Annadal Foundation, Maastricht, The Netherlands; and a grant from the Associazione Italiana per la Ricerca sul Cancro (AIRC), Milan, Italy. 


\section{References:}

1 Spivak JL, Barosi G, Tognoni G, Barbui T, Finazzi G, Marchioli R, Marchetti M. Chronic myeloproliferative disorders. Hematology / the Education Program of the American Society of Hematology American Society of Hematology. 2003: 200-24.

2 Elliott MA, Tefferi A. Thrombosis and haemorrhage in polycythaemia vera and essential thrombocythaemia. British journal of haematology. 2005; 128: 275-90.

3 Pearson TC. The risk of thrombosis in essential thrombocythemia and polycythemia vera. Seminars in oncology. 2002; 29: 16-21.

4 Carobbio A, Finazzi G, Guerini V, Spinelli O, Delaini F, Marchioli R, Borrelli G, Rambaldi A, Barbui T. Leukocytosis is a risk factor for thrombosis in essential thrombocythemia: interaction with treatment, standard risk factors, and Jak2 mutation status. Blood. 2007; 109: 2310-3.

5 Landolfi R, Di Gennaro L, Barbui T, De Stefano V, Finazzi G, Marfisi R, Tognoni G, Marchioli R. Leukocytosis as a major thrombotic risk factor in patients with polycythemia vera. Blood. 2007; 109: 2446-52.

6 Austin SK, Lambert JR. The JAK2 V617F mutation and thrombosis. British journal of haematology. 2008; 143: 307-20.

7 Lussana F, Caberlon S, Pagani C, Kamphuisen PW, Buller HR, Cattaneo M. Association of V617F Jak2 mutation with the risk of thrombosis among patients with essential thrombocythaemia or idiopathic myelofibrosis: a systematic review. Thrombosis research. 2009; 124: 409-17. S00493848(09)00112-1 [pii] 10.1016/j.thromres.2009.02.004.

8 Landolfi R, Rocca B, Patrono C. Bleeding and thrombosis in myeloproliferative disorders: mechanisms and treatment. Critical reviews in oncology/hematology. 1995; 20: 203-22.

9 Cortelazzo S, Viero P, Bassan R, Barbui T. Spectrum of platelet aggregation abnormalities in myeloproliferative diseases. La Ricerca in clinica e in laboratorio. 1981; 11: 35-42.

10 Wehmeier A, Sudhoff T, Meierkord F. Relation of platelet abnormalities to thrombosis and hemorrhage in chronic myeloproliferative disorders. Seminars in thrombosis and hemostasis. 1997; 23: 391-402.

11 Jensen MK, de Nully Brown P, Lund BV, Nielsen OJ, Hasselbalch HC. Increased platelet activation and abnormal membrane glycoprotein content and redistribution in myeloproliferative disorders. British journal of haematology. 2000; 110: 116-24.

12 Harrison CN. Platelets and thrombosis in myeloproliferative diseases. Hematology / the Education Program of the American Society of Hematology American Society of Hematology. 2005: 409-15.

13 Falanga A, Marchetti M, Vignoli A, Balducci D, Barbui T. Leukocyte-platelet interaction in patients with essential thrombocythemia and polycythemia vera. Experimental hematology. 2005; 33: 523-30.

14 Falanga A, Marchetti M, Vignoli A, Balducci D, Russo L, Guerini V, Barbui T. V617F JAK-2 mutation in patients with essential thrombocythemia: relation to platelet, granulocyte, and plasma hemostatic and inflammatory molecules. Experimental hematology. 2007; 35: 702-11.

15 Falanga A, Marchetti M, Barbui T, Smith CW. Pathogenesis of thrombosis in essential thrombocythemia and polycythemia vera: the role of neutrophils. Seminars in hematology. 2005; 42: 239-47.

16 Arellano-Rodrigo E, Alvarez-Larran A, Reverter JC, Villamor N, Colomer D, Cervantes F. Increased platelet and leukocyte activation as contributing mechanisms for thrombosis in essential thrombocythemia and correlation with the JAK2 mutational status. Haematologica. 2006; 91: 16975.

17 Heemskerk JW, Bevers EM, Lindhout T. Platelet activation and blood coagulation.

Thrombosis and haemostasis. 2002; 88: 186-93. 


\section{CHAPTER V}

18 Monroe DM, Hoffman M, Roberts HR. Platelets and thrombin generation. Arteriosclerosis, thrombosis, and vascular biology. 2002; 22: 1381-9.

19 Hemker HC, Al Dieri R, De Smedt E, Beguin S. Thrombin generation, a function test of the haemostatic-thrombotic system. Thrombosis and haemostasis. 2006; 96: 553-61.

20 Tefferi A, Thiele J, Orazi A, Kvasnicka HM, Barbui T, Hanson CA, Barosi G, Verstovsek S, Birgegard G, Mesa R, Reilly JT, Gisslinger H, Vannucchi AM, Cervantes F, Finazzi G, Hoffman R, Gilliland DG, Bloomfield CD, Vardiman JW. Proposals and rationale for revision of the World Health Organization diagnostic criteria for polycythemia vera, essential thrombocythemia, and primary myelofibrosis: recommendations from an ad hoc international expert panel. Blood. 2007; 110: 1092-7.

21 Cortelazzo S, Marchetti M, Orlando E, Falanga A, Barbui T, Buchanan MR. Aspirin increases the bleeding side effects in essential thrombocythemia independent of the cyclooxygenase pathway: role of the lipoxygenase pathway. American journal of hematology. 1998; 57: 277-82. 22 Marchetti M, Castoldi E, Spronk HM, van Oerle R, Balducci D, Barbui T, Rosing J, Ten Cate $\mathrm{H}$, Falanga A. Thrombin generation and activated protein $\mathrm{C}$ resistance in patients with essential thrombocythemia and polycythemia vera. Blood. 2008; 112: 4061-8.

23 Faber CG, Lodder J, Kessels F, Troost J. Thrombin generation in platelet-rich plasma as a tool for the detection of hypercoagulability in young stroke patients. Pathophysiology of haemostasis and thrombosis. 2003; 33: 52-8.

24 Tripodi A, Primignani M, Chantarangkul V, Clerici M, Dell'Era A, Fabris F, Salerno F, Mannucci PM. Thrombin generation in patients with cirrhosis: the role of platelets. Hepatology. 2006; 44: 440-5. 10.1002/hep.21266.

25 Rugeri L, Beguin S, Hemker C, Bordet JC, Fleury R, Chatard B, Negrier C, Dargaud Y. Thrombin-generating capacity in patients with von Willebrand's disease. Haematologica. 2007; 92: 1639-46.

26 Duckers C, Simioni P, Spiezia L, Radu C, Dabrilli P, Gavasso S, Rosing J, Castoldi E. Residual platelet factor $\mathrm{V}$ ensures thrombin generation in patients with severe congenital factor $\mathrm{V}$ deficiency and mild bleeding symptoms. Blood. 2010; 115: 879-86. blood-2009-08-237719 [pii] 10.1182/blood-2009-08-237719.

27 Arellano-Rodrigo E, Alvarez-Larran A, Reverter JC, Colomer D, Villamor N, Bellosillo B, Cervantes F. Platelet turnover, coagulation factors, and soluble markers of platelet and endothelial activation in essential thrombocythemia: relationship with thrombosis occurrence and JAK2 V617F allele burden. American journal of hematology. 2009; 84: 102-8.

28 Ollivier V, Wang J, Manly D, Machlus KR, Wolberg AS, Jandrot-Perrus M, Mackman N. Detection of endogenous tissue factor levels in plasma using the calibrated automated thrombogram assay. Thrombosis research. 125: 90-6.

29 Finazzi G, Barbui T. Evidence and expertise in the management of polycythemia vera and essential thrombocythemia. Leukemia. 2008; 22: 1494-502.

30 Randi ML, Ruzzon E, Luzzatto G, Tezza F, Girolami A, Fabris F. Safety profile of hydroxyurea in the treatment of patients with Philadelphia-negative chronic myeloproliferative disorders. Haematologica. 2005; 90: 261-2.

31 Cortelazzo S, Finazzi G, Ruggeri M, Vestri O, Galli M, Rodeghiero F, Barbui T. Hydroxyurea for patients with essential thrombocythemia and a high risk of thrombosis. The New England journal of medicine. 1995; 332: 1132-6.

32 Ricksten A, Palmqvist L, Johansson P, Andreasson B. Rapid decline of JAK2V617F levels during hydroxyurea treatment in patients with polycythemia vera and essential thrombocythemia. Haematologica. 2008; 93: 1260-1.

33 Maugeri N, Giordano G, Petrilli MP, Fraticelli V, de Gaetano G, Cerletti C, Storti S, Donati MB. Inhibition of tissue factor expression by hydroxyurea in polymorphonuclear leukocytes from patients with myeloproliferative disorders: a new effect for an old drug? J Thromb Haemost. 2006; 4: 2593-8. 
34 Cella G, Marchetti M, Vianello F, Panova-Noeva M, Vignoli A, Russo L, Barbui T, Falanga A. Nitric oxide derivatives and soluble plasma selectins in patients with myeloproliferative neoplasms. Thrombosis and haemostasis. 2010; 104: 151-6. 09-09-0663 [pii] 10.1160/TH09-09-0663.

35 Moore C, Tymvios C, Emerson M. Functional regulation of vascular and platelet activity during thrombosis by nitric oxide and endothelial nitric oxide synthase. Thrombosis and haemostasis. 2010; 104: 342-9. 09-11-0764 [pii]

10.1160/TH09-11-0764.

36 Hsiao HH, Yang MY, Liu YC, Lee CP, Yang WC, Liu TC, Chang CS, Lin SF. The association of JAK2V617F mutation and leukocytosis with thrombotic events in essential thrombocythemia. Experimental hematology. 2007; 35: 1704-7.

37 Speletas M, Katodritou E, Daiou C, Mandala E, Papadakis E, Kioumi A, Ritis K, Korantzis I. Correlations of JAK2-V617F mutation with clinical and laboratory findings in patients with myeloproliferative disorders. Leukemia research. 2007; 31: 1053-62.

38 Finazzi G, Rambaldi A, Guerini V, Carobbo A, Barbui T. Risk of thrombosis in patients with essential thrombocythemia and polycythemia vera according to JAK2 V617F mutation status. Haematologica. 2007; 92: 135-6.

39 Kralovics R, Passamonti F, Buser AS, Teo SS, Tiedt R, Passweg JR, Tichelli A, Cazzola M, Skoda RC. A gain-of-function mutation of JAK2 in myeloproliferative disorders. The New England journal of medicine. 2005; 352: 1779-90.

40 Kittur J, Knudson RA, Lasho TL, Finke CM, Gangat N, Wolanskyj AP, Li CY, Wu W, Ketterling RP, Pardanani A, Tefferi A. Clinical correlates of JAK2V617F allele burden in essential thrombocythemia. Cancer. 2007; 109: 2279-84.

41 Michiels JJ, Berneman Z, Schroyens W, Koudstaal PJ, Lindemans J, Neumann HA, van Vliet HH. Platelet-mediated erythromelalgic, cerebral, ocular and coronary microvascular ischemic and thrombotic manifestations in patients with essential thrombocythemia and polycythemia vera: a distinct aspirin-responsive and coumadin-resistant arterial thrombophilia. Platelets. 2006; 17: 52844. 


\section{CHAPTER 6}

JAK2V617F mutation and hydroxyurea treatment as determinants of immature platelet parameters in Essential Thrombocythemia and Polycythemia Vera patients

Marina Panova-Noeva, Marina Marchetti, Sabrina Buoro, Laura Russo, Annamaria Leuzzi, Guido Finazzi, Alessandro Rambaldi, Cosimo Ottomano, Hugo ten Cate, and Anna Falanga.

Blood. 2011;118(9):2599-601. Epub 2011 Jul 12. 


\begin{abstract}
Immature platelets (IPF), which are hemostatically more active than mature platelets, have been found elevated in Essential Thrombocythemia (ET) and Polycythemia Vera (PV), two myeloproliferative neoplasms (MPN) characterized by an increased risk of thrombosis. It is not known whether the IPF levels are influenced by pathogenetic factors including JAK2V617F mutational status, or by treatment regimen. To address this point, in 46 ET and 38 PV consecutive patients, we measured IPF and correlated the results to JAK2V617F mutation and myelosuppressive treatment with hydroxyurea (HU). This analysis provides two new elements regarding IPF and MPN. The first finding is that the JAK2V617F mutation is linked to the quantity of IPF in patients with MPN, which might contribute to the prothrombotic phenotype in these patients. The second finding is that IPF is susceptible to myelosuppressive treatment, which may additionally explain the favourable effect of HU therapy on MPN outcome as well as the associated thrombotic risk.
\end{abstract}




\section{Introduction}

Circulating platelets are heterogeneous in size and structure. A small percentage of circulating platelets (i.e. 2\%) are the so-called reticulated or immature platelets (IPF), recently released from the bone marrow. In-vitro studies show that newly formed murine platelets have increased hemostatic activity compared to mature platelets, as demonstrated by the increased response to thrombin and higher expression of surface P-selectin.[1]

Elevated numbers of IPF population have been described in two myeloproliferative neoplasms (MPN) characterized by an increased thrombotic risk, i.e. Essential Thrombocythemia (ET) and Polycythemia Vera (PV), as well as in other thrombotic disorders.[2-4] It is not known whether this increase is influenced by pathogenetic factors including JAK2V617F mutational status, or by treatment regimen in ET and PV patients. Therefore, in this study we enrolled ET and PV patients to characterize immature platelet parameters according to JAK2V617F mutation and treatment.

\section{Methods}

IPF were measured in whole blood by the fully automated hematology analyser XE-2100 (Sysmex Co., Kobe, Japan) and are described as total IPF count, \% of IPF and H-IPF, the latter representing the percentage of platelets within the IPF area with a major amount of m-RNA and thus with the highest fluorescent intensity.[5-6] The collection of venous blood samples and JAK2V617F mutation analysis were performed as previously described.[7] All statistical analyses were done with SPSS version 15 (SPSS, Chicago, IL). The results are presented as mean \pm standard deviation. The intergroup data comparisons were performed using the Student t-test or the nonparametric Mann-Whitney-Wilcoxon $\mathrm{U}$ test, according to the distribution of the test variables. All reported $\mathrm{P}$ values are two sided with a type I error rate of $5 \%$.

\section{Results and Discussion}

This study was conducted in 42 healthy subjects and in a consecutive series of 46 ET and 38 PV patients. Twenty three ET and 18 PV were receiving cytoreductive therapy with hydroxyurea (HU), 35 (16 ET and 19 PV) were on aspirin alone and 8 ( $7 \mathrm{ET}$ and $1 \mathrm{PV}$ ) were not receiving any cytoreductive or aspirin treatment. Twenty three ET patients (50\%) and 34 PV patients $(89 \%)$ have the JAK2V617F mutation. The mutation in all ET patients was heterozygous, whereas among PV patients, 27 were heterozygous and 7 were homozygous for the JAK2V617F mutation. Two PV patients, negative for JAK2V617F, were positive for the JAK2 exon12 mutation. 
Both ET and PV patients had significantly higher platelet and IPF counts compared to controls $(\mathrm{p}<0.01)$. In addition, PV patients had significantly $(\mathrm{p}<0.01)$ higher hematocrit, white blood cell count, \% of IPF and H-IPF compared to both controls and ET patients. Compared to control subjects, JAK2V617F positive patients showed significantly $(\mathrm{p}<0.05)$ higher platelet $(522 \pm 260$ vs $238 \pm 58$ $\left.\mathrm{x} 10^{9} / \mathrm{L}\right)$ and IPF count ( $15 \pm 14$ vs $\left.5.0 \pm 2.0 \times 10^{9} / \mathrm{L}\right), \%$ of IPF $(2.8 \pm 1.6$ vs $2.2 \pm 1 \%)$ and $\mathrm{H}-\mathrm{IPF}(0.9 \pm 0.6$ vs $0.6 \pm 0.3 \%)$, whereas JAK2V617F negative patients had significantly higher platelet $\left(594 \pm 283 \times 10^{9} / \mathrm{L}\right)$ and IPF counts $\left(12 \pm 8 \times 10^{9} / \mathrm{L}\right)$. Figure 1 shows the data after grouping the patients according to both JAK2V617F mutation and HU treatment. Non-HU JAK2V617F positive patients showed significantly $(\mathrm{p}<0.05)$ higher platelet count (Figure 1A), IPF count (Figure 1B), \% of IPF (Figure 1C) and of H-IPF (Figure 1D) compared to control subjects. In addition, non-HU JAK2V617F positive patients showed significantly higher IPF count also compared to non-HU JAK2V617F negative patients and HU treated JAK2V617F positive and negative patients (Figure 1B). Within nonHU treated subjects, JAK2V617F positive patients showed a significantly higher $\%$ of H-IPF compared to JAK2V617F negative patients (Figure 1D). Finally, within patients negative for JAK2V617F mutation, no significant differences in IPF parameters were observed between HU and non-HU treated patients. Differently, within patients positive for JAK2V617F mutation, HU treated patients showed significantly lower $(\mathrm{p}<0.05)$ IPF parameters compared to non-HU treated patients (IPF count: $8.7 \pm 4$ vs $22 \pm 18 \times 10^{9} / \mathrm{L}$; IPF\%: $2.4 \pm 1.0$ vs $3.3 \pm 2.1$ ).

Multivariate regression analysis adjusted for age, sex, JAK2V617F mutational status and HU therapy confirmed that JAK2V617F mutation is significantly associated $(\mathrm{p}<0.01)$ with higher $\%$ of IPF $(B=0.42)$ and H-IPF $(B=0.38)$, and IPF count $(B=0.7)$; while $\mathrm{HU}$ treatment is significantly associated $(\mathrm{p}<0.01)$ with lower $\%$ of IPF $(B=-0.43)$ and H-IPF $(B=-0.32)$, and IPF counts $(B=-0.45)$.

The standard flow cytometric measurement of IPF is considered imprecise, time consuming, expensive and most importantly no inter-laboratory consensus of the normal range has been obtained as yet.[5, 8] Therefore, we have evaluated the percentage of IPF in controls and patients by the recently established fully automated and rapid Sysmex XE-2100 method. The new XE-2100 expands the quantitative analytic range to reticulocytes, immature granulocytes and to optical fluorescent platelet count. The reference range in our study for the $\%$ of IPF in healthy subjects using this method was $0.7-6 \%$ with a mean value of $2.2 \%$, which is in agreement with other studies. $[5,9]$

The measurement of IPF has been considered useful in assessing the treatment response and thrombotic risk in patients with thrombocytosis, both primary and secondary.[10] Increased IPF has also been associated with increased thrombotic risk, i.e. in acute coronary syndromes and in cardioembolic stroke.[4, 11] In addition, increased \% of IPF and H-IPF has been associated with increased platelet aggregation in high risk patients with coronary artery disease.[6] Similarly, renal transplant recipients which are at increased risk for 
cardiovascular mortality showed higher \% of IPF and H-IPF associated with increased platelet aggregation.[12] Due to an increased platelet turnover, MPN patients have a higher percentage of IPF compared to healthy controls.[3] In our study we found that the absolute counts of IPF, were significantly $(p<0.01)$ increased in both ET and PV patients compared to controls, while the \% of both IPF and H-IPF were significantly increased in PV patients only. The analysis according to JAK2V617F mutational status and HU treatment showed that nonHU treated MPN mutation positive patients had significantly higher \% of IPF and H-IPF compared to control subjects. These findings suggest that JAK2V617F mutation might be an important factor related to the increased $\%$ of IPF and H-IPF in MPN patients. The adjusted multivariate analysis demonstrating that JAK2V617F mutation is associated with increased IPF count, \% of IPF and H-IPF confirmed our results. Interestingly, our study showed that within patients positive for JAK2V617F mutation, HU-treated patients have significantly lower IPF parameters compared to non-HU treated patients, which was not observed within JAK2V617F negative patients. This finding is in line with a recently published study showing in MPN subjects positive for JAK2V617F mutation an increased chemosensitivity to HU.[13]

Figure 1: IPF parameters according to JAK2V617F mutation and therapy. The data are reported as mean \pm SD. CTR=Controls; HU=Hydroxyurea; JAK2+=JAK2V617F positive patients; JAK2=JAK2V617F negative patients. ${ }^{*}$ p $<0.05$ vs CTR; $\S \mathrm{p}<0.05$ vs HU JAK2+; $€$ p $<0.05$ vs HU JAK2+, HU JAK2-; \&p<0.05 vs non-HU JAK2-, HU JAK2-, HU JAK2+; **p<0.05 vs non-HU JAK2-.

A.

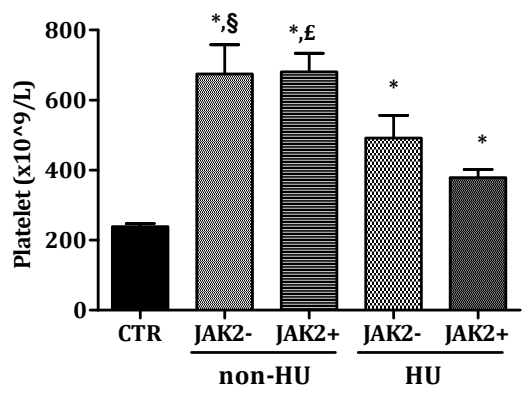

C.

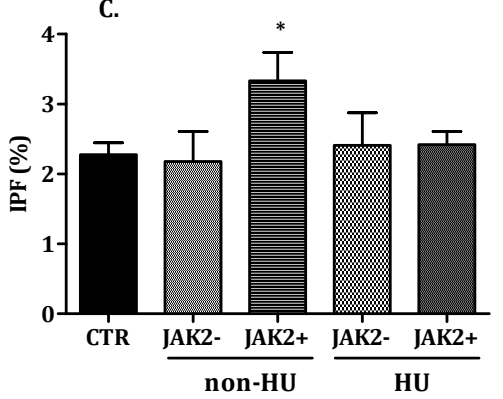

B.

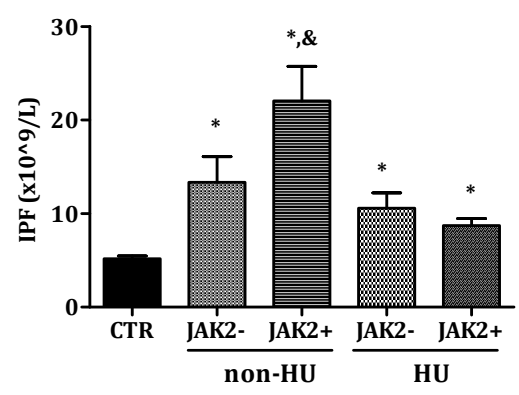

D.

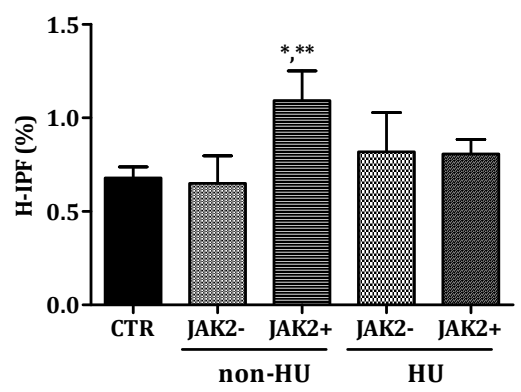


In conclusion, this study provides two new elements regarding the association between IPF and MPN. The first finding is that the JAK2V617F mutation is linked to the quantity of IPF in patients with MPN, which might contribute to the prothrombotic phenotype in these patients. The second finding is that IPF is susceptible to HU treatment, which may additionally explain the favourable effect of this therapy on MPN as well as the associated thrombotic risk. New prospective studies are warranted to evaluate the usefulness of IPF as a cellular marker to predict thrombosis in MPN patients.

\section{Acknowledgements}

This study was partially supported by the MPD-RC NIH grant; a grant from the Annadal Foundation, Maastricht, The Netherlands; and a grant from the Associazione Italiana per la Ricerca sul Cancro (AIRC), Milan, Italy.

\section{Authorship}

P.N.M. designed and performed research, collected the clinical data, analyzed and interpreted data, and wrote the paper; M.M. designed research, analyzed and interpreted data, and wrote the paper; A.F. designed research, interpreted data and contributed to writing the paper; H.t.C. contributed to writing the paper; B.S. performed research; L.R. and A.L. performed research and recruited healthy control subjects; A.R and G.F. contributed to patient recruitment; O.C. contributed to critical review and discussion of the results.

Conflict-of-interest disclosure: The authors declare no competing financial interest. 


\section{References:}

1 Harrison P, Robinson MS, Mackie IJ, Machin SJ. Reticulated platelets. Platelets. 1997; 8: 379-83.

2 Watanabe K, Kawai Y, Takeuchi K. [Reticulated platelets--automated measurement and clinical utility]. [Rinsho ketsueki] The Japanese journal of clinical hematology. 1995; 36: 267-72. 3 Ryningen A, Apelseth T, Hausken T, Bruserud O. Reticulated platelets are increased in chronic myeloproliferative disorders, pure erythrocytosis, reactive thrombocytosis and prior to hematopoietic reconstitution after intensive chemotherapy. Platelets. 2006; 17: 296-302.

4 Grove EL, Hvas AM, Kristensen SD. Immature platelets in patients with acute coronary syndromes. Thrombosis and haemostasis. 2009; 101: 151-6.

5 Briggs C, Kunka S, Hart D, Oguni S, Machin SJ. Assessment of an immature platelet fraction (IPF) in peripheral thrombocytopenia. British journal of haematology. 2004; 126: 93-9.

6 Cesari F, Marcucci R, Caporale R, Paniccia R, Romano E, Gensini GF, Abbate R, Gori AM. Relationship between high platelet turnover and platelet function in high-risk patients with coronary artery disease on dual antiplatelet therapy. Thrombosis and haemostasis. 2008; 99: 930-5. 7 Marchetti M, Castoldi E, Spronk HM, van Oerle R, Balducci D, Barbui T, Rosing J, Ten Cate $\mathrm{H}$, Falanga A. Thrombin generation and activated protein $\mathrm{C}$ resistance in patients with essential thrombocythemia and polycythemia vera. Blood. 2008; 112: 4061-8.

8 Robinson MS, Mackie IJ, Khair K, Liesner R, Goodall AH, Savidge GF, Machin SJ, Harrison P. Flow cytometric analysis of reticulated platelets: evidence for a large proportion of non-specific labelling of dense granules by fluorescent dyes. British journal of haematology. 1998; 100: 351-7. 9 Briggs C, Hart D, Kunka S, Oguni S, Machin SJ. Immature platelet fraction measurement: a future guide to platelet transfusion requirement after haematopoietic stem cell transplantation. Transfusion medicine (Oxford, England). 2006; 16: 101-9.

10 Rinder HM, Schuster JE, Rinder CS, Wang C, Schweidler HJ, Smith BR. Correlation of thrombosis with increased platelet turnover in thrombocytosis. Blood. 1998; 91: 1288-94.

11 Nakamura T, Uchiyama S, Yamazaki M, Okubo K, Takakuwa Y, Iwata M. Flow cytometric analysis of reticulated platelets in patients with ischemic stroke. Thrombosis research. 2002; 106: 171-7.

12 Cesari F, Marcucci R, Gori AM, Caporale R, Fanelli A, Paniccia R, Zanazzi M, Bertoni E, Larti A, Salvadori M, Gensini GF, Abbate R. High platelet turnover and reactivity in renal transplant recipients patients. Thrombosis and haemostasis. 2010; 104: 804-10. 10-02-0124 [pii] 10.1160/TH10-02-0124.

13 Sirhan S, Lasho TL, Hanson CA, Mesa RA, Pardanani A, Tefferi A. The presence of JAK2V617F in primary myelofibrosis or its allele burden in polycythemia vera predicts chemosensitivity to hydroxyurea. American journal of hematology. 2008; 83: 363-5. 10.1002/ajh.21149. 


\section{CHAPTER 7}

Evaluation of Aspirin use on Platelet Function by Platelet Function Analyser-100 and Thrombin Generation Assay in patients with Essential Thrombocythemia and Polycythemia Vera

Marina Panova-Noeva, Marina Marchetti, Sabrina Buoro, Laura Russo, Guido Finazzi, Alessandro Rambaldi, Cosimo Ottomano, Hugo ten Cate, Anna Falanga.

Manuscript in preparation. 


\section{Summary}

Antiplatelet therapy with aspirin (ASA) is now a standard regimen for prevention of thrombosis in myeloproliferative neoplasm (MPN) patients. In this study we performed the PFA-100 assay in whole blood and the thrombin generation (TG) assay in platelet rich plasma (PRP) in a group of 46 essential thrombocythemia (ET) and 38 polycythemia vera (PV) patients to evaluate the effect of ASA on platelet adhesive and procoagulant properties. PFA-100 collagenepinephrine closure time was significantly $(\mathrm{p}<0.01)$ prolonged in both ET and PV patients compared to healthy controls. However, the PFA-100 also showed flow obstruction in $20 \%$ of MPN patients after collagen-adenosine diphosphate and in $15 \%$ of patients after collagen-epinephrine trigger, the majority of them while on ASA. Higher platelet count and immature platelet fraction were associated with shorter collagen-adenosine diphosphate closure time $(\mathrm{R}=-0.5$, $\mathrm{p}<0.05$ for both). The results from the TG assay showed significantly increased TG measured in PRP from both ET and PV patients compared to controls. ASA treated JAK2V617F positive patients had higher TG compared to ASA treated JAK2V617F negative patients. Within JAK2V617F positive patients, we found a significant association between platelet and/or immature platelet count and TG ( $R=0.3, p<0.05$ for both).

This study demonstrates that PFA-100 and TG assay are potentially relevant methods for monitoring ASA effectiveness in MPN patients. Elevated immature platelet parameters are suggested important factors influencing increased platelet adhesive and procoagulant properties. New prospective studies are warranted to evaluate the usefulness of PFA-100 and TG assay in identifying MPN patients at higher risk for thrombosis. 


\section{Introduction}

Essential Thrombocythemia (ET) and Polycythemia Vera (PV) are two myeloproliferative neoplasms (MPN) characterized by a hypercoagulable state and an increased rate of thrombotic complications that significantly impact patients' prognosis and quality of life. The pathogenesis of thrombosis is multifactorial and includes abnormalities in both quantitative and qualitative characteristics of circulating blood cells, including platelets, red and white blood cells [1].

A broad number of studies have investigated the contribution of platelets in the onset of the thrombophilic state in these diseases, and it is now clear that the increased platelet count does not play a dominant role in the risk of thrombosis [2]. Rather, platelet qualitative abnormalities have been implicated in the pathogenesis of hypercoagulability in ET and PV patients. Our and other groups have observed that platelets circulate in an activated state (i.e. higher surface expression P-selectin and tissue factor, TF), and show an increased tendency to form microaggregates with leukocytes [3-4]. The JAK2V617F mutation has been particularly correlated with an activation of hemostasis, leukocytes and platelets [4-6]. More recently, we also described in these patients a greater capacity of platelets to induce thrombin generation (TG), which was in part attributable to a higher platelet surface TF activity [7]. In contrast, a recent study evaluating TG capacity of polymorphonucler neutrophils did not show any difference between MPN patients and healthy controls [8].

Antiplatelet therapy with low dose aspirin (ASA) has been associated with reduced risk for thrombosis in PV patients [9].Despite the lack of data from randomized controlled clinical trials in ET patients, ASA use has been shown effective in alleviating vasomotor (microvascular) disturbances in these patients [10-11]. Furthermore, ASA therapy has been considered beneficial in preventing complications during pregnancy (i.e. fetal loss, intrauterine growth retardation, pre-eclampsia and arterial hypertension), particularly in patients positive for JAK2V617F mutation [12]. Therefore, ASA is now a standard treatment regimen for prevention of thrombosis in both low and high risk for thrombosis ET and PV patients [13]. However, despite the standard low dose ASA use, some MPN patients continue to show abnormal platelet aggregation and persistent thromboxane biosynthesis [14-15]. Whereas no information is available for the percentage of MPN patients as ASA non responders, in patients with cardiovascular diseases this phenomenon ranges from $1 \%$ to $45 \%$.[16]

The present study has been designed to characterize the effect of ASA on platelet adhesive and procoagulant function in ET and PV patients. Particularly, the PFA-100 was used to evaluate platelet adhesion capacity in response to platelet physiological agonists (i.e. collagen/adenosine diphosphate and collagen/epinephrine), and the Calibrated Automated Thrombogram (CAT) assay was used to measure platelet thrombin generation (TG) potential. Furthermore, we have evaluated the potential use of PFA-100 and CAT assay in detecting ET 
and PV non-responders on ASA. The results of our study were analysed according to patients' haematological characteristics, treatment regimen and JAK2V617F mutational status.

\section{Subjects and methods}

\section{Subjects}

This study has been conducted in blood samples obtained from 41 healthy subjects, 46 consecutive ET and 38 PV patients. The healthy subjects were hospital employees while the patients were recruited from Bergamo hospital between June 2008 and June 2009. The local Ethics committee (Comitato di Bioetica, Ospedali Riuniti, Bergamo, Italy) approved the study and all blood samples were obtained after informed consent. ET and PV patients were diagnosed according to the WHO criteria [17] and the procedures followed were in accordance with the Helsinki declaration of 1975 as revised in 2000 . None of the patients were taking anticoagulant drugs, oral contraceptives or hormone replacement therapy. Among the patients, 41 (23 ET and 18 PV) were receiving cytoreductive therapy with hydroxyurea (HU), 35 (16 ET and $19 \mathrm{PV}$ ) were on ASA alone and 8 (7ET and 1PV) were not receiving any cytoreductive or ASA treatment. Twenty three ET patients (50\%) and 34 PV patients (89\%) carried the JAK2V617F mutation. All ET patients positive for JAK2V617F were heterozygous, whereas among PV patients, 27 were heterozygous and 7 homozygous for the mutation. Two PV patients negative for JAK2V617F were positive for JAK2 exon12 mutation. None of the healthy controls were taking any antiplatelet or anti-inflammatory drugs in the last 10 days prior to blood drawing.

\section{Collection of blood samples}

Blood samples were drawn early in the morning after applying a light tourniquet. After discarding the first $3 \mathrm{ml}$, the blood was collected into sterile siliconized tubes containing K3-ethylenediamine tetraacetic acid (K3-EDTA) for molecular biology studies and blood cell count analysis or trisodium citrate (0.129M, 1:9 vol:vol) for coagulation studies.

\section{Platelet Rich Plasma (PRP) preparation}

Within 30 minutes from blood draw, platelet rich plasma (PRP) was separated by centrifugation of whole blood for $10 \mathrm{~min}$ at $280 \mathrm{~g}$ at room temperature (RT). The rest of the blood sample was centrifuged at 3,500g for 20 min to obtain platelet poor plasma, which was utilized to dilute PRP to obtain a concentration of 150,000 platelets/ $\mu \mathrm{l}$. 


\section{Routine haematological assays}

Whole blood analysis of white blood cell differential count, hematocrit, platelet count, mean platelet volume and immature platelet parameters (IPF count, \% of IPF and H-IPF) were determined by a Sysmex-XE 2100 haematology analyzer (Sysmex Co., Kobe, Japan).

\section{Platelet function analysis by PFA-100}

PFA-100 analysis was performed in whole blood as described previously [5].The result, expressed in seconds (sec.), is the closure time reflecting the platelet function in primary haemostasis after collagen and adenosine diphosphate (CADP) or collagen and epinephrine (CEPI) stimulation. All measurements were performed in duplicate. In case of a result $>300 \mathrm{sec}$., and/or flow obstruction (defined as sudden stoppage of blood flow during the test) additional two consecutive measurements have been performed from the same sample. When the status remained the same, the result of the sample has been recorded as $300 \mathrm{sec}$. and/or null result respectively.

\section{Thrombin generation assay}

TG was performed in PRP using the CAT assay. Briefly, $20 \mu \mathrm{l}$ of $1 \mathrm{pM}$ TF were added into TG wells and $20 \mu \mathrm{l}$ of calibrator (with activity of $600 \mathrm{nM}$ alpha2Mthrombin complex) into thrombin calibrator (TC) well. Eighty $\mu$ l of PRP were added to both wells (TG and TC well). After 10 min prewarming at $37^{\circ} \mathrm{C}$ inside the fluorimeter (Fluoroscan Ascent, Thermo Labsystems, Helsinki, Finland), the reaction was started by the addition of $20 \mu \mathrm{l}$ of $\mathrm{CaCl} 2 /$ fluorogenic substrate (ZGly-Gly-Arg-AMC; Bachem, Bubendorf, Switzerland) mixture. The TG curves were calculated using Thrombinoscope software (Thrombinoscope, Maastricht, The Netherlands) by comparing the signals from the TG well and the TC well. TG curves were described in terms of peak height, the maximum concentration of thrombin formed, expressed in nM thrombin.

\section{JAK2V617F mutation analysis}

The presence of the somatic V617F mutation of the Janus 2 tyrosine kinase (JAK2) gene was tested on DNA obtained from K3-EDTA anticoagulated blood samples using the Puregene DNA isolation kit (Gentra systems, Minneapolis MN, USA). Polymerase chain reaction was performed as described previously [5].

\section{Statistical analysis}

All statistical analyses were done with SPSS version 15 (SPSS, Chicago, IL). Continuous variables are expressed as mean \pm standard deviation (SD). All reported $\mathrm{P}$ values are two sided with a type I error rate of $5 \%$. The intergroup data comparisons were performed using the Student t-test or the nonparame- 
tric Mann-Whitney-Wilcoxon U test, according to the distribution of the test variables. Correlation and linear regression analysis was performed and the regression coefficient expressed as B represents the absolute change of the dependent variable when the independent variable increases by 1 unit.

\section{Results}

\section{Subjects' hematological characteristics}

Baseline and hematological characteristics are described in Table 1 . The mean platelet count in healthy subjects was $238 \times 10^{9} / \mathrm{L}$, with range $144-398 \times 10^{9} / \mathrm{L}$. Both ET and PV patients had significantly higher platelet and IPF count compared to controls $(\mathrm{p}<0.01)$. In addition, PV patients had significantly $(\mathrm{p}<0.01)$ higher hematocrit, white blood cell, \% of IPF and H-IPF compared to both controls and ET patients. The analysis according to treatment showed no significant differences for all hematological characteristics between ASA treated and non-treated patients (data not shown). Differently, patients on HU showed significantly lower platelet $\left(408 \pm 162 \times 10^{9} / \mathrm{L}\right)$ and IPF count $\left(9.2 \pm 4.4 \times 10^{9} / \mathrm{L}\right)$ compared to non treated patients (platelet:767 \pm 382 ; IPF count: $21 \pm 11 \times 10^{9} / \mathrm{L}$ ) and ASA treated patients (platelet:637 \pm 234 ; IPF count:18 $\pm 17 \times 10^{9} / \mathrm{L}$ ).

Table 1. Study subjects characteristics. IPF $=$ Immature Platelet Fraction; ${ }^{*} \mathrm{p}<0.05$ and ${ }^{* *} \mathrm{p}<0.01$ vs Controls; $\&$ p $<0.01$ vs ET.

\begin{tabular}{lccc}
\hline & $\begin{array}{c}\text { CONTROLS } \\
\mathbf{( 4 1 )}\end{array}$ & $\begin{array}{c}\text { ET } \\
\mathbf{( 4 6 )}\end{array}$ & $\begin{array}{c}\text { PV } \\
\mathbf{( 3 8 )}\end{array}$ \\
\hline Males/Females & $21 / 20$ & $15 / 31$ & $17 / 21$ \\
Age (years) & $55(27-76)$ & $54(23-79)$ & $60(20-79)$ \\
Hematocrit (\%) & $41.7(36-45)$ & $41(31-47.3)$ & $45.6(37.8-50)^{* *, \&}$ \\
White Blood Cells (10\%/L) & $6.3(3.9-9.2)$ & $6.9(3.6-14.4)$ & $10(3.6-39.9)^{* *, \&}$ \\
Platelets (109/L) & $238(144-398)$ & $574(208-1413)^{* *}$ & $495(93-1278)^{* *}$ \\
Mean Platelet Volume (fL) & $10.6(8.3-12.4)$ & $10.4(8.5-12.5)$ & $10.3(8.8-11.3)$ \\
IPF (109/L) & $5(1.6-9.7)$ & $12.1(3.3-40.6)^{* *}$ & $16.7(3.3-103)^{* *}$ \\
IPF (\%) & $2.2(0.7-6)$ & $2.2(0.5-6.5)$ & $3.3(1.4-11.2)^{* *, \&}$ \\
H-IPF (\%) & $0.6(0.1-2)$ & $0.7(0.2-2.3)$ & $1.1(0.4-4.2)^{* *, \&}$ \\
\hline
\end{tabular}




\section{PFA-100 results}

The mean closure time in healthy controls was $95 \pm 19$ sec with CEPI, and $73 \pm 10$ sec with CADP, and the two measurements were significantly and highly correlated $(\mathrm{R}=0.85, \mathrm{p}<0.001)$. CEPI closure time was significantly $(\mathrm{p}<0.01)$ prolonged in both ET $(149 \pm 105 \mathrm{sec})$ and PV $(179 \pm 95 \mathrm{sec})$ subjects compared to healthy controls, while CADP closure times were not significantly different vs controls (ET: $63 \pm 34$; PV: $66 \pm 38 \mathrm{sec}$ ). No significant differences were observed in CEPI and CADP closure times between ET and PV patients.

ET and PV patients on ASA ( $n=35)$ and on HU+ASA ( $n=33$ ) had significantly $(\mathrm{p}<0.05)$ prolonged CEPI closure times compared to control subjects (Figure 1A). Thirteen patients on ASA (37\%) and 9 on HU+ASA (27\%) showed a CEPI closure time $>300 \mathrm{sec}$ (Figure 1A). No significantly different CADP closure time was observed between different subgroups (Figure 1B). In addition, no influence of JAK2V617F mutational status was found in CEPI and CADP closure times (data not shown).

Figure 1. CEPI and CADP closure time in MPN patients according to therapy. CTR=Control; NT= non treated; $\mathrm{ASA}=$ Aspirin; HU= Hydroxyurea; ${ }^{*} \mathrm{p}<0.01$ vs CTR.

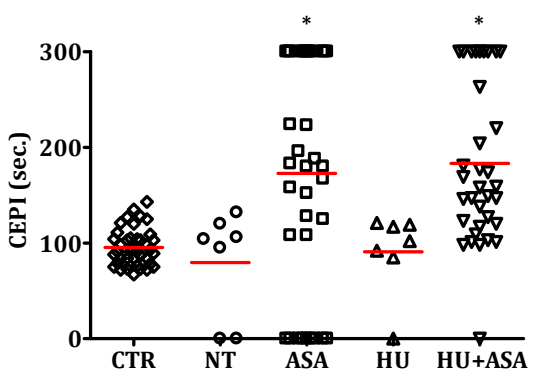

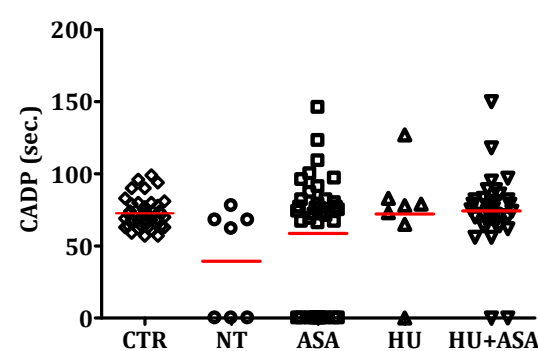

Flow obstruction, which was not observed in control subjects, occurred in blood samples from 17 patients (9 ET and 8 PV) with CADP (20\%) and from 13 patients ( $9 \mathrm{ET}$ and $4 \mathrm{PV}$ ) with CEPI $(15 \%)$. The majority of patients were on ASA (CADP: 11; CEPI: 9 patients) or NT (CADP: 3; CEPI: 2 patients) while only few on HU+ASA (CADP: 2; CEPI: 1 patient) and HU (CADP:1; CEPI:1 patient). Seventeen patients experiencing flow obstruction with the CADP assay, had platelet count, IPF count, \% of IPF and H-IPF significantly higher $(p<0.05)$ compared to the remaining patients (Table 2). Only platelet and IPF counts were significantly different between subjects with and without flow obstruction by the CEPI assay. These 2 groups of subjects had no significantly different hematocrit and white blood cell values. 
Table 2. PFA-100 analysis in MPN patients.

\begin{tabular}{lcccccc}
\hline & \multicolumn{3}{c}{ CADP (seconds) } & \multicolumn{3}{c}{ CEPI (seconds) } \\
\hline Flow obstruction & $\begin{array}{c}\text { Yes } \\
(\mathrm{n}=17)\end{array}$ & $\begin{array}{c}\text { No } \\
(\mathrm{n}=67)\end{array}$ & $\mathrm{p}=$ & $\begin{array}{c}\text { Yes } \\
(\mathrm{n}=13)\end{array}$ & $\begin{array}{c}\text { No } \\
(\mathrm{n}=71)\end{array}$ & $\mathrm{p}=$ \\
\hline Hematocrit (\%) & $42.3 \pm 3.4$ & $42.8 \pm 4.4$ & n.s. & $42 \pm 3.8$ & $42.8 \pm 4.3$ & n.s. \\
WBC (109/L) & $10 \pm 3.6$ & $7.9 \pm 4.9$ & n.s. & $8.8 \pm 2.8$ & $8.2 \pm 5$ & n.s. \\
Platelet (10\%/L) & $847 \pm 342$ & $459 \pm 174$ & 0.000 & $879 \pm 302$ & $470 \pm 199$ & 0.000 \\
IPF (109/L) & $28.1 \pm 22$ & $10.6 \pm 5.4$ & 0.000 & $25.8 \pm 24$ & $11.8 \pm 7.4$ & 0.000 \\
IPF (\%) & $3.8 \pm 2.8$ & $2.4 \pm 1.1$ & 0.003 & $3.1 \pm 3$ & $2.6 \pm 1.4$ & n.s. \\
H-IPF (\%) & $1.3 \pm 1.1$ & $0.8 \pm 0.4$ & 0.005 & $1.06 \pm 1.1$ & $0.8 \pm 0.5$ & n.s. \\
\hline
\end{tabular}

The correlation analysis (Table 3) showed that higher total platelet and IPF counts, \% of IPF and H-IPF are associated with shorter CADP, while higher total platelet and IPF counts are associated with shorter CEPI closure time only.

Table 3. Correlation analysis in MPN patients.

$R=$ Pearson correlation coefficient; $p$ significant $<0.05$.

\begin{tabular}{lcc}
\hline & $\begin{array}{c}\text { CADP } \\
\mathbf{R}(\mathbf{p})\end{array}$ & $\begin{array}{c}\text { CEPI } \\
\mathbf{R}(\mathbf{p})\end{array}$ \\
\hline Platelet $(\mathbf{x 1 0} / \mathbf{L})$ & $-0.503(0.000)$ & $-0.330(0.002)$ \\
$\mathbf{I P F}(\mathbf{x 1 0} / \mathbf{L})$ & $-0.460(0.000)$ & $-0.221(0.043)$ \\
$\mathbf{I P F}(\%)$ & $-0.263(0.016)$ & -0.030 (n.s.) \\
H-IPF (\%) & $-0.232(0.034)$ & -0.022 (n.s.) \\
\hline
\end{tabular}

\section{Thrombin Generation in PRP}

In agreement with our previous findings [7], the TG potential measured in PRP was significantly $(\mathrm{p}<0.01)$ higher in both ET and PV patients compared to healthy controls. The further analysis according to treatment showed that ET patients on ASA ( $149 \pm 35 \mathrm{nM}$ thrombin) and HU (148 $\pm 39 \mathrm{nM}$ thrombin) had 
lower TG compared to NT patients $(177 \pm 61 \mathrm{nM}$ thrombin) however without reaching a statistical significance $(\mathrm{p}=0.1)$. While no significant differences were observed for ET patients on ASA and HU, PV patients on HU $(148 \pm 49 \mathrm{nM}$ thrombin) showed significantly lower $(\mathrm{p}<0.05)$ TG compared to ASA treated patients ( $175 \pm 25 \mathrm{nM}$ thrombin). Only one PV patient was untreated, therefore the comparison analysis to ASA and HU treated PV patients was not possible.

The analysis based on JAK2V617F mutation showed that ASA treated JAK2V617F positive patients (174 $\pm 26 \mathrm{nM}$ thrombin) had higher TG compared to ASA treated JAK2V617F negative patients $(151 \pm 37 \mathrm{nM}$ thrombin, $\mathrm{p}=0.05)$. No significant differences were observed for TG between JAK2V617F positive $(146 \pm 41 \mathrm{nM}$ thrombin) and negative patients on $\mathrm{HU}(154 \pm 33 \mathrm{nM}$ thrombin, $\mathrm{p}=0.59)$.

In healthy and JAK2V617F negative subjects no significant correlations were found between TG and hematological parameters. Differently, in JAK2V617F positive patients, we found a significant association between platelet and/or IPF count and TG (R=0.3, $\mathrm{p}<0.05$ for both).

\section{Correlation analysis: PFA-100 and CAT assay}

In ASA treated patients positive for JAK2V617F mutation we observed a significant and negative correlation between CADP closure time and TG $(\mathrm{R}=-0.452$, $\mathrm{p}=0.04$ ). No significant correlations were observed in the other patient subgroups between the both assays.

\section{Discussion}

ASA use has been widely employed for prevention of thrombosis in MPN patients [13]. Large metaanalysis showed a significant benefit of ASA use in reduction of occlusive vascular events.[18-19]. However, recent observations have highlighted wide biological variability in the interindividual response to ASA's antiplatelet effects. In $10-20 \%$ of patients recurrent vascular events occurred despite treatment with ASA, referred to as treatment failure [20]. Understanding the mechanisms responsible for this phenomenon may be useful in improving management of patients whose biological response to ASA is impaired. The platelet adhesive function measured by PFA-100 has been extensively utilized in monitoring antiplatelet therapy, predominantly ASA but also clopidogrel and non steroidal antiinflamatory drugs that strongly influence closure time results.

Our study showed that CEPI closure time is significantly influenced by ASA treatment in MPN patients. Further, we observed that MPN patients with shorter CADP and CEPI closure times have significantly higher platelet and IPF count. In addition, the shorter CADP time was associated with higher \% of IPF and $\mathrm{H}$ IPF. Therefore, the results of our study might suggest the importance of IPF as a 
more reactive fraction of platelets to increased platelet adhesiveness, particularly to collagen and ADP stimulus.

While PFA-100 assay is primarily used as a screening tool for von Willebrand's disease, recent research has been focused more on the potential for the PFA100 to identify patients at higher risk for thrombosis.[21] Indeed, shorter CEPI closure time as well as shorter CADP time has been linked to higher risk for thrombosis.[22] Primarily ASA nonresponders have been identified among older patients, patients with acute vascular events and those with type 2 diabetes [20]. A shorter CADP closure time has been identified in patients with ST segment elevation myocardial infarction and was an independent predictor of a poor outcome [23]. In addition, shorter CEPI closure time found more frequent in patients with recent myocardial infarction, followed by patients with unstable angina and less frequent in patients with stable coronary artery disease, may reflect an ongoing thrombotic state and reduced responsiveness to ASA [24].

PFA-100 has been shown to be a reliable and rapid method in measuring ASA antiplatelet effects in patients with a high platelet count, such as ET or reactive thrombocythosis patients when compared to optical aggregometry [25]. This assay might be potentially useful in MPN patients to evaluate both the responsiveness to ASA treatment by the CEPI assay and platelet adhesiveness by the CADP assay. Prospective studies are needed to investigate whether CADP assay can be a potential marker in identifying MPN patients at higher risk for thrombosis.

We have recently demonstrated that platelet-associated TG is significantly increased in both ET and PV patients compared to controls [7]. In the present study, we observed higher TG in ASA treated JAK2V617F positive patients compared to ASA treated JAK2V617F negative patients. No difference was observed in TG between JAK2V617F positive and negative patients on HU. Our recent study showed elevated IPF parameters in both ET and PV patients, and particularly in JAK2V617F positive patients [26]. In the present study we found that higher IPF count is associated with higher TG, and particularly in patients positive for JAK2V617F mutation. Therefore, we suggest that the increased IPF count is a relevant factor influencing increased TG in these patients. In addition we showed that MPN patients on HU have significantly lower TG, particularly in JAK2V617F positive patients [7]. Our recent study showed that HU-treated patients had lower levels of IPF, suggesting another potential protective mechanism of $\mathrm{HU}$, through reducing the most reactive fraction of the platelets, the IPF [26].

The characteristics of newly formed platelets may explain the pathological PFA100 assay results and the increased TG assessed by the CAT assay in MPN patients. Several mechanisms can explain the increased prothrombotic potential of IPF in patients with an increased platelet turnover. IPF are greater in mass 
and are enzymatically and metabolically more active than mature platelets. These platelets aggregate faster after collagen stimulation and have an increased levels of platelet surface proteins, such as P-selectin and GPIIb/IIIa [27].

Our study showed that despite taking ASA, patients with higher IPF had shorter CADP and CEPI closure time and higher TG. Indeed, we observed a significant correlation between shorted CADP closure time and higher TG in ASA treated JAK2V617F positive patients. Recent studies suggest a possible role of IPF in resistance to antiplatelet therapy by expressing more COX-2 resulting in an increased thromboxane production [28]. In addition, hyperreactivity while on ASA and increased ASA resistance has been associated with the presence of uninhibited COX-1 and COX-2 due to increased levels of immature platelets [29]. Dragani et al. have recently shown that residual thromboxane A2 production in ASA treated ET patients is likely due to expression of unacetylated COX-1 and COX-2 in newly formed platelets [15]. Furthermore, a recent study in high risk patients with coronary artery disease, has demonstrated increased residual platelet reactivity in patients with increased \% of IPF and H-IPF while on dual antiplatelet therapy [30].

This study provides new insight into platelet pathophysiology of patients with ET and PV. In addition it demonstrates that PFA-100 and CAT assay are potentially useful methods in monitoring ASA effectiveness in MPN patients. Elevated IPF parameters are suggested important factors influencing increased platelet adhesive and procoagulant properties. New prospective studies are warranted to evaluate the reliability of PFA-100 and CAT assay in identifying MPN patients at higher risk for thrombosis. 


\section{References:}

1 Elliott MA, Tefferi A. Thrombosis and haemorrhage in polycythaemia vera and essential thrombocythaemia. British journal of haematology. 2005; 128: 275-90.

2 Carobbio A, Thiele J, Passamonti F, Rumi E, Ruggeri M, Rodeghiero F, Randi ML, Bertozzi I, Vannucchi AM, Antonioli E, Gisslinger H, Buxhofer-Ausch V, Finazzi G, Gangat N, Tefferi A, Barbui T. Risk factors for arterial and venous thrombosis in WHO-defined essential thrombocythemia: an international study of 891 patients. Blood. 2011. blood-2011-02-339002 [pii] 10.1182/blood-2011-02-339002.

3 Falanga A, Marchetti M, Vignoli A, Balducci D, Barbui T. Leukocyte-platelet interaction in patients with essential thrombocythemia and polycythemia vera. Experimental hematology. 2005; 33: 523-30.

4 Arellano-Rodrigo E, Alvarez-Larran A, Reverter JC, Villamor N, Colomer D, Cervantes F. Increased platelet and leukocyte activation as contributing mechanisms for thrombosis in essential thrombocythemia and correlation with the JAK2 mutational status. Haematologica. 2006; 91: 16975.

5 Falanga A, Marchetti M, Vignoli A, Balducci D, Russo L, Guerini V, Barbui T. V617F JAK-2 mutation in patients with essential thrombocythemia: relation to platelet, granulocyte, and plasma hemostatic and inflammatory molecules. Experimental hematology. 2007; 35: 702-11.

6 Passamonti F, Rumi E, Pietra D, Della Porta MG, Boveri E, Pascutto C, Vanelli L, Arcaini L, Burcheri S, Malcovati L, Lazzarino M, Cazzola M. Relation between JAK2 (V617F) mutation status, granulocyte activation, and constitutive mobilization of CD34+ cells into peripheral blood in myeloproliferative disorders. Blood. 2006; 107: 3676-82. 2005-09-3826 [pii] 10.1182/blood-2005-09-3826.

7 Panova-Noeva M, Marchetti M, Spronk HM, Russo L, Diani E, Finazzi G, Salmoiraghi S, Rambaldi A, Barbui T, Ten Cate H, Falanga A. Platelet-induced thrombin generation by the calibrated automated thrombogram assay is increased in patients with essential thrombocythemia and polycythemia vera. American journal of hematology. 2011; 86: 337-42. 10.1002/ajh.21974.

8 Perrin J, Ranta D, Empereur F, Vigneron C, Feugier P, Lecompte T. Polymorphonuclear neutrophils from JAK2(V617F) positive MPD patients do not support hypercoagulability: A study with calibrated automated thrombography (CAT). Blood cells, molecules \& diseases. 2011; 46: 235 8. S1079-9796(11)00004-0 [pii]

10.1016/j.bcmd.2011.01.003.

9 Landolfi R, Marchioli R, Kutti J, Gisslinger H, Tognoni G, Patrono C, Barbui T. Efficacy and safety of low-dose aspirin in polycythemia vera. The New England journal of medicine. 2004; 350: 114-24. 10.1056/NEJMoa035572 350/2/114 [pii].

10 Michiels JJ, Berneman Z, Schroyens W, Koudstaal PJ, Lindemans J, Neumann HA, van Vliet HH. Platelet-mediated erythromelalgic, cerebral, ocular and coronary microvascular ischemic and thrombotic manifestations in patients with essential thrombocythemia and polycythemia vera: a distinct aspirin-responsive and coumadin-resistant arterial thrombophilia. Platelets. 2006; 17: 52844. JK20142193125470 [pii] 10.1080/09537100600758677.

11 Michiels JJ, Berneman Z, Schroyens W, van Urk H. Aspirin-responsive painful red, blue, black toe, or finger syndrome in polycythemia vera associated with thrombocythemia. Ann Hematol. 2003; 82: 153-9. 10.1007/s00277-002-0593-x.

12 Passamonti F, Rumi E, Randi ML, Morra E, Cazzola M. Aspirin in pregnant patients with essential thrombocythemia: a retrospective analysis of 129 pregnancies. J Thromb Haemost. 2010; 8: 411-3. JTH3686 [pii] 10.1111/j.1538-7836.2009.03686.x. 
13 Tefferi A, Vainchenker W. Myeloproliferative neoplasms: molecular pathophysiology, essential clinical understanding, and treatment strategies. J Clin Oncol. 2011; 29: 573-82.

JC0.2010.29.8711 [pii] 10.1200/JC0.2010.29.8711.

14 Myers TJ, Steinberg WM, Rickles FR. Polycythemia vera and mesenteric arterial thrombosis. A disease association resulting from decreased platelet sensitivity to aspirin. Archives of internal medicine. 1979; 139: 695-8.

15 Dragani A, Pascale S, Recchiuti A, Mattoscio D, Lattanzio S, Petrucci G, Mucci L, Ferrante E, Habib A, Ranelletti FO, Ciabattoni G, Davi G, Patrono C, Rocca B. The contribution of cyclooxygenase1 and -2 to persistent thromboxane biosynthesis in aspirin-treated essential thrombocythemia: implications for antiplatelet therapy. Blood. 2010; 115: 1054-61. blood-2009-08-236679 [pii] 10.1182/blood-2009-08-236679.

16 Ben-Dor I, Kleiman NS, Lev E. Assessment, mechanisms, and clinical implication of variability in platelet response to aspirin and clopidogrel therapy. Am J Cardiol. 2009; 104: 227-33. S0002-9149(09)00732-2 [pii] 10.1016/j.amjcard.2009.03.022.

17 Tefferi A, Thiele J, Orazi A, Kvasnicka HM, Barbui T, Hanson CA, Barosi G, Verstovsek S, Birgegard G, Mesa R, Reilly JT, Gisslinger H, Vannucchi AM, Cervantes F, Finazzi G, Hoffman R, Gilliland DG, Bloomfield CD, Vardiman JW. Proposals and rationale for revision of the World Health Organization diagnostic criteria for polycythemia vera, essential thrombocythemia, and primary myelofibrosis: recommendations from an ad hoc international expert panel. Blood. 2007; 110: $1092-7$.

18 Collaborative meta-analysis of randomised trials of antiplatelet therapy for prevention of death, myocardial infarction, and stroke in high risk patients. BMJ. 2002; 324: 71-86.

19 Bartolucci AA, Tendera M, Howard G. Meta-Analysis of Multiple Primary Prevention Trials of Cardiovascular Events Using Aspirin. Am J Cardiol. 2011. S0002-9149(11)01013-7 [pii] 10.1016/j.amjcard.2011.02.325.

20 Crescente M, Di Castelnuovo A, Iacoviello L, Vermylen J, Cerletti C, de Gaetano G. Response variability to aspirin as assessed by the platelet function analyzer (PFA)-100. A systematic review. Thrombosis and haemostasis. 2008; 99: 14-26. 08010014 [pii] 10.1160/TH07-08-0530.

21 Favaloro EJ, Kershaw G, Bukuya M, Hertzberg M, Koutts J. Laboratory diagnosis of von Willebrand disorder (vWD) and monitoring of DDAVP therapy: efficacy of the PFA-100 and vWF:CBA as combined diagnostic strategies. Haemophilia. 2001; 7: 180-9. hae487 [pii].

22 Smit JJ, van Werkum JW, ten Berg J, Slingerland R, Ottervanger JP, Heestermans T, Dill T, Hamm C, van 't Hof AW. Prehospital triple antiplatelet therapy in patients with acute ST elevation myocardial infarction leads to better platelet aggregation inhibition and clinical outcome than dual antiplatelet therapy. Heart. 2010; 96: 1815-20. hrt.2010.201889 [pii] 10.1136/hrt.2010.201889.

23 Frossard M, Fuchs I, Leitner JM, Hsieh K, Vlcek M, Losert H, Domanovits H, Schreiber W, Laggner AN, Jilma B. Platelet function predicts myocardial damage in patients with acute myocardial infarction. Circulation. 2004; 110: 1392-7. 10.1161/01.CIR.0000141575.92958.9C 01.CIR.0000141575.92958.9C [pii].

24 Linden MD, Furman MI, Frelinger AL, 3rd, Fox ML, Barnard MR, Li Y, Przyklenk K, Michelson AD. Indices of platelet activation and the stability of coronary artery disease. J Thromb Haemost. 2007; 5: 761-5. JTH2462 [pii] 10.1111/j.1538-7836.2007.02462.x.

25 Tsantes AE, Mantzios G, Giannopoulou V, Tsirigotis P, Bonovas S, Rapti E, Mygiaki E, Kartasis Z, Sitaras NM, Dervenoulas J, Travlou A. Monitoring aspirin treatment in patients with thrombocytosis: comparison of the platelet function analyzer (PFA)-100 with optical aggregometry. Thrombosis research. 2008; 123: 100-7. S0049-3848(08)00091-1 [pii] 


\section{CHAPTER VII}

10.1016/j.thromres.2008.03.008.

26 Panova-Noeva M, Marchetti M, Buoro S, Russo L, Leuzzi A, Finazzi G, Rambaldi A, Ottomano C, Ten Cate H, Falanga A. JAK2V617F mutation and hydroxyurea treatment as determinants of immature platelet parameters in essential thrombocythemia and polycythemia vera patients. Blood. 2011. blood-2011-02-339655 [pii]

10.1182/blood-2011-02-339655.

27 Tschoepe D, Roesen P, Esser J, Schwippert B, Nieuwenhuis HK, Kehrel B, Gries FA. Large platelets circulate in an activated state in diabetes mellitus. Seminars in thrombosis and hemostasis. 1991; 17: 433-8.

28 Rocca B, Secchiero P, Ciabattoni G, Ranelletti FO, Catani L, Guidotti L, Melloni E, Maggiano $\mathrm{N}$, Zauli G, Patrono C. Cyclooxygenase-2 expression is induced during human megakaryopoiesis and characterizes newly formed platelets. Proceedings of the National Academy of Sciences of the United States of America. 2002; 99: 7634-9.

29 Guthikonda S, Lev EI, Patel R, DeLao T, Bergeron AL, Dong JF, Kleiman NS. Reticulated platelets and uninhibited COX-1 and COX-2 decrease the antiplatelet effects of aspirin. J Thromb Haemost. 2007; 5: 490-6.

30 Cesari F, Marcucci R, Caporale R, Paniccia R, Romano E, Gensini GF, Abbate R, Gori AM. Relationship between high platelet turnover and platelet function in high-risk patients with coronary artery disease on dual antiplatelet therapy. Thrombosis and haemostasis. 2008; 99: 930-5. 
Evaluation of Aspirin use on Platelet Function by Platelet Function Analyser-100 and TG Assay in ET and PV patients 


\section{CHAPTER 8}

ADP-induced whole blood aggregation and
platelet-associated thrombin generation
(TG) are increased in Essential Thrombo-
cythemia (ET) and Polycythemia Vera (PV)
patients

Marina Panova-Noeva, Marina Marchetti, Annamaria Leuzzi, Laura Russo, Guido Finazzi, Alessandro Rambaldi, Hugo ten Cate, Anna Falanga.

Manuscript in preparation. 


\section{Abstract}

Background: Patients with Essential Thrombocythemia (ET) and Polycythemia Vera (PV) are characterized by an increased rate of thrombotic complications and by several abnormalities of platelets, more pronounced in JAK2V617F positive patients.

Objectives: The objective of this study was to evaluate the platelet aggregation and procoagulant potential induced by several different agonists in ET and PV patients.

Patients/Methods: Samples from 65 ET and 51 PV patients were analysed by whole blood impedance aggregometry and by Calibrated Automated Thrombogram (CAT) assay in platelet rich plasma (PRP), respectively. In addition, we evaluated the platelet phospholipid contribution to thrombin generation (TG) by addition of Annexin V in both resting and ADP induced conditions.

Results: The results show that ET and PV patients presented with significantly higher ADP induced whole blood platelet aggregation and TG compared to controls. The highest values were observed in JAK2V617F positive patients and in patients on aspirin. JAK2 $6617 \mathrm{~F}$ positive patients on aspirin also showed significantly less inhibited TG compared to control subjects upon addition of Annexin $\mathrm{V}$ in both resting and ADP stimulated conditions.

Conclusions: For the first time we demonstrated that platelets from ET and PV patients are more reactive to ADP, in terms of both increased platelet aggregation in a whole blood system, and as an enhanced TG, particularly in JAK2V617F positive patients. These data support the hypothesis that the use of ADP receptor-inhibitors, in addition to aspirin, might be considered in the prevention of thrombosis in these conditions, by allowing a more complete inhibition of platelet functions. 


\section{Introduction}

Essential Thrombocythemia (ET) and Polycythemia Vera (PV) are myeloproliferative neoplasms (MPN) characterized by an increased rate of thrombotic complications, more pronounced in JAK2V617F positive patients [1]. The frequency of thrombosis (arterial, venous and microcirculatory) at the initial presentation vary from $11-25 \%$ in ET patients and from $12-39 \%$ in PV patients [2]. Numerous platelet abnormalities, both quantitative and qualitative, have been identified in ET and PV patients, however none of these findings have been clearly linked to thrombotic complications [3]. Studies on platelet expression of procoagulant and adhesive molecules revealed that platelets circulate in an activated status in ET and PV patients [4-5]. In general, the activation of platelets results in exposure of phosphatidylserine (PS) on their surface that strongly propagates the coagulation process by assembly of tenase and prothrombinase complexes [6]. In addition, activated platelets express increased tissue factor $(\mathrm{TF})$, the major initiator of the coagulation process, on their surface [7].

The use of aspirin for prevention of thromboembolic complications is widely recommended and utilised in both ET and PV patients, either at low or at high risk for thrombosis [8-10]. In the randomized controlled trial including 518 PV patients, low dose aspirin was associated with reduced risk of the combined end point of nonfatal myocardial infarction, nonfatal stroke, or death from cardiovascular causes [9]. Despite the lack of data from randomized controlled trials in ET patients, aspirin use has been shown effective in alleviating vasomotor (microvascular) disturbances in these patients [11]. However, a recent study in ET patients has demonstrated that low-dose aspirin given in the recommended dosing interval once daily is unable to fully inhibit thromboxane production [12]. Furthermore, platelet adhesion and aggregation in vivo is influenced by a number of different agonists that act on pathways that are not all blocked by thromboxane inhibition.

In this study we applied whole blood aggregometry, determined by Multiplate analysis, to assess overall platelet aggregability induced by several different agonists in both ET and PV patients, as compared with healthy controls. In addition, the procoagulant effect of platelets activated by adenosine diphosphate (ADP), was evaluated using the Calibrated Automated Thrombogram (CAT) assay. ADP is a strong platelet agonist that acts on two platelet receptors, P2Y1 and P2Y12. Binding of ADP to the P2Y12 receptor results in dense granule release, platelet aggregation and thrombus growth and stabilization [13]. In addition, ADP enhances alpha granule release, facilitating TF and P-selectin translocation to the platelet surface [14]. While the platelet's phospholipid contribution to thrombin generation (TG) in healthy subjects is well recognised, the potential platelet phospholipid contribution to TG in patients at risk of thrombosis, including MPN patients, is unknown. To address this question, we used, for the first time, the CAT assay to evaluate the contribution of platelets to TG in 
both resting and ADP induced conditions. All the results were analysed according to patients' presence of JAK2V617F mutation and treatment regimen.

\section{Subjects and methods}

\section{Subjects}

This study has been conducted in blood samples obtained from 76 healthy subjects, as compared to 65 consecutive ET and 51 PV patients. The healthy subjects were hospital employees while the patients were recruited from the Bergamo hospital between June 2008 and June 2009. The local Ethics committee (Comitato di Bioetica, Ospedali Riuniti, Bergamo, Italy) approved the study and all blood samples were obtained after informed consent. ET and PV patients were diagnosed according to the WHO criteria [15] and the procedures followed were in accordance with the Helsinki declaration of 1975 as revised in 2000. None of the patients were taking anticoagulant and hormone replacement therapy. None of the controls were taking antiplatelet or antiinflammatory agents in the past 10 days prior the blood drawing.

\section{Collection of blood samples}

Blood samples were drawn early in the morning after applying a light tourniquet. After discarding the first $3 \mathrm{ml}$, the blood was collected into sterile siliconized tubes containing K3-ethylenediamine tetraacetic acid (K3-EDTA) for molecular biology studies and blood cell count analysis or trisodium citrate (0,129M, 1:9 vol:vol) for coagulation studies.

\section{Platelet Rich Plasma (PRP) preparation}

Within 30 minutes from the blood draw, PRP was separated by centrifugation of whole blood for $10 \mathrm{~min}$ at $280 \mathrm{~g}$ at room temperature (RT). The rest of the blood sample was centrifuged at $3500 \mathrm{~g}$ for 20 min to obtain platelet poor plasma, which was utilized to dilute PRP at a fixed concentration of 150,000 platelets $/ \mu$ l.

\section{Routine haematological assays}

Whole blood analysis of white blood cell differential count, hematocrit, platelet count and mean platelet volume were determined by a Sysmex-XE 2100 haematology analyzer (Sysmex Co., Kobe, Japan).

\section{Whole blood aggregometry}

Whole blood aggregation was performed in a subgroup of subjects, 19 controls and 26 patients (15 ET and 11 PV patients), using a new generation impedance 
aggregometer "Multiplate" (Dynabyte, Munich, Germany) according to the manufacturer instructions. The assay is based on platelet adhesion upon activation resulting in aggregation onto the metal sensor wires present in the test tube, thus increasing the electrical impedance between the wires. Platelet aggregation was initiated using collagen $(100 \mu \mathrm{g} / \mathrm{ml})$, ADP $(0.2 \mathrm{mM})$, thrombin receptor activating peptide (TRAP, $1 \mathrm{mM}$ ) and arachidonic acid (ASPI test, $15 \mathrm{mM}$ ) provided by the manufacturer (Dynabyte, Munich, Germany). In the test cell, whole citrated blood $(300 \mu \mathrm{L})$ was diluted in 1:2 vol/vol with 0.025 $\mathrm{mmol} / \mathrm{L} \mathrm{CaCl} 2$ in saline solution for collagen, ADP and TRAP test and with $0.9 \%$ saline solution for ASPI test, all maintained at $37^{\circ} \mathrm{C}$ for 3 minutes. At the end of the incubation time, agonists were added and the increased impedance due to attachment of platelets to the electrodes was continuously measured over a period of 6 minutes. Aggregation measured was reported as area under the aggregation curve, AUC, expressed in $\mathrm{AU}^{*}$ min.

\section{CAT assay}

TG was continuously measured in freshly isolated PRP using the CAT assay. Briefly, $20 \mu \mathrm{l}$ of Hepes buffer were added into TG wells while $20 \mu \mathrm{l}$ of calibrator (with activity of $600 \mathrm{nM}$ alpha2M-thrombin complex) into thrombin calibrator (TC) well. Eighty $\mu$ l of PRP were added to both wells (TG and TC well). After 10 min prewarming at $37^{\circ} \mathrm{C}$ inside the fluorimeter (Fluoroscan Acsent, Thermo Labsystems, Helsinki, Finland), the reaction was started by the addition of $20 \mu \mathrm{l}$ of $\mathrm{CaCl} 2$ / fluorogenic substrate (Z-Gly-Gly-Arg-AMC; Bachem, Bubendorf, Switzerland) mixture. The TG was studied in 3 different conditions, i.e. in presence of ADP, recombinant human Annexin V (rh Annexin V) and in presence of both ADP and rh Annexin V. For the ADP induced TG, the PRP was preincubated for 10 min inside the fluorimeter with low $(1.6 \mu \mathrm{M})$ and high $(8.3 \mu \mathrm{M})$ concentration of ADP. Furthermore, in a subgroup of subjects (34 controls, 33 ET and 29 PV patients), the isolated PRP was preincubated with rh Annexin V (PS binding protein) for $10 \mathrm{~min}$ while shaking inside the fluorimeter, whereas for the TG induced by both ADP and Annexin V, the isolated PRP was preincubated with Annexin $\mathrm{V}$ and high $(8.3 \mu \mathrm{M})$ concentration ADP. ADP $(1 \mathrm{mM})$ was purchased by Mascia Brunelli (Milan, Italy) and rh Annexin V $(30 \mu \mathrm{g})$ was purchased by Bender MedSystems (Vienna, Austria). The TG curves were calculated using Thrombinoscope software (Thrombinoscope, Maastricht, The Netherlands) by comparing the signals from the TG well and the TC well. TG curves were described in terms of peak height (maximum concentration of thrombin formed).

\section{JAK2V617F mutation analysis}

The presence of the somatic V617F mutation of the Janus 2 tyrosine kinase (JAK2) gene was tested on DNA obtained from K3-EDTA anticoagulated blood samples using the Puregene DNA isolation kit (Gentra systems, Minneapolis MN, USA). Polymerase chain reaction was performed as described previously [7]. 


\section{Statistical analysis}

Data were compared between groups using the Student t test or the nonparametric Mann-Whitney-Wilcoxon U test, according to the distribution of the test variables. The multiple intergroup comparisons were performed using the nonparametric Dunn's multiple comparison test. All statistical analyses were done with GraphPad Prism 5 (La Jolla, CA, USA).

\section{Results}

\section{Basic haematological characteristics}

Table 1 shows the study population clinical and hematological characteristics. ET and PV patients had significantly higher total platelet, leukocyte and neutrophil counts compared to controls. In addition, PV patients had significantly higher neutrophil counts compared to ET patients. Among ET patients, 38 (58\%) were JAK2V617F positive with $<50 \%$ allele burden while the rest were JAK2 negative. Differently, 48 (94\%) PV patients were positive for JAKV617F mutation of which $41(85 \%)$ had $<50 \%$ allele burden and $7(15 \%)$ had $>50 \%$ allele burden for the JAKV617F mutation. Three PV patients negative for JAK2V617F mutation were positive of JAK2 exon 12 mutation.

Table 1. Study subject characteristics. Data are reported as number or mean (range); ${ }^{*}<0.05$ vs controls; ${ }^{* *} \mathrm{p}<0.01$ vs ET.

\begin{tabular}{lccc}
\hline & CONTROLS & ET & PV \\
\hline Number & 76 & 65 & 51 \\
Males/Females & $35 / 41$ & $24 / 41$ & $31 / 20$ \\
Age (years) & $55(28-75)$ & $58(23-81)$ & $62(20-84)$ \\
Platelets (10 $/$ L) & $243(151-419)$ & $570^{*}(208-1451)$ & $484^{*}(168-1278)$ \\
Leukocytes (10 $/$ L) & $6.3(3.7-11.3)$ & $7.4^{*}(3.1-16.3)$ & $8.8^{*}(3.1-39.9)$ \\
Neutrophils (10 $/ \mathbf{L})$ & $3.5(1.4-7.7)$ & $4.7^{*}(1.6-11.1)$ & $6.4^{* * * *}(2-36.4)$ \\
Hematocrit (\%) & $42(35.2-45)$ & $41(35-49)$ & $44(34-49)$ \\
History of thrombosis (\%) & $/$ & $11(17 \%)$ & $11(22 \%)$ \\
JAK2V617F (\%) & $/$ & $38(58 \%)$ & $48(94 \%)$ \\
\hline
\end{tabular}


At enrolment into the study, $56 \mathrm{MPN}$ (27 ET and $29 \mathrm{PV}$ ) patients were receiving cytoreductive treatment with HU. Twenty seven ET and 21 PV patients received aspirin (ASA) alone. Eleven ET and 1 PV patient were not taking any cytoreductive and/or antiplatelet therapy.

Twenty two patients (11 ET and $11 \mathrm{PV}$ ) had a positive history for at least one major thrombotic event.

\section{Platelet aggregation in whole blood by the Multiplate analyser}

Both ET and PV patients showed significantly higher $(\mathrm{p}<0.05)$ ADP (ET: 800 \pm 240 ; PV: 824 $\pm 223 \mathrm{AU}^{*} \mathrm{~min}$ ) and TRAP (ET: 1102 \pm 199 ; PV: $1153 \pm 150 \mathrm{AU}^{*} \mathrm{~min}$ ) induced aggregation compared to control subjects (ADP: 558 \pm 235 ; TRAP: $967 \pm 165 \mathrm{AU}^{*} \mathrm{~min}$ ). No significant differences were observed for collagen and ASPI induced whole blood aggregation between the control subjects and MPN patients. The analysis according to JAK2V617F mutation demonstrated that compared to controls, JAK2V617F positive patients showed significantly higher ADP $\left(817 \pm 119\right.$ AU*min $\left.^{*}\right)$ and TRAP $\left(1104 \pm 194 \mathrm{AU}^{*} \mathrm{~min}\right)$ induced aggregation, while JAK2 negative subjects showed no significant differences (ADP: $725 \pm 265$; TRAP: $1077 \pm 165 \mathrm{AU}^{*} \mathrm{~min}$ ). No significant differences were observed between JAK2V617F positive and negative subjects. Figure 1 shows the results of whole blood platelet aggregation in MPN patients according to treatment regimen. Non treated subjects showed the highest platelet aggregating potential in all four agonists induced conditions (Figure 1), however the statistical analysis was limited by the small sample size $(n=3)$. Compared to controls, ASA treated patients $(n=12)$ showed significantly higher $(\mathrm{p}<0.005)$ aggregation induced by ADP (Figure 1A) and TRAP (Figure 1B). Compared to HU treated patients $(n=11)$, ASA treated patients showed significantly higher aggregation induced by TRAP only (Figure 1B). Platelet aggregation induced by collagen (Figure 1C) and ASPI (Figure 1D) showed no significant differences between ASA treated patients and control subjects. Differently, HU treated patients showed significantly reduced aggregation when induced by collagen compared to control subjects (Figure 1C).

\section{TG of PRP triggered by ADP}

PRP from both ET and PV patients generated significantly $(\mathrm{p}<0.05)$ higher peak levels in basal (hepes buffer; ET: $130 \pm 30$, PV: $140 \pm 54 \mathrm{nM}$ thrombin), as well as after low (1.6 $\mu \mathrm{M}$; ET: $138 \pm 32, \mathrm{PV}: 149 \pm 53 \mathrm{nM}$ thrombin) and high $(8.3 \mu \mathrm{M}$; ET: $159 \pm 36$, PV: $174 \pm 60 \mathrm{nM}$ thrombin) ADP stimulated conditions compared to control subjects (basal: $110 \pm 28$, low ADP: $114 \pm 23$, high ADP: $135 \pm 30 \mathrm{nM}$ thrombin). 
Figure 1. Platelet aggregation in whole blood by the Multiplate analyser. ${ }^{*} \mathrm{p}<0.005$ vs CTR; **p<0.05 vs CTR; \&p<0.05 vs HU+ASA ;NT=non treated; ASA=Aspirin; HU=hydroxyurea;

A.

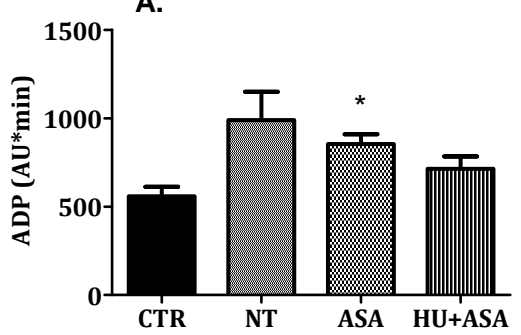

C.

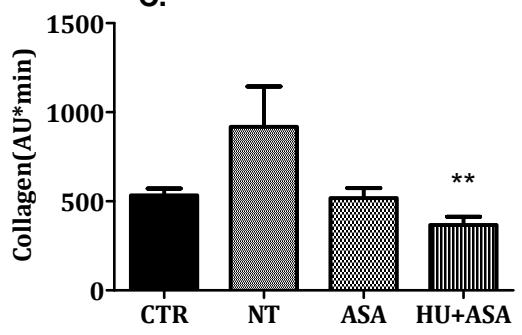

B.

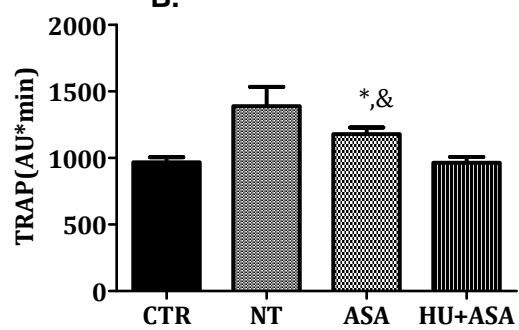

D.

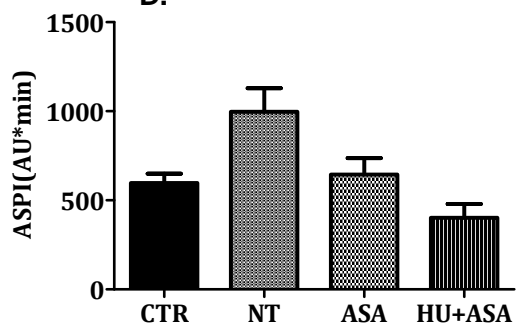

Figure 2. TG of PRP induced by low and high concentration ADP. ${ }^{*} \mathrm{p}<0.05$ vs CTR; NT=non treated, ASA=Aspirin, HU=hydroxyurea, neg.=JAK2 negative; pos.=JAK2V617F positive.

\section{A. Low ADP induced TG}

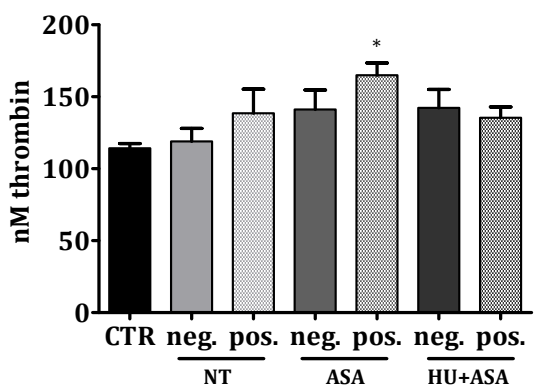

B. High ADP induced TG

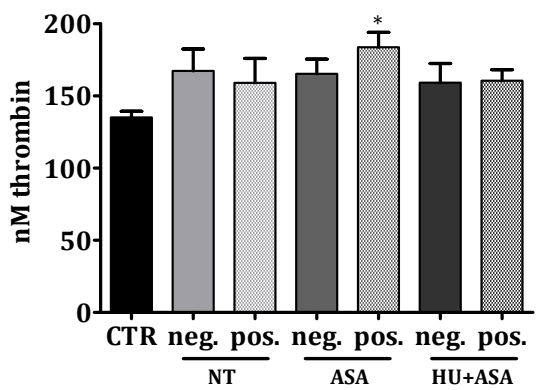

JAK2V617F positive patients showed a significant increase of basal TG from $139 \pm 44 \mathrm{nM}$ thrombin to $146 \pm 45 \mathrm{nM}$ and $171 \pm 52 \mathrm{nM}$ thrombin after low or high ADP stimulation, respectively ( $\mathrm{p}<0.0001$ for all). In contrast, JAK2 negative subjects, showed significantly different TG at the high (164 $\pm 35 \mathrm{nM}$ thrombin), but not at the low ADP induced condition $(139 \pm 35 \mathrm{nM}$ thrombin), as compared to the basal condition $(133 \pm 32 \mathrm{nM}$ thrombin). Figure 2 shows the TG induced by low and high ADP in patients according to both JAK2V617F mutational status and treatment regimen. The multigroup comparison analysis showed that ASA treated JAK2V617F positive patients generated the highest TG peak when sti- 
mulated by low (Figure 2A) and high ADP (Figure 2B), which were significantly different $(\mathrm{p}<0.01)$ from control subjects.

\section{Effect of Annexin V on TG in basal and in ADP induced conditions}

To investigate the participation of anionic phospholipids on activated platelets in TG process, we have preincubated the isolated PRP with the PS binding protein, rh Annexin V. As shown in Figure 3, preliminary experiments were performed in PRP from five control subjects with increasing concentration of Annexin $\mathrm{V}$ (i.e. $0.25 \mathrm{ng} / \mathrm{ml}, 1.25 \mathrm{ng} / \mathrm{ml}$ and $2.5 \mathrm{ng} / \mathrm{ml}$ ). The results showed that already at a low concentration of Annexin V $(0.25 \mathrm{ng} / \mathrm{ml}) \mathrm{TG}$ resulted in lagtime delay to $30 \mathrm{~min}$, and in reduced TG peak. Complete inhibition of TG was observed at $1.25 \mathrm{ng} / \mathrm{ml}$ of Annexin $\mathrm{V}$, and further increasing the concentration did not result in any additional change. The concentration of $1.25 \mathrm{ng} / \mathrm{ml}$ Annexin $\mathrm{V}$ was used for the further analysis in both ET and PV patients and control subjects.

As presented in Figure 4A, in the presence of Annexin V, PV patients $(n=29)$ showed significantly $(\mathrm{p}<0.05)$ higher TG $(18 \pm 23 \mathrm{nM}$ thrombin) compared to control subjects $(n=34 ; 5 \pm 11 \mathrm{nM}$ thrombin), while no significant difference was observed for ET patients ( $\mathrm{n}=33 ; 6 \pm 10 \mathrm{nM}$ thrombin). The analysis according to JAK2V617F mutation showed that both ET and PV mutation positive patients $(n=48)$ generated significantly more thrombin compared to control subjects (Figure 4B). In addition, JAK2V617F positive patients showed higher TG values compared to JAK2 negative subjects $(n=14)$, however without reaching statistical significance $(\mathrm{p}=0.18)$. The further analysis according to both JAK2V617F mutation and therapy, showed that JAK2V617F positive patients on ASA had the highest TG, significantly different from control subjects (Figure 4C).

When the CAT assay was measured in PRP stimulated by the high concentration of ADP and in the presence of $1.25 \mathrm{ng} / \mathrm{ml}$ Annexin V, the TG in controls, ET and PV patients were restored on average with $45 \%, 47 \%$ and $59 \%$, respectively (not significantly different in ET and PV patients compared to control subjects) compared to TG in the presence of $1.25 \mathrm{ng} / \mathrm{ml}$ Annexin $\mathrm{V}$ only. The analysis based on JAK2V617F mutation and therapy showed that JAK2V617F positive patients on ASA had less inhibited TG by Annexin V in presence of high ADP concentration, significantly higher compared to control subjects (Figure 5). 
Figure 3. TG of PRP from control subjects in presence of increasing concentrations of Annexin $\mathrm{V}$.

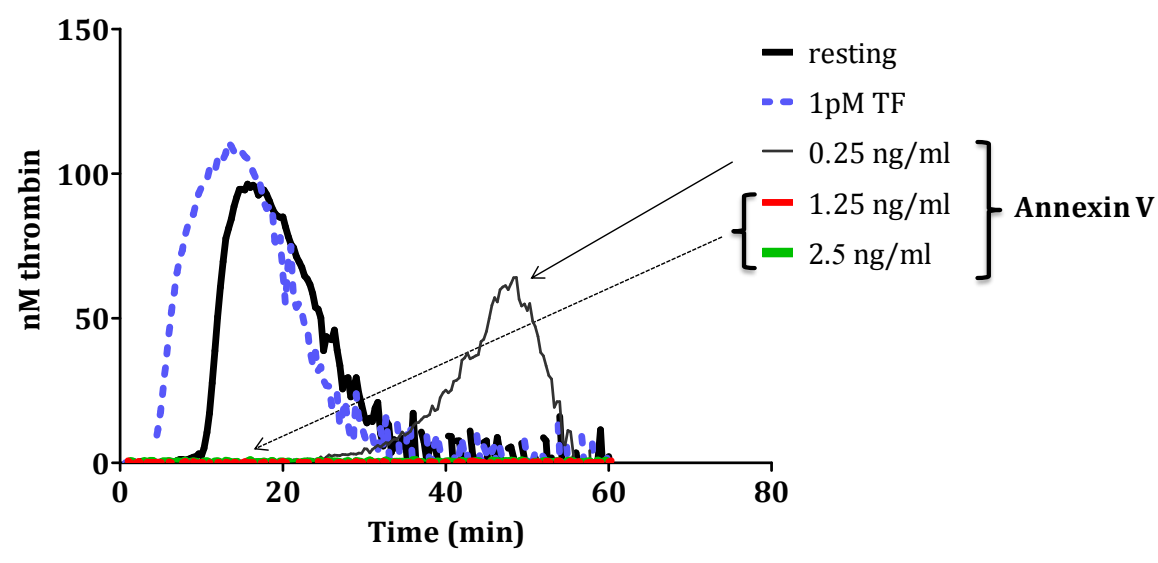

Figure 4. TG of PRP according to disease, JAK2V617F status and therapy
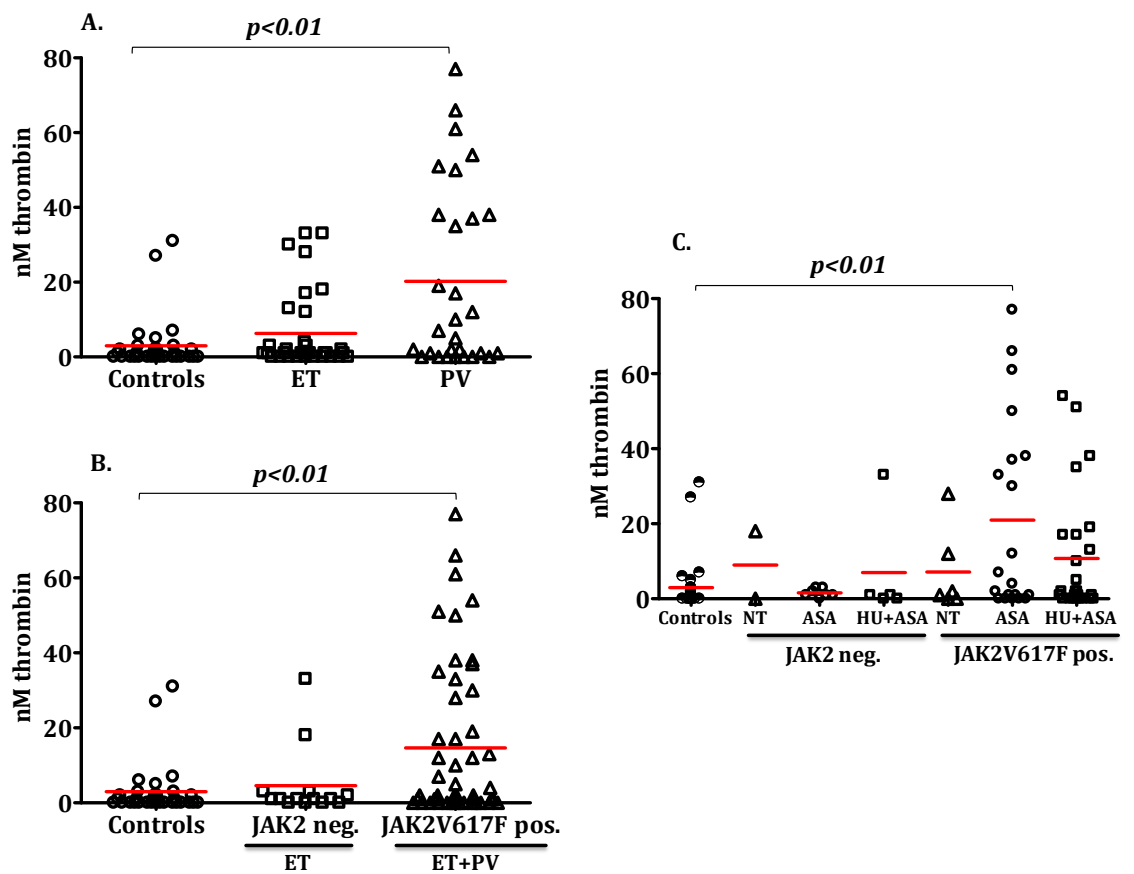
Figure 5. Effect of Annexin V on TG in ADP-stimulated condition

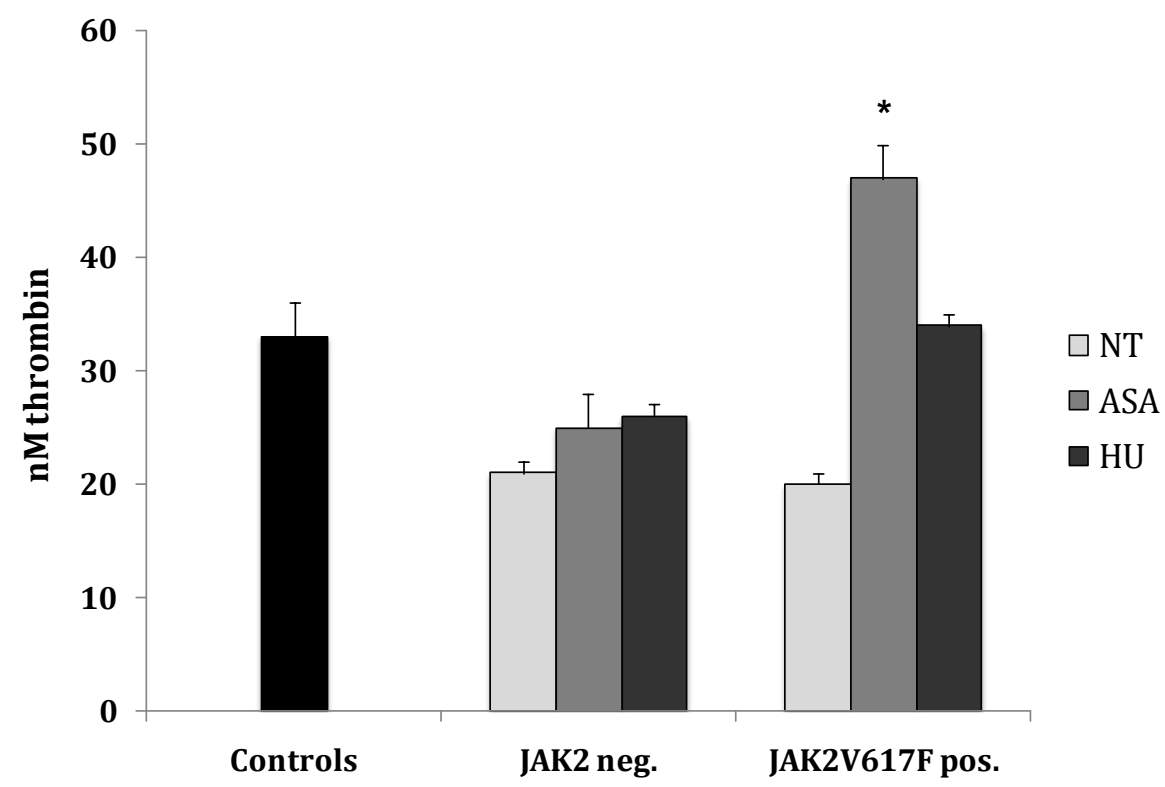

\section{Discussion}

Recent studies indicate that platelets in MPN patients circulate in an activated state, particularly in JAK2V617F positive patients $[4-5,16]$. In this study we have evaluated in a group of ET and PV patients, the platelet reactivity to different agonists in terms of proaggregating potential by using the multiple electrode platelet aggregometry and the platelet reactivity to ADP in terms of procoagulant responses by using the CAT assay. We demonstrated for the first time that platelets from ET and PV patients are more reactive to ADP, not only in terms of increased platelet aggregation in a whole blood system, but also enhanced thrombin generation, particularly in those positive for the JAK2V617F mutation. We also observed evidence of ASA failure, chronically administered to MPN patients, to fully inhibit platelet reactivity as shown by increased ADP and TRAP induced platelet aggregation, as well as ADP induced TG. Finally, we demonstrated a powerful inhibitory effect of Annexin $\mathrm{V}$ on platelet associated TG suggesting the critical participation of PS on activated platelet surface in thrombin formation process.

In vivo, the most important platelet aggregating agents are collagen in the vessel wall, ADP from the red blood cells or released from the activated platelets, thromboxane A2 from stimulated platelets and thrombin. The synergistic effect of different platelet agonists on the increased platelet reactivity and therefore 
inability of ASA alone to adequately reduce the risk of thrombosis in high risk for thrombosis has been observed in many studies. Combined treatment with ASA and ADP receptor inhibitors (i.e. clopidogrel, prasugrel and ticagrelor) has now been established in patients with coronary artery disease [17-19]. Whether this combined antiplatelet therapy would also be more effective and sufficiently safe in other patient populations, such as with MPN, is however uncertain [20].

Platelet function inhibitors are widely utilized for thromboprophylaxis in ET and PV patients [10]. An increased reactivity of platelets to ADP from these patients, despite taking ASA, has previously been shown by light transmission platelet aggregometry studies, which might explain the failure of ASA to fully protect these patients from thrombosis, mainly those at high risk [21]. While the ADP activation pathway is critical for platelet aggregation, less is known about its role to the initiation of blood coagulation by platelets.

The results of platelet aggregometry analysis showed significantly higher ADP and TRAP induced platelet aggregation for both ET and PV patients compared to control subjects. The highest ADP and TRAP induced platelet aggregating potential was observed in JAK2V617F positive patients. Interestingly, ASA treated patients even showed significantly higher ADP and TRAP induced aggregation compared to control subjects suggesting persistent platelet reactivity while on ASA. A study limitation is that we were unable to compare patients before and after ASA exposure, such that the degree of absolute lack of inhibition by ASA cannot be assessed.

The initial effect of platelets on the thrombin generating process can be readily assessed by the CAT assay performed in PRP. We have recently shown that MPN patients have an increased platelet-associated TG potential compared to controls [22]. The results of the TG assay in the present study also showed that platelets from both ET and PV patients are more responsive to ADP compared to control subjects' platelets. In particular, platelets from JAK2V617F positive patients when stimulated by high-ADP generated the highest peak compared to both basal and low-ADP induced TG. The analysis according to both JAK2V617F mutation and therapy showed that ASA treated mutation positive patients have the highest thrombin generating potential, significantly different from controls subjects.

ADP influences platelet activation mediated by the three ADP receptors P2X1, P2Y1 and P2Y12 which are responsible for rapid calcium entry, rapid calcium mobilization by phospholipase $C ß$ activation and inhibition of adenylyl cyclase activity essential for full platelet aggregation, respectively [23-24]. In-vitro studies have demonstrated that ADP receptors are also implicated in the exposure of platelet stored TF and P-selectin. In particular, the inhibition of P2Y12 receptor resulted in 33\% decreased TF-dependent factor Xa activity in healthy subjects receiving clopidogrel [14]. The findings of our and other groups have demonstrated an increased platelet surface TF and P-selectin expression par- 
ticularly in ET and PV JAK2V617F positive patients [7, 25]. Our study found an increased platelet reactivity to ADP as observed by higher platelet aggregating and procoagulant potential particularly in subjects positive for JAK2V617F mutation. Further studies are needed to investigate the particular prothrombotic mechanisms of ADP stimulation and the possible implication and contribution of the consequently increased TF expression on platelet surface on hypercoagulability in MPN patients.

The externalization of anionic phospholipids on platelet surface, particularly PS, is a crucial determinant of platelet-associated TG. Indeed, in control subjects we observed complete inhibition of TG when Annexin-V protein was added in the system. However, PRP from PV patients, despite the large reduction of TG in the presence of Annexin V, still generated significantly higher thrombin compared to control subjects. Further analysis showed that the highest TG is determined by the presence of JAK2V617F mutation. Indeed, both ET and PV JAK2V617F positive patients showed significantly higher TG compared to control subjects. Compared to controls, only ASA treated subjects showed significantly higher TG in presence of Annexin V. The increased TG in MPN patients, particularly in JAK2V617F positive patients, in the presence of Annexin V, suggests an increased PS expression in these patients compared to controls and JAK2 negative subjects, as previously published.[26] However, other or additional mechanisms have been proposed, including Annexin V inhibited TF deencryptation process, inhibition of tenase and prothrombinase and interference with the action of factor VIIa-TF complex on blood coagulation [27-29].

In conclusion, our results support the hypothesis that the use of ADP receptorinhibitors, in addition to ASA, might be of help in the prevention of thrombosis in these conditions, by allowing a more complete inhibition of platelet functions. In addition, our study suggests that negatively charged phospholipids exposed on activated platelets might be a specific target for the antithrombotic therapy in MPN patients at high risk for thrombosis. These targets may be a suitable subject for further clinical studies in patients with MPN. 


\section{References:}

1 Carobbio A, Finazzi G, Antonioli E, Guglielmelli P, Vannucchi AM, Dellacasa CM, Salmoiraghi S, Delaini F, Rambaldi A, Barbui T. JAK2V617F allele burden and thrombosis: a direct comparison in essential thrombocythemia and polycythemia vera. Experimental hematology. 2009; 37: 1016-21. S0301-472X(09)00219-7 [pii] 10.1016/j.exphem.2009.06.006.

2 Landolfi R, Rocca B, Patrono C. Bleeding and thrombosis in myeloproliferative disorders: mechanisms and treatment. Critical reviews in oncology/hematology. 1995; 20: 203-22.

3 Landolfi R, Di Gennaro L, Falanga A. Thrombosis in myeloproliferative disorders: pathogenetic facts and speculation. Leukemia. 2008; 22: 2020-8.

$4 \quad$ Falanga A, Marchetti M, Vignoli A, Balducci D, Barbui T. Leukocyte-platelet interaction in patients with essential thrombocythemia and polycythemia vera. Experimental hematology. 2005; 33: 523-30.

5 Arellano-Rodrigo E, Alvarez-Larran A, Reverter JC, Villamor N, Colomer D, Cervantes F. Increased platelet and leukocyte activation as contributing mechanisms for thrombosis in essential thrombocythemia and correlation with the JAK2 mutational status. Haematologica. 2006; 91: 16975.

6 Heemskerk JW, Bevers EM, Lindhout T. Platelet activation and blood coagulation. Thrombosis and haemostasis. 2002; 88: 186-93.

7 Falanga A, Marchetti M, Vignoli A, Balducci D, Russo L, Guerini V, Barbui T. V617F JAK-2 mutation in patients with essential thrombocythemia: relation to platelet, granulocyte, and plasma hemostatic and inflammatory molecules. Experimental hematology. 2007; 35: 702-11.

8 Harrison CN, Campbell PJ, Buck G, Wheatley K, East CL, Bareford D, Wilkins BS, van der Walt JD, Reilly JT, Grigg AP, Revell P, Woodcock BE, Green AR. Hydroxyurea compared with anagrelide in high-risk essential thrombocythemia. The New England journal of medicine. 2005; 353: 33-45. 353/1/33 [pii] 10.1056/NEJMoa043800.

9 Landolfi R, Marchioli R, Kutti J, Gisslinger H, Tognoni G, Patrono C, Barbui T. Efficacy and safety of low-dose aspirin in polycythemia vera. The New England journal of medicine. 2004; 350: 114-24. 10.1056/NEJMoa035572

350/2/114 [pii].

10 Tefferi A. Annual Clinical Updates in Hematological Malignancies: A Continuing Medical Education Series: Polycythemia vera and essential thrombocythemia: 2011 update on diagnosis, risk-stratification, and management. American journal of hematology. 2011; 86: 292-301. 10.1002/ajh.21946.

11 Michiels JJ, Berneman Z, Schroyens W, Koudstaal PJ, Lindemans J, Neumann HA, van Vliet HH. Platelet-mediated erythromelalgic, cerebral, ocular and coronary microvascular ischemic and thrombotic manifestations in patients with essential thrombocythemia and polycythemia vera: a distinct aspirin-responsive and coumadin-resistant arterial thrombophilia. Platelets. 2006; 17: 52844.

12 Dragani A, Pascale S, Recchiuti A, Mattoscio D, Lattanzio S, Petrucci G, Mucci L, Ferrante E, Habib A, Ranelletti FO, Ciabattoni G, Davi G, Patrono C, Rocca B. The contribution of cyclooxygenase1 and -2 to persistent thromboxane biosynthesis in aspirin-treated essential thrombocythemia: implications for antiplatelet therapy. Blood. 2010; 115: 1054-61. blood-2009-08-236679 [pii] 10.1182/blood-2009-08-236679.

13 Dorsam RT, Kunapuli SP. Central role of the P2Y12 receptor in platelet activation. The Journal of clinical investigation. 2004; 113: 340-5. 
14 Leon C, Alex M, Klocke A, Morgenstern E, Moosbauer C, Eckly A, Spannagl M, Gachet C, Engelmann B. Platelet ADP receptors contribute to the initiation of intravascular coagulation. Blood. 2004; 103: 594-600.

15 Tefferi A, Thiele J, Orazi A, Kvasnicka HM, Barbui T, Hanson CA, Barosi G, Verstovsek S, Birgegard G, Mesa R, Reilly JT, Gisslinger H, Vannucchi AM, Cervantes F, Finazzi G, Hoffman R, Gilliland DG, Bloomfield CD, Vardiman JW. Proposals and rationale for revision of the World Health Organization diagnostic criteria for polycythemia vera, essential thrombocythemia, and primary myelofibrosis: recommendations from an ad hoc international expert panel. Blood. 2007; 110: 1092-7.

16 Jensen MK, de Nully Brown P, Lund BV, Nielsen OJ, Hasselbalch HC. Increased platelet activation and abnormal membrane glycoprotein content and redistribution in myeloproliferative disorders. British journal of haematology. 2000; 110: 116-24.

17 Anderson JL, Adams CD, Antman EM, Bridges CR, Califf RM, Casey DE, Jr., Chavey WE, 2nd, Fesmire FM, Hochman JS, Levin TN, Lincoff AM, Peterson ED, Theroux P, Wenger NK, Wright RS. 2011 ACCF/AHA Focused Update Incorporated Into the ACC/AHA 2007 Guidelines for the Management of Patients With Unstable Angina/Non-ST-Elevation Myocardial Infarction: A Report of the American College of Cardiology Foundation/American Heart Association Task Force on Practice Guidelines. Circulation. 2011. CIR.0b013e318212bb8b [pii] 10.1161/CIR.0b013e318212bb8b.

18 Behan MW, Chew DP, Aylward PE. The role of antiplatelet therapy in the secondary prevention of coronary artery disease. Curr Opin Cardiol. 2010; 25: 321-8.

10.1097/HCO.0b013e328338f7b5.

19 Squizzato A, Keller T, Romualdi E, Middeldorp S. Clopidogrel plus aspirin versus aspirin alone for preventing cardiovascular disease. Cochrane database of systematic reviews (Online). 2011: CD005158. 10.1002/14651858.CD005158.pub3.

20 Hankey GJ, Johnston SC, Easton JD, Hacke W, Mas JL, Brennan D, Mak KH, Bhatt DL, Fox KA, Topol EJ. Effect of clopidogrel plus ASA vs. ASA early after TIA and ischaemic stroke: a substudy of the CHARISMA trial. Int J Stroke. 2011; 6: 3-9. 10.1111/j.1747-4949.2010.00535.x.

21 Nurden P, Bihour C, Smith M, Raymond JM, Nurden AT. Platelet activation and thrombosis: studies in a patient with essential thrombocythemia. American journal of hematology. 1996; 51 : 79-84. 10.1002/(SICI)1096-8652(199601)51:1<79::AID-AJH13>3.0.CO;2-6 [pii] 10.1002/(SICI)1096-8652(199601)51:1<79::AID-AJH13>3.0.CO;2-6.

22 Panova-Noeva M, Marchetti M, Spronk HM, Russo L, Diani E, Finazzi G, Salmoiraghi S, Rambaldi A, Barbui T, Ten Cate H, Falanga A. Platelet-induced thrombin generation by the calibrated automated thrombogram assay is increased in patients with essential thrombocythemia and polycythemia vera. American journal of hematology. 2011; 86: 337-42. 10.1002/ajh.21974.

23 Cattaneo M, Gachet C. The platelet ADP receptors. Haematologica. 2001; 86: 346-8.

24 Gachet C. ADP receptors of platelets and their inhibition. Thrombosis and haemostasis. 2001; 86: 222-32.

25 Arellano-Rodrigo E, Alvarez-Larran A, Reverter JC, Colomer D, Villamor N, Bellosillo B, Cervantes F. Platelet turnover, coagulation factors, and soluble markers of platelet and endothelial activation in essential thrombocythemia: relationship with thrombosis occurrence and JAK2 V617F allele burden. American journal of hematology. 2009; 84: 102-8.

26 Presseizen K, Friedman Z, Shapiro H, Radnay J, Ellis MH. Phosphatidylserine expression on the platelet membrane of patients with myeloproliferative disorders and its effect on plateletdependent thrombin formation. Clin Appl Thromb Hemost. 2002; 8: 33-9.

27 Thiagarajan P. New targets for antithrombotic drugs. Am J Cardiovasc Drugs. 2002; 2: 227-35. 020402 [pii].

28 Key NS, Bach RR. Tissue factor as a therapeutic target. Thrombosis and haemostasis. 2001; 85: 375-6. 01030375 [pii]. 
29 Lettino M, Toschi V. Direct antithrombins: new perspectives in cardiovascular medicine. Curr Med Chem Cardiovasc Hematol Agents. 2004; 2: 267-75. 


\section{CHAPTER 9}

Nitric oxide derivatives and soluble plasma selectins in patients with myeloproliferative neoplasms

Giuseppe Cella, Marina Marchetti, Fabrizio Vianello, Marina Panova-Noeva, Alfonso Vignoli, Laura Russo, Tiziano Barbui, and Anna Falanga

Thromb Haemost. 2010;104(1):151-6. Epub 2010 Apr 29. 


\section{Summarry}

Essential thrombocythaemia (ET) and polycythemia vera (PV) are characterized by a high incidence of thrombotic complications due to high shear stress of the vessel wall, blood hyperviscosity and hypoxaemia, all factors responsible for chronic endothelial dysfunction and platelet and leukocyte activation. We evaluated the activation status of vascular cells in 18 consecutive ET and 14 PV patients by measuring the plasma levels of the nitric oxide derivatives (NOx) (i.e. nitrites and nitrates) and of soluble selectins of platelet (P-selectin), endothelial cell (P-selectin and E-selectin) and leukocyte (L-selectin) origin. The effect of hydroxyurea (HU) therapy on these parameters was also investigated. NOx were significantly $(\mathrm{p}<0.01)$ increased in ET patients treated with HU $(11.5$ $\pm 2.6 \mathrm{nM}$ ) compared to non-HU treated ET $(1.41 \pm 0.3 \mathrm{nM})$ and to controls (4.78 $\pm 2.49 \mathrm{nM}$ ). Multivariate analysis confirmed HU therapy as an independent predictor of higher NOx levels in ET. In addition, NOx significantly correlated with haematocrit. Plasma P-selectin was significantly elevated in ET (350 \pm 40 ng/106 platelets) and PV (482 $\pm 53 \mathrm{ng} / 106$ platelets) patients compared to controls $(120 \pm 8 \mathrm{ng} / 106$ platelets $)$. In PV, also E-selectin $(23.8 \pm 4.2 \mathrm{ng} / \mathrm{ml})$ was significantly increased compared to controls $(11.2 \pm 1.1 \mathrm{ng} / \mathrm{ml} ; \mathrm{p}<0.01)$. Pselectin was significantly correlated to platelet $(\mathrm{R}=0.33 ; \mathrm{p}=0.01)$ and leukocyte count $(\mathrm{R}=0.6 ; \mathrm{p}=0.000)$, while E-selectin $(\mathrm{R}=0.34 ; \mathrm{p}=.014)$ and sL-selectin $(\mathrm{R}=0.3 ; \mathrm{p}=0.03)$ were correlated with leukocyte count only. In the multivariate analysis, NOx predicted increased levels of E-selectin in ET, but not in PV patients. Our data demonstrate that ET and PV are characterised by an altered pattern of soluble selectins and NOx. HU-mediated increase of NOx levels could represent an additional antithrombotic mechanism of this drug. 


\section{Introduction}

Essential Thrombocythemia (ET) and Polycythemia Vera (PV) are chronic myeloproliferative neoplasms (MPN) characterized by a high incidence of thrombohaemorrhagic complications and microvascular ischemic manifestations (i.e. erythromelalgia, paresthesias, acrocyanosis and dizziness) [1]. These two diseases present with high peripheral blood hyperviscosity due to an increased number of circulating leukocytes, platelets and erythrocytes. This favors cellcell interaction, leading to the formation of increased numbers of plateletleukocyte aggregates [2-3]. In addition, in these subjects, neutrophils circulate in an activated state and release high quantity of proteases (i.e. elastase and metalloproteases) in circulation which can induce a procoagulant phenotype of endothelial cells and platelets, thus contributing to a hypercoagulable state [4]. Furthermore, high-shear stress of the vessel wall in association with blood hyperviscosity and hypoxemia has been advocated as responsible for the occurrence of chronic endothelial dysfunction and platelet activation in ET and PV patients [5].

The endothelium plays a pivotal role in regulating blood flow. In part, this results from the capacity of quiescent endothelial cells to generate an active antithrombotic surface that facilitates the transit of plasma and cellular constituents throughout the vasculature [6]. Perturbations, such as those that may occur at sites of inflammation or high hydrodynamic shear stress, disrupt these activities and induce endothelial cells to create a prothrombotic microenvironment [7]. Blood flow is also regulated, in part, through secretion and uptake of vasoactive substances by the endothelium such as nitric oxide (NO) and endothelin [8].

Selectins constitute a family of adhesion molecules designated by the prefixes $\mathrm{E}$ (endothelial), P (platelet) and L (leukocyte). E- and P-selectin are expressed by endothelial cells, while P-selectin is expressed also by platelets. L-selectin is expressed by leukocytes only [9]. They are up-regulated in a variety of disease states, and, in some instances are released into the circulation where they can be detected in soluble form [10-12]. The plasma levels of the different selectins have been used as indexes of endothelial, platelet, and leukocyte activation. Raised soluble E-selectin levels have been found in patients with cancer, coronary-artery disease, hypertension and diabetes [13-14]. Similarly, raised levels of soluble P-selectin have been found in patients with cardiovascular diseases and diabetes mellitus [15-16].

It has been previously shown that patients with MPN present with endothelial dysfunction, a well-known risk factor for vascular disease [17-19]. This derangement may play a role in the thrombotic diathesis of patients with ET and PV $[3,7]$. However, the pathogenesis of endothelial dysfunction in ET and PV still remains incompletely defined. In this study we evaluated whether a pecu- 
liar pattern of NO metabolities (nitrites and nitrates, NOx) and circulating selectins may characterize subjects affected by ET and PV subjects.

\section{Materials and methods}

A total of 32 consecutive patients diagnosed with ET and PV attending the outpatients' clinic of the Hematology Department of the Ospedali Riuniti of Bergamo (Italy) entered the study. Of these, 18 subjects ( 6 males, 12 females; age range 23-74 years) were diagnosed with ET and 14 subjects ( 8 males and 6 females; age range 20-87 years) were diagnosed with PV. A group of 19 healthy subjects (11 females, 8 males; age range 26-81 years) acted as controls for the study. Both ET and PV patients were diagnosed according to the Polycythemia Vera Study Group criteria [20]. None of the patients were on anticoagulant therapy and none of the healthy controls were taking any medication at the time of enrolment. The study was approved by the local ethics committee (Comitato di Bioetica, Ospedali Riuniti di Bergamo, Italy). All blood samples were obtained with the subject's informed consent.

\section{Blood sample collection}

Venous blood was collected early in the morning (after at least 12-hour fasting), and before any drug administration, into sterile siliconized tubes containing trisodium citrate $(0.129 \mathrm{~mol} / \mathrm{l}, 1: 10 \mathrm{vol} / \mathrm{vol})$ or ethylenediaminetetraacetic acid (EDTA). Platelet-poor plasma was obtained by centrifugation of blood at 3,000 $\mathrm{x} g$ for $20 \mathrm{~min}$ at room temperature, snap-frozen in aliquots and stored at $-80^{\circ} \mathrm{C}$ until testing.

\section{Routine hematological assays}

White blood cell differential count (WBC), haematocrit, haemoglobin, red blood cell (RBC) and platelet counts were determined by automated method using a NE800 Analyzer (Dasit, Milan, Italy).

\section{Nitric oxide}

Plasma levels of NO were determined as a measure of nitrate (NO2) + nitrite (NO3) metabolites using a commercial ELISA kit (Cayman, Ann Arbor, MI, USA). Results are expressed as nM.

\section{Soluble selectins}

The plasma levels of E-, L, and P-selectin were measured using commercially available ELISA kits (R\&D Systems Inc., Minneapolis, MN, USA). The results are expressed in $\mathrm{ng} / \mathrm{ml}$, and for P-selectin also as $\mathrm{ng} / 10^{6}$ platelets. 


\section{CHAPTER IX}

\section{JAK2 V617F mutation analysis}

The presence of the somatic V617F mutation of the Janus 2 tyrosine kinase (JAK2) gene was tested on DNA obtained from K3-EDTA anticoagulated blood samples using the Puregene DNA isolation kit (Gentra systems, Minneapolis MN, USA). Polymerase chain reaction was performed as described previously [3].

\section{Statistical analysis}

All results are expressed as mean \pm standard error of the mean (SEM). Analysis of the differences was performed by Mann Whitney U test. Differences were considered significant at a p-value $<0.05$. Linear regression analysis was performed using the SPSS software 15 statistical package (SPSS, Chicago, IL, USA).

\section{Results}

\section{Study population characteristics}

The haematological characteristics of the subjects enrolled into the study are shown in Table 1. Platelet, leukocyte counts and haematocrit values were significantly increased $(\mathrm{p}<0.01)$ in both ET and PV patients compared to healthy controls. Additionally, ET patients had significantly increased $(\mathrm{p}<0.01)$ platelet count compared to PV patients, while PV patients had significantly higher $(\mathrm{p}<0.01)$ haematocrit value compared to ET patients. At the time of enrolment, nine ET patients (50\%) and five PV patients (35.7\%) were treated with hydroxyurea (HU). Three PV patients were on phlebotomy treatment. The JAK2 V617F mutation was detected in eight ET and $13 \mathrm{PV}$ patients. The occurrence of thrombosis was registered in 10 patients (4 ET and 6 PV). Particularly, five patients (2 ET and 3 PV) were diagnosed with cerebrovascular accidents, and five patients (2 ET and $3 \mathrm{PV}$ ) with deep vein thrombosis (DVT).

In the follow-up period between 2000 and 2009, two patients primarily diagnosed with ET transformed in PV, while new thrombotic events were diagnosed (4 cerebrovascular events and 5 DVT) in nine patients (4 ET and 5 PV). The univariate analysis showed that patients carriers of the JAK2V617F mutation had more vascular events $(n=21$, both prior diagnosis and in the follow-up period) compared to wild-type patients $(n=11, p=0.06)$. The multivariate analysis adjusted for age, sex, JAK2V617F mutational status, therapy and platelet count at baseline, showed that a thrombotic event at follow-up was significantly predicted by male sex $(B=-0.434, p=0.02)$, JAK2V617F $(B=0.508, p=0.016)$, and platelet count $(B=0.5, p=0.017)$. Additionally, the Chi-square test revealed that a high leukocyte count $\left(>10 \times 10^{9} / \mathrm{L}\right)$ at enrolment significantly predicted thrombosis in the follow-up period (Yates chi-square $=3.2$ ). 
Table 1. Characteristics of MPN patients and controls at enrolment into the study.

DVT: deep venous thrombosis; PE: pulmonary embolism; CVA: cerebrovascular accident. HU: Hydroxyurea ${ }^{*} p<0.01$ vs Controls; $\S p<0.01$ vs ET.

\begin{tabular}{|llll|}
\hline & Controls & ET & PV \\
\hline Male/female (n) & $8 / 11$ & $6 / 12$ & $8 / 6$ \\
\hline Age, years (range) & $57.7(26-81)$ & $51(23-74)$ & $66(20-87)$ \\
\hline $\begin{array}{l}\text { White blood cells } \\
\text { (x109/L) }\end{array}$ & $5.9(4-8.3)$ & $9.9(6.3-15.9)^{*}$ & $12.2(7.8-25.5)^{*}$ \\
\hline Platelets (x10 $/ \mathrm{L})$ & $248(124-432)$ & $785(333-1500)^{*}$ & $418(208-996)^{*}, \S$ \\
\hline Hemoglobin (g/L) & $136(12.5-15.8)$ & $146(12.1-20.1)$ & $182(15.7-22.3)^{*}, \S$ \\
\hline Hematocrit (\%) & $40(38-43)$ & $45(37-67)^{*}$ & $58(46-68)^{*, \S}$ \\
\hline JAK-V617F (\%) & - & $8(44)$ & $13(93)$ \\
\hline N. of patients on HU & - & 9 & 5 \\
\hline $\begin{array}{l}\text { Thromboembolic } \\
\text { events }\end{array}$ & - & 4 & 6 \\
\hline PE/DVT & & 2 & 3 \\
\hline CVA & & 3 & 3 \\
\hline
\end{tabular}

\section{Plasma levels of NOx}

We measured nitrites and nitrates plasma levels as a surrogate of NO. As shown in Figure 1 (left panel), NOx plasma levels were significantly higher in PV patients $(8.35 \pm 1.48 \mathrm{nM})$ compared to control subjects $(4.33 \pm 0.52 \mathrm{nM} ; \mathrm{p}<0.01)$. Additionally, PV patients had higher NOx values compared to ET patients but without reaching a statistical significance. No significant differences were observed between ET patients and controls.

MPN patients receiving HU had significantly increased plasma concentration of NOx $(10.6 \pm 1.9 \mathrm{nM}, \mathrm{p}<0.05)$ compared to non-HU treated patients $(4.7 \pm 1.2 \mathrm{nM})$. The analysis according to disease subgroup (i.e. ET or PV) showed that ET patients on HU had significantly higher $(\mathrm{p}<0.01)$ levels of NOx $(11.5 \pm 2.6 \mathrm{nM})$ compared to non-HU treated ET patients (1.41 $\pm 0.3 \mathrm{nM}$ ) (Figure 1, right panel). Differently, NOx levels were similar among HU-treated and non-HU treated PV patients (Fig.1, right panel). After adjusting for age, sex, JAK2 V617F muta- 
tional status and therapy, HU treatment significantly predicts an increased level of plasma NOx in ET $(B=0.57, p<0.01)$, but not in PV patients.

The correlation analysis showed that in all subjects, plasma NOx were directly correlated with haematocrit value $(R=0.45, p=0.001)$. However, the analysis performed according to the disease type, showed that NOx remained significantly correlated with the haematocrit value in ET patients only $(R=0.8$, $\mathrm{p}<0.001$ ).

Figure 1: Plasma levels of NOx. Histograms represent the average plasma levels of NOx in controls, ET and PV patients (left panel), and of NOx levels in ET and PV according to HU therapy (right panel). ${ }^{*}=$ p $<0.05$ vs. $C ;{ }^{* *}=p<0.05$.
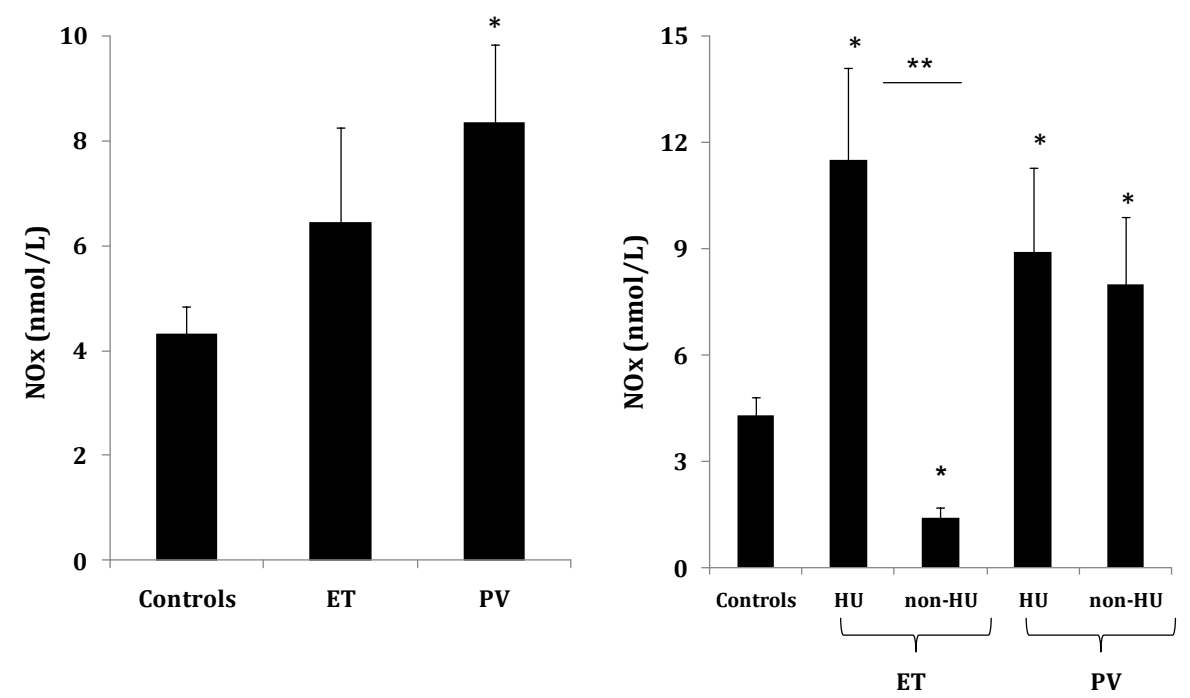

\section{Plasma soluble selectins}

Soluble E-selectin (17.8 $\pm 2.3 \mathrm{ng} / \mathrm{ml})$ and P-selectin (408 $\pm 33.8 \mathrm{ng} / 10^{6}$ platelets) were significantly increased in MPN patients compared to controls (Eselectin: $11.2 \pm 1.1 \mathrm{ng} / \mathrm{ml}$; p<0.05, P-selectin: $120.2 \pm 8 \mathrm{ng} / 10^{6}$ platelets; $\mathrm{p}<0.01$ ). Soluble L-selectin levels were not significantly different in patients compared to controls.

As shown at Figure 2, ET patients had increased levels of E-, P- and L-selectin compared to controls reaching the statistical significance for P-selectin only (ET: $351 \pm 41 ; \mathrm{p}<0.01$ vs controls). PV patients had significantly increased values of E-selectin $(23.8 \pm 4.2 \mathrm{p}<0.001)$ and P-selectin $(481.5 \pm 53 \mathrm{ng} / \mathrm{ml}$; $\mathrm{p}<0.001)$ compared to controls and to ET patients $(\mathrm{p}<0.05$ for both); whereas L-selectin was slightly increased but not statistically different. HU treatment did 
not affect E-, P- and L-selectin plasma concentrations in either ET or PV patients.

Figure 2: Plasma levels of selectins. Histograms show the average levels of E-selectin, P-selectin and L-selectin in controls (C), ET and PV patients. ${ }^{*}=p<0.05$ vs. C; $\S=p<0.05$ vs. ET.
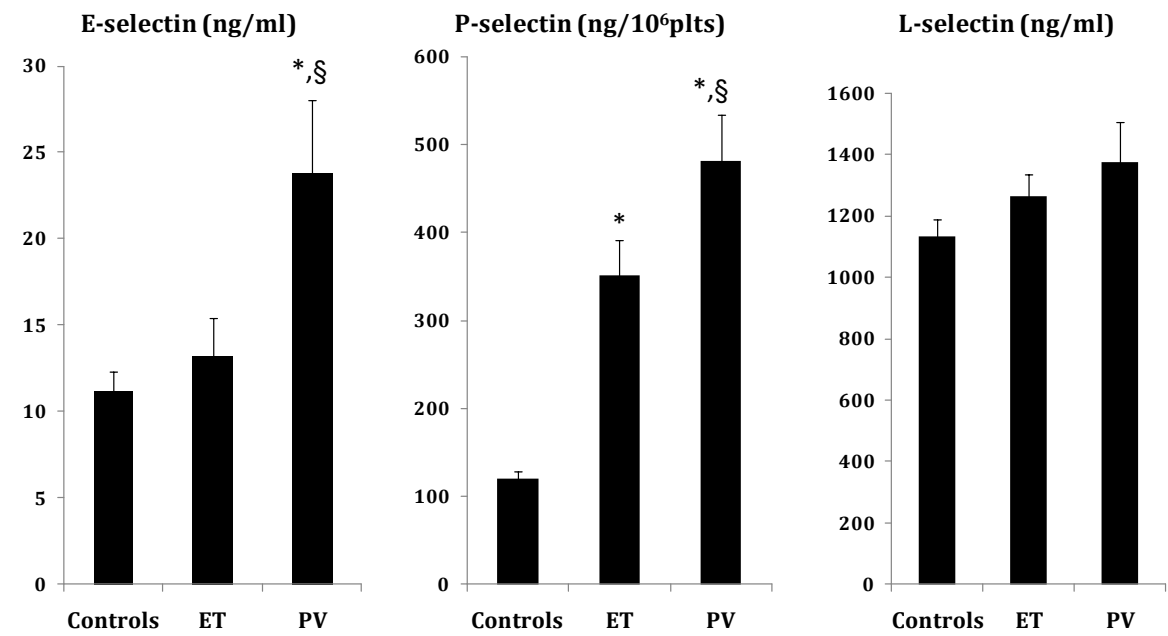

P-selectin was directly correlated to either platelet $(\mathrm{R}=0.33 ; \mathrm{p}=0.01)$ and leukocyte counts $(\mathrm{R}=0.6 ; \mathrm{p}=0.001)$, while E-selectin $(\mathrm{R}=0.34 ; \mathrm{p}=.014)$ and L-selectin $(\mathrm{R}=0.3 ; \mathrm{p}=0.03)$ with leukocyte count only. In addition, in ET patients, E-selectin was significantly and directly correlated to NOx levels $(R=0.5, p<0.01)$. As shown in Table 2, after adjusting for age, sex, JAK2V617F status and therapy, NOx levels significantly predicted an increased E-selectin levels in ET patients $(\mathrm{B}=1.072 . \mathrm{p}=0.012)$.

Table 2: Multiple regression analysis in MPN patients. The plasma levels of E-selectin (dependent variable) were adjusted for age, sex, JAK2V617F status, therapy (HU) and plasma NOx levels.

\begin{tabular}{|l|c|c|}
\hline Variable & $\begin{array}{c}\text { regression } \\
\text { coefficient } \boldsymbol{B}\end{array}$ & $\mathbf{p}=$ \\
\hline Age & -0.002 & 0.995 \\
\hline JAK2 & -0.167 & 0.428 \\
\hline Therapy & 0.234 & 0.361 \\
\hline NO & -0.547 & 0.085 \\
\hline
\end{tabular}




\section{CHAPTER IX}

As HU treatment may directly affect NO generation, patients on HU therapy were stratified according to the weekly dosage $(<5 \mathrm{~g}$ or $>5 \mathrm{~g})$ of the antimetabolite. As shown in Table 3, MPN patients on higher dosage of HU (i.e. $>5 \mathrm{~g}$ /week) showed higher NOx plasma levels but this difference was not statistically significant. At the same time, higher dosage of HU did not significantly affect selectin plasma levels.

Table 3: Haematological parameters, selectins and NOx levels according to weekly HU dosage.

\begin{tabular}{|c|c|c|c|}
\hline HU (grams)/week & $\begin{array}{l}<5 \mathrm{gr} . \\
(n=7)\end{array}$ & $\begin{array}{l}>5 \mathrm{gr} . \\
(n=7)\end{array}$ & $P=$ \\
\hline Platelet $\left(\mathrm{x10}^{9} / \mathrm{L}\right)$ & $465.7 \pm 275$ & $658 \pm 442$ & 0.34 \\
\hline WBC $\left(\times 10^{9} / \mathrm{L}\right)$ & $14.4 \pm 6$ & $10.7 \pm 5.3$ & 0.24 \\
\hline Hematocrit (\%) & $55.7 \pm 7.7$ & $49.7 \pm 11.7$ & 0.27 \\
\hline NO (nmol/L) & $5.6 \pm 4.4$ & $9.6 \pm 6.1$ & 0.18 \\
\hline sL (ng/ml) & $1,406.6 \pm 497$ & $1,204 \pm 294$ & 0.37 \\
\hline$s E(n g / m l)$ & $18.5 \pm 4.3$ & $16 \pm 16.2$ & 0.71 \\
\hline sP (ng/10 ${ }^{6}$ platelets) & $463 \pm 245$ & $340 \pm 202$ & 0.32 \\
\hline
\end{tabular}

\section{Discussion}

The present study investigated the plasma levels of NO derivatives, and soluble E-, P- and L-selectins as markers of endothelial, platelet and leukocyte activation in 32 patients with MPN. NO is produced by vascular endothelium and platelets and it mediates vascular relaxation in response to vasoactive substances and shear stress. It provides anti-proliferative and antithrombotic functions by inhibiting vascular smooth muscle cell proliferation, monocyte adhesion, platelet aggregation, and thrombosis [17].

Our study found an increased level of circulating NOx in MPN patients compared to healthy controls. The sub-analysis of data according to therapy regimen showed that ET patients on treatment at the time of study enrolment with HU presented with the highest levels of plasma NOx. The results were also confirmed by the adjusted multivariate analysis. This suggests that, in this type of disease, the administration of $\mathrm{HU}$ can be responsible of the increased plasma NOx levels, as observed in patients with sickle cell anaemia [18]. The effect of HU on NOx levels may contribute to the well known ability of HU to prevent thromboembolic complications in ET patients [19]. The group of ET patients 
not receiving $\mathrm{HU}$ at the time of enrolment presented with the lowest levels of NOx, when compared to both controls and PV patients. This is in agreement with a study demonstrating that in MPN patients with thrombocytosis the production of NO by platelets is impaired [21].

Differently, in PV patients, plasma NOx levels were increased independently from HU treatment, therefore in this type of MPN, other mechanisms can be responsible for this observation. It has been described that in patients with vascular haemodynamic disorders (i.e. recent acute myocardial infarction, and progressive renal dysfunction) the plasma levels of NOx are significantly increased, probably due to NO production by perturbed endothelial cells a s a protective antithrombotic mechanism [22-24]. We can hypothesise that in our PV patients the same mechanism is active compensating blood flow disturbances secondary to the high haematocrit values. In addition, regarding $\mathrm{HU}$ therapy, it might be possible that we could not detect appreciable differences in NOxlevels between HU-treated and non HU-treated patients because of the high levels of NOx even in the absence of treatment, and of the small group of patients. Our findings have significant clinical implications as increased NOx levels have been shown to represent an important antithrombotic mechanism in the presence of extremely high erythrocyte concentrations [25].

The main drawback of the use of total NOx as a measure of NO synthesis is that nitrates may arise from sources other than the metabolism of NO. Among the most important confounding factors, the contribution of dietary nitrite/nitrate intake to plasma NO is of relevance. To minimize the dietary interference blood samples were collected after at least 12 hours fasting and before any drug administration. In fact, as the half-life of nitrate is about 8 hours, about $70 \%$ of exogenously derived nitrate seems to be cleared from the plasma after overnight fasting. In our and others experience, this approach can be considered effective in measuring the basal production of NO derivatives [26].

Our results on plasma selectin levels show that all three markers (E-, P- and Lselectins) were increased in MPN patients compared to controls. P-selectin is an adhesion molecule stored within the Weibel-Palade body of endothelial cells as well as the alpha-granule of platelets and can be detected in soluble form after shedding from the cell membrane. Several studies have reported increased levels of this marker in several thrombotic diseases like vascular disorders and MPN [27]. In addition, high levels of P-selectin membrane expression have been found on platelets from ET patients with thrombosis, suggesting a role of Pselectin and platelet activation in the pathogenesis of thrombosis in ET [26]. Our data confirm that P-selectin is increased in MPN patients, with highest levels observed in PV patients. As P-selectin can also be released from activated endothelium, the fact that E-selectin was concomitantly found to be significantly higher in PV patients, might further support the occurrence of endothelial perturbation in these patients. Musolino et al. found increased plasma levels of P- and E-selectins in both ET and PV patients, suggesting that sustained endo- 
thelium and platelet activation in these patients might contribute to the pathogenesis of thrombosis [28]. We found a direct correlation between plasma Pselectin levels and platelet count in all subjects.

In addition, we found a significant correlation between E-selectin and NOx levels suggesting an increased endothelial activation in MPN patients. Of interest, plasma selectins have been shown to correlate with bone marrow proliferation [29], therefore this may also account for the increased levels of selectins in a condition of hypercellular bone marrow as occurred in patients with MPN.

L-selectin is known to be expressed and shed only by leukocytes. We found higher levels of L-selectin in ET and PV patients compared to healthy controls. The increased plasma levels of L-selectin might suggest an activation of leukocytes in MPN patients. This phenomenon has been previously observed by the finding of an increased expression of cell surface (i.e. CD11b, CD14, LAP and TF) and plasma levels (i.e. elastase and myeloperoxidase) of markers of neutrophil activation. $[3,7]$

To identify possible predictors for thrombosis in the follow-up period in our group of patients, we performed a multivariate analysis. The results showed that the platelet count at enrollment, male sex and JAK2V617F mutation were all significantly associated with higher risk for thrombosis in the follow-up period. The nine patients who developed thrombosis were $67 \%$ males, $89 \%$ carriers of JAK2V617F mutation, with a mean platelet count higher that the nonthrombotic patients. This is in agreement with a recently published study that found a significant association between the presence of JAK2V617F mutation and the vascular events [30]. Furthermore, a recent study from our group found that a leukocyte count at baseline $>10 \times 10^{9} / \mathrm{L}$ in MPN patients is associated with an increased risk of thrombosis in the follow-up period [31]. The same analysis performed in our study further confirmed this observation.

In conclusion, our data demonstrate, for the first time, that HU is associated to increased plasma levels of NOx in patients with MPN. Whether HU-induced NO production and cytotoxicity may be relevant in the treatment of MPN would deserve further studies.

\section{What is known on this topic:}

1. Patients with ET and PV have endothelial dysfunction, a well-known risk factor for vascular disease.

2. Endothelial dysfunction may play a role in the thrombotic risk of patients with ET and PV.

3. Plasma levels of selectins and nitric oxide (NO) are important factors regulating endothelium function.

4. It is unclear whether an interplay between selectins and NO does exist and how the cytoreductive treatment with HU does affect these markers in patients with ET and PV. 
Nitric oxide derivatives and soluble plasma selectins in patients with MPN

\section{What this paper adds:}

1. We demonstrate for the first time that HU is associated to increased levels of NO in patients with MPN.

2. HU-induced NO production may be relevant in ameliorating endothelial dysfunction in patients with ET and PV. 


\section{CHAPTER IX}

\section{References:}

1 Landolfi R, Rocca B, Patrono C. Bleeding and thrombosis in myeloproliferative disorders: mechanisms and treatment. Critical reviews in oncology/hematology. 1995; 20: 203-22.

2 Falanga A, Marchetti M, Vignoli A, Balducci D, Barbui T. Leukocyte-platelet interaction in patients with essential thrombocythemia and polycythemia vera. Experimental hematology. 2005; 33: 523-30.

3 Falanga A, Marchetti M, Vignoli A, Balducci D, Russo L, Guerini V, Barbui T. V617F JAK-2 mutation in patients with essential thrombocythemia: relation to platelet, granulocyte, and plasma hemostatic and inflammatory molecules. Experimental hematology. 2007; 35: 702-11.

$4 \quad$ Falanga A, Marchetti M, Barbui T, Smith CW. Pathogenesis of thrombosis in essential thrombocythemia and polycythemia vera: the role of neutrophils. Seminars in hematology. 2005; 42: 239-47.

$5 \quad$ Elliott MA, Tefferi A. Thrombosis and haemorrhage in polycythaemia vera and essential thrombocythaemia. Br J Haematol. 2005; 128: 275-90.

6 Cines DB, Pollak ES, Buck CA, Loscalzo J, Zimmerman GA, McEver RP, Pober JS, Wick TM, Konkle BA, Schwartz BS, Barnathan ES, McCrae KR, Hug BA, Schmidt AM, Stern DM. Endothelial cells in physiology and in the pathophysiology of vascular disorders. Blood. 1998; 91: 3527-61.

7 Falanga A, Marchetti M, Evangelista V, Vignoli A, Licini M, Balicco M, Manarini S, Finazzi G, Cerletti C, Barbui T. Polymorphonuclear leukocyte activation and hemostasis in patients with essential thrombocythemia and polycythemia vera. Blood. 2000; 96: 4261-6.

8 Freedman JE, Loscalzo J. Nitric oxide and its relationship to thrombotic disorders. J Thromb Haemost. 2003; 1: 1183-8.

9 Carlos TM, Harlan JM. Leukocyte-endothelial adhesion molecules. Blood. 1994; 84: 2068101.

10 Gearing AJ, Newman W. Circulating adhesion molecules in disease. Immunol Today. 1993; 14: 506-12.

11 Cella G, Bellotto F, Tona F, Sbarai A, Mazzaro G, Motta G, Fareed J. Plasma markers of endothelial dysfunction in pulmonary hypertension. Chest. 2001; 120: 1226-30.

12 Krieglstein CF, Granger DN. Adhesion molecules and their role in vascular disease. Am J Hypertens. 2001; 14: 44S-54S.

13 Blann AD, Tse W, Maxwell SJ, Waite MA. Increased levels of the soluble adhesion molecule E-selectin in essential hypertension. Journal of hypertension. 1994; 12: 925-8.

14 Gearing AJ, Hemingway I, Pigott R, Hughes J, Rees AJ, Cashman SJ. Soluble forms of vascular adhesion molecules, E-selectin, ICAM-1, and VCAM-1: pathological significance. Annals of the New York Academy of Sciences. 1992; 667: 324-31.

15 Jilma B, Fasching P, Ruthner C, Rumplmayr A, Ruzicka S, Kapiotis S, Wagner OF, Eichler

HG. Elevated circulating P-selectin in insulin dependent diabetes mellitus. Thrombosis and haemostasis. 1996; 76: 328-32.

16 Blann AD, Faragher EB, McCollum CN. Increased soluble P-selectin following myocardial infarction: a new marker for the progression of atherosclerosis. Blood Coagul Fibrinolysis. 1997; 8: 383-90.

17 Keynes RG, Garthwaite J. Nitric oxide and its role in ischaemic brain injury. Curr Mol Med. 2004; 4: 179-91.

18 Glover RE, Ivy ED, Orringer EP, Maeda H, Mason RP. Detection of nitrosyl hemoglobin in venous blood in the treatment of sickle cell anemia with hydroxyurea. Molecular pharmacology. 1999; 55: 1006-10.

19 Cortelazzo S, Finazzi G, Ruggeri M, Vestri O, Galli M, Rodeghiero F, Barbui T. Hydroxyurea for patients with essential thrombocythemia and a high risk of thrombosis. The New England journal of medicine. 1995; 332: 1132-6. 
20 Michiels JJ, De Raeve H, Berneman Z, Van Bockstaele D, Hebeda K, Lam K, Schroyens W. The 2001 World Health Organization and updated European clinical and pathological criteria for the diagnosis, classification, and staging of the Philadelphia chromosome-negative chronic myeloproliferative disorders. Semin Thromb Hemost. 2006; 32: 307-40.

21 Rejto L, Huszka M, Kaplar M, Udvardy M. Effects of in vitro platelet activation on platelet derived nitric oxide production in healthy humans and in chronic myeloproliferative diseases with elevated platelet counts. Platelets. 2003; 14: 283-6.

22 Ferlito S, Gallina M. Nitrite, endothelin and E-selectin plasma levels after arginine infusion in normal and vasculopathic subjects. Minerva cardioangiologica. 1998; 46: 471-7.

23 Kayali Z, Herring J, Baron P, Franco E, Ojogho O, Smith J, Watkins G, Smith D, Lamin V, Hoang T, Sharma R, Mathahs M, Sowers L, Brown KE, Schmidt WN. Increased plasma nitric oxide, Larginine, and arginase-1 in cirrhotic patients with progressive renal dysfunction. Journal of gastroenterology and hepatology. 2009; 24: 1030-7.

24 Caimi G, Montana M, Calandrino V, Caruso M, Carollo C, Catania A, Lo Presti R. Nitric oxide metabolites (nitrite and nitrate) in young patients with recent acute myocardial infarction. Clinical hemorheology and microcirculation. 2008; 40: 157-63.

25 Shibata J, Hasegawa J, Siemens HJ, Wolber E, Dibbelt L, Li D, Katschinski DM, Fandrey J, Jelkmann W, Gassmann M, Wenger RH, Wagner KF. Hemostasis and coagulation at a hematocrit level of 0.85: functional consequences of erythrocytosis. Blood. 2003; 101: 4416-22.

26 Karakantza M, Giannakoulas NC, Zikos P, Sakellaropoulos G, Kouraklis A, Aktypi A, Metallinos IC, Theodori E, Zoumbos NC, Maniatis A. Markers of endothelial and in vivo platelet activation in patients with essential thrombocythemia and polycythemia vera. International journal of hematology. 2004; 79: 253-9.

27 Andre P. P-selectin in haemostasis. Br J Haematol. 2004; 126: 298-306.

28 Musolino C, Alonci A, Bellomo G, Tringali O, Spatari G, Quartarone C, Rizzo V, Calabro L, Bagnato G, Frisina N. Myeloproliferative Disease: Markers of Endothelial and Platelet Status in Patients with Essential Thrombocythemia and Polycythemia Vera. Hematology (Amsterdam, Netherlands). 2000; 4: 397-402.

29 Jilma B, Eichler HG, Becherer A, Brugger S, Kalhs P, Stohlawetz P, Kapiotis S, Kapiotis S. Kinetics of circulating selectin levels during bone marrow aplasia. European journal of haematology. 1998; 61: 36-41.

30 Bang SM, Lee JS, Ahn JY, Lee JH, Hyun MS, Kim BS, Park MR, Chi HS, Kim HY, Kim HJ, Lee MH, Kim H, Won JH, Yoon HJ, Oh DY, Nam EM, Bae SH, Kim BK. Vascular events in Korean patients with myeloproliferative neoplasms and their relationship to JAK2 mutation. Thrombosis and haemostasis. 2009; 101: 547-51.

31 Carobbio A, Finazzi G, Guerini V, Spinelli O, Delaini F, Marchioli R, Borrelli G, Rambaldi A, Barbui T. Leukocytosis is a risk factor for thrombosis in essential thrombocythemia: interaction with treatment, standard risk factors, and Jak2 mutation status. Blood. 2007; 109: 2310-3. 


\section{CHAPTER 10}

Summary, General Discussion and Conclusions 


\section{Summary and General Discussion}

Thrombosis is a frequent clinical complication in cancer patients. Since its first recognition in the 19th century by Armand Trousseau, many investigators contributed to further enlighten the link between cancer and thrombosis. While now it is a common knowledge that thromboembolic disease is often an early manifestation and frequent cause of morbidity and mortality in cancer patients, the specific pathogenetic mechanisms are still under investigation. Whereas much is known about the role of platelets in hemostasis, in recent years it is more and more recognized that platelets play a more complex role in cancer. As presented in Chapter 1, the interaction between platelets and tumor cells supports the growth and dissemination of malignant cells. In addition, platelets participate in tumor progression by generating thrombin, a central enzyme of the coagulation cascade. Thrombin generation has been linked to several steps of tumor progression, most likely acting through protease activated receptor (PAR) mediated cell signaling pathways.

In part one, Chapter 2, a review on tumor cell-induced procoagulant mechanisms summarizes important current concepts regarding the interactions between cancer cells and hemostasis, supporting a hypercoagulable state in patients resulting in a greater risk of thromboembolic complications. In Chapter 3 , the current recommendations for prevention and treatment of venous thromboembolism (VTE) are discussed. Low molecular weight heparin (LMWH) remains the best treatment option for initial and long term treatment of VTE in cancer patients. In addition, numerous studies suggest a survival benefit for cancer patients treated with LMWH.[1-2]

The main objective of this thesis was to evaluate platelet-associated hypercoagulability in patients with Myeloproliferative Neoplasms (MPN), particularly in Essential Thrombocythemia (ET) and Polycythemia Vera (PV) patients. These particular clinical conditions have been chosen because their clinical course is strongly affected by the disease-related thrombosis. Also, management of these patients remains highly dependent on the patient's thrombotic risk (in Chapter 1).

The thrombotic tendency in this population has been evaluated using the new calibrated automated thrombogram (CAT) assay, measuring thrombin generation (TG) in platelet poor plasma, platelet rich plasma and in platelet lysates. Part two, Chapter 4, explores pre-analytical conditions that might influence invitro measurements of TG. Effects of blood collection method and addition of corn trypsin inhibitor to abolish in-vitro contact activation in TG measurements are investigated. Our study showed no need of corn trypsin inhibitor in TG assays with $1 \mathrm{pM}$ tissue factor initiation or higher. 
Part three of this thesis focuses on hypercoagulability in ET and PV patients, and particularly on platelet associated hypercoagulability. As described in Chapter 5 a study was performed in a group of 140 MPN patients (80 ET and 60 PV) in order to characterize for the first time the TG potential expressed by platelets from these subjects, as compared to platelets obtained from 72 healthy subjects and to identify what factors might be responsible for platelet TG. The TG parameters of interest (i.e., lag time, peak height, and slope) were evaluated in relation to platelet counts, platelet surface tissue factor (TF) and Pselectin levels, JAK2V617F mutational status, and patients' therapy. The analysis showed that patients positive for the JAK2V617F mutation were characterized by the highest TG potential, platelet surface TF and P-selectin levels. Patients on hydroxyurea (HU) were characterized by a significantly lower TG potential compared to non-HU treated patients, with the lowest values observed in $\mathrm{HU}$ treated JAK2V617F positive patients. Patients not receiving HU showed higher TG potential associated with JAK2V617F allele burden increment. This study suggests a platelet-dependent form of hypercoagulability in MPN patients, particularly in those positive for the JAK2V617F mutation. In addition, it shows a more beneficial effect of HU in subjects positive for JAK2V617F mutation, which significantly affects their prothrombotic phenotype.

While it is known that ET and PV patients are characterized by an increased number of circulating immature platelets, no information was available on whether this increase is influenced by pathogenetic factors including JAK2V617F mutational status, or by treatment regimen in these patients.[3] Therefore, we enrolled 46 ET and 38 PV patients to characterize the immature platelet parameters (IPF) measured by a new automated hematology analyzer (Chapter 6). Our results revealed two new elements regarding the association between MPN patients and IPF. The first finding is that the JAK2V617F mutation is linked to the quantity of IPF in patients with MPN, which might contribute to the prothrombotic phenotype in these patients. The second finding is that IPF is susceptible to HU treatment, which may additionally explain the favorable effect of this therapy on MPN as well as the associated thrombotic risk.

Antiplatelet therapy with low dose aspirin has been shown to reduce the risk of thrombosis (i.e. major venous thrombosis, pulmonary embolism, myocardial infarction and stroke) in PV patients.[4] Recently, low dose aspirin has been shown effective in reducing the incidence of venous thrombosis in JAK2V617F positive ET patients and to lower the rate of arterial thrombosis in patients with associated cardiovascular risk factors.[5] However, the large multicenter, controlled randomized clinical trial ECLAP, showed that low dose aspirin does not significantly reduce overall or cardiovascular mortality in PV patients. [4] So far, no study has investigated this issue in ET patients. Therefore, it remains uncertain whether low dose aspirin completely inhibits platelet function in MPN patients. In Chapter 7 we performed the PFA-100 assay in whole blood and the CAT assay in platelet rich plasma in a group of $46 \mathrm{ET}$ and $38 \mathrm{PV}$ patients to evaluate the effect of aspirin on platelet adhesive and procoagulant characte- 
ristics. Our results showed higher TG in aspirin treated JAK2V617F positive compared to aspirin treated JAK2V617F negative patients. In the PFA-100 assay flow arrest was noted in $20 \%$ of MPN patients after collagen-adenosine diphosphate (CADP) and in 15\% of these patients after collagen-epinephrine (CEPI) trigger, the majority taking aspirin. Higher immature platelet parameters from both ET and PV patients were significantly associated with shorter CADP closure time. In addition, in JAK2V617F positive patients, we found a significant and positive association between immature platelet count and TG. Our study suggests that elevated immature platelet parameters are important factors influencing increased platelet adhesive and procoagulant properties. Despite taking aspirin, patients with higher immature platelets had shorter CADP and CEPI closure time and higher TG. Recent observations have highlighted a wide biological variability in the interindividual response to aspirin's antiplatelet effects. $10-20 \%$ of patients experienced recurrent vascular events despite treatment with aspirin, referred to as treatment failure.[6] Recent studies suggest a possible role of immature platelets in so called resistance to antiplatelet therapy by expressing more COX-2 resulting in an increased thromboxane production.[7] In addition, hyperreactivity of younger platelets and incompletely inhibited COX-1 and COX-2 have been advocated for reduced antiplatelet effect of aspirin and aspirin resistance in patients with increased levels of immature platelets.[8] A recent study by Dragani et al. showed that low dose aspirin is unable to fully inhibit thromboxane A2 biosynthesis in ET patients. The residual thromboxane A2 in these patients is likely due to expression of unacetylated COX-1 and COX-2 in newly formed platelets [9].

Platelet adhesion and aggregation in vivo are influenced by a number of different agonists acting also through other than thromboxane dependent pathways. As described in Chapter 8 a study was performed in a group of $65 \mathrm{ET}$ and $51 \mathrm{PV}$ patients to evaluate platelet reactivity to different agonists using the multiple electrode platelet aggregometry and platelet reactivity to ADP in terms of procoagulant responses by using the CAT assay. We demonstrated that platelets from ET and PV patients are more reactive to ADP, not only in terms of increased platelet aggregation in a whole blood system, but also enhanced TG, particularly in those positive for the JAK2V617F mutation. We also observed evidence of aspirin failure, chronically administered to MPN patients, to fully inhibit platelet reactivity as shown by increased ADP and thrombin receptor activating peptide induced platelet aggregation, as well as ADP induced TG.

While the platelet's phospholipid contribution to TG in healthy subjects is well recognized, the potential platelet phospholipid contribution to TG in patients at risk of thrombosis, including MPN patients, is unknown. We demonstrated a powerful inhibitory effect of Annexin $\mathrm{V}$ on platelet associated TG indicating the critical participation of phosphatidylserine on the activated platelet surface in the thrombin formation process. 
Hydroxyurea (HU) is a recommended treatment approach in high risk patients.[10] It has been demonstrated efficient in reducing thrombotic events in high risk patients for thrombosis in a seminal randomized clinical trial.[11] Besides its myelosuppressive actions, additional mechanisms have been advocated to explain the anti-thrombotic effect of $\mathrm{HU}$, including qualitative changes in circulating blood cells (i.e. decreased expression of tissue factor), decreased expression of endothelial adhesion molecules and enhanced nitric oxide production.[12] Nitric oxide is produced by vascular endothelium and platelets and it mediates vascular relaxation in response to vasoactive substances and shear stress. It provides anti-proliferative and antithrombotic functions by inhibiting vascular smooth muscle cell proliferation, monocyte adhesion, platelet aggregation, and thrombosis.[13] Our study found an increased level of circulating nitric oxide metabolites in MPN patients, particularly in ET patients, compared to healthy controls (Chapter 9). In addition, we observed increasing levels of nitric oxide metabolites upon increasing weakly dosage of HU.[14] Whether HUinduced nitric oxide production may be relevant in the treatment of MPN would deserve further studies. 


\section{Conclusions and recommendations}

Thrombosis is a frequent complication in patients with cancer. In patients with hematological malignancies, such as MPN, thrombotic events are a major cause of increased morbidity and mortality. The pathogenesis of the activation of blood coagulation in these patients is complex. Platelets have an important role in this process.

This thesis presents studies exploring the platelet-associated hypercoagulability in patients with ET and PV. Measurements of the overall coagulation by the new thrombin generation technique provide important information of the coagulation state in these patients. Our results indicate that platelets of patients with ET and PV have a higher prothrombotic potential as assessed by the increased TG produced in platelet rich plasma or induced by isolated platelets.

The JAK2V617F mutation has been reported in nearly all patients with PV and in more than half of patients with ET. This acquired mutation has been associated with severity of disease and increased expression of soluble or cellular biomarkers of clotting system activation. Indeed, our study confirmed a hypercoagulable state in patients positive for the JAK2V617F mutation, associated with the highest TG values. We also observed that the JAK2V617F mutation is linked to a larger number of immature platelets, which might contribute to the prothrombotic phenotype in these patients. Furthermore, in these patients we showed increased platelet reactivity to ADP, in terms of both increased platelet aggregation in a whole blood system, and as an enhanced TG.

The results of the studies presented provide a starting point to further research on the association between platelet TG and/or immature platelets and thrombotic events in these patients. The current formal risk categorization includes only age and history of thrombosis in classifying patients as low or high risk for thrombosis. However, the results from the epidemiological studies suggest that better stratification of patients is necessary to improve prevention of thrombosis. Our studies suggest that particular attention is needed for JAK2V617F positive patients who despite aspirin use show higher TG potential and a higher percentage of immature platelets. Future research should also focus on designing an improved risk assessment model including both clinical and laboratory variables to better predict thrombosis in MPN patients. TG and immature platelet count could be included in such a risk model. Prospectively, such a model may be used by clinicians for assessing risk for thrombosis in patients seen in clinical practice.

Dual antiplatelet therapy has proven successful in patients with cardiovascular diseases. Our finding for an increased platelet reactivity to ADP, measured by whole blood aggregometry and TG assay, necessitates further research on the mechanisms involved that may potentiate the platelet associated hypercoagulability in MPN patients. Whether the use of ADP receptor-inhibitors, in addition to aspirin, might be of help in the prevention of thrombosis in MPN pa- 


\section{CHAPTER X}

tients, by providing a more complete inhibition of platelet functions, remains to be investigated. The potential benefit from such approach can only be proven in comparative, clinical trials. 


\section{References:}

1 Hettiarachchi RJ, Smorenburg SM, Ginsberg J, Levine M, Prins MH, Buller HR. Do heparins do more than just treat thrombosis? The influence of heparins on cancer spread. Thrombosis and haemostasis. 1999; 82: 947-52. 99080947 [pii].

2 Kakkar VV, Hoppenstead DA, Fareed J, Kadziola Z, Scully M, Nakov R, Breddin HK. Randomized trial of different regimens of heparins and in vivo thrombin generation in acute deep vein thrombosis. Blood. 2002; 99: 1965-70.

3 Ryningen A, Apelseth T, Hausken T, Bruserud O. Reticulated platelets are increased in chronic myeloproliferative disorders, pure erythrocytosis, reactive thrombocytosis and prior to hematopoietic reconstitution after intensive chemotherapy. Platelets. 2006; 17: 296-302.

4 Landolfi R, Marchioli R, Kutti J, Gisslinger H, Tognoni G, Patrono C, Barbui T. Efficacy and safety of low-dose aspirin in polycythemia vera. The New England journal of medicine. 2004; 350: 114-24. 10.1056/NEJMoa035572

$350 / 2 / 114$ [pii].

5 Alvarez-Larran A, Cervantes F, Pereira A, Arellano-Rodrigo E, Perez-Andreu V, Hernandez-Boluda JC, Ayats R, Salvador C, Muntanola A, Bellosillo B, Vicente V, Hernandez-Nieto L, Burgaleta C, Xicoy B, Besses C. Observation versus antiplatelet therapy as primary prophylaxis for thrombosis in low-risk essential thrombocythemia. Blood. 2010; 116: 1205-10; quiz 387. blood2010-01-263319 [pii] 10.1182/blood-2010-01-263319.

6 Crescente M, Di Castelnuovo A, Iacoviello L, Vermylen J, Cerletti C, de Gaetano G. Response variability to aspirin as assessed by the platelet function analyzer (PFA)-100. A systematic review. Thrombosis and haemostasis. 2008; 99: 14-26. 08010014 [pii] 10.1160/TH07-08-0530.

7 Rocca B, Secchiero P, Ciabattoni G, Ranelletti FO, Catani L, Guidotti L, Melloni E, Maggiano $\mathrm{N}$, Zauli G, Patrono C. Cyclooxygenase-2 expression is induced during human megakaryopoiesis and characterizes newly formed platelets. Proceedings of the National Academy of Sciences of the United States of America. 2002; 99: 7634-9.

8 Guthikonda S, Lev EI, Patel R, DeLao T, Bergeron AL, Dong JF, Kleiman NS. Reticulated platelets and uninhibited COX-1 and COX-2 decrease the antiplatelet effects of aspirin. J Thromb Haemost. 2007; 5: 490-6.

9 Dragani A, Pascale S, Recchiuti A, Mattoscio D, Lattanzio S, Petrucci G, Mucci L, Ferrante E, Habib A, Ranelletti FO, Ciabattoni G, Davi G, Patrono C, Rocca B. The contribution of cyclooxygenase1 and -2 to persistent thromboxane biosynthesis in aspirin-treated essential thrombocythemia: implications for antiplatelet therapy. Blood. 2010; 115: 1054-61. blood-2009-08-236679 [pii] 10.1182/blood-2009-08-236679.

10 Tefferi A. Annual Clinical Updates in Hematological Malignancies: A Continuing Medical Education Series: Polycythemia vera and essential thrombocythemia: 2011 update on diagnosis, risk-stratification, and management. American journal of hematology. 2011; 86: 292-301. 10.1002/ajh.21946.

11 Cortelazzo S, Finazzi G, Ruggeri M, Vestri O, Galli M, Rodeghiero F, Barbui T. Hydroxyurea for patients with essential thrombocythemia and a high risk of thrombosis. The New England journal of medicine. 1995; 332: 1132-6.

12 Maugeri N, Giordano G, Petrilli MP, Fraticelli V, de Gaetano G, Cerletti C, Storti S, Donati MB. Inhibition of tissue factor expression by hydroxyurea in polymorphonuclear leukocytes from patients with myeloproliferative disorders: a new effect for an old drug? J Thromb Haemost. 2006; 4: 2593-8.

13 Keynes RG, Garthwaite J. Nitric oxide and its role in ischaemic brain injury. Curr Mol Med. 2004; 4: 179-91. 


\section{CHAPTER X}

14 Cella G, Marchetti M, Vianello F, Panova-Noeva M, Vignoli A, Russo L, Barbui T, Falanga A. Nitric oxide derivatives and soluble plasma selectins in patients with myeloproliferative neoplasms. Thrombosis and haemostasis. 2010; 104: 151-6. 09-09-0663 [pii] 10.1160/TH09-09-0663. 


\section{Curriculum Vitae}

Marina Panova-Noeva was born on February $4^{\text {th }}, 1976$ in Skopje, Macedonia. After graduating high school (gymnasium) at "Rade Jovcevski Korcagin" Skopje in 1994, she started her medical training at the Medical Faculty, "Ss Cyril and Methodius" University in Skopje. In June 2001 she obtained "Doctor of Medicine" title. Afterwards, she did a 1 year residency training at the University clinical center in Skopje and in 2003 she passed the professional examination and obtained a medical license for work.

In the period from 2001 and 2004, Marina Panova-Noeva was also involved in the work of an International health organization, Project HOPE, acting as a medical program coordinator. In 2004 she started her postgraduate study in public health at "La Sapienza" University in Rome. In 2005 she was admitted to the Erasmus Mundus program and in 2006 obtained her degree of European Master of Science in International Health from Queen Margaret University, Edinburgh, UK; Karolinska Institute, Stockholm, Sweden and Vrije University Amsterdam, the Netherlands. In December 2006 she started her specialization in Internal Medicine at the Medical Faculty in Skopje.

In July 2007 Marina Panova-Noeva started her PhD studies at the Laboratory of "Thrombosis and Cancer" in Ospedali Riuniti of Bergamo, Italy directed by Doctor Anna Falanga. The research performed was part of the collaborative project between Ospedali Riuniti of Bergamo and Maastricht University. The project aim was to study coagulation problems in patients with haematological malignancies, in particular patients with Essential Thrombocythemia and Polycythemia Vera. Her research was supervised by both Doctor Anna Falanga (Bergamo) and Prof. dr. Hugo ten Cate (Maastricht).

In September 2010, Marina Panova-Noeva continued her specialization in Internal Medicine in Skopje, Macedonia. She is married to Igor Noev and in September 2011 gave birth to their son Matej. 


\section{Publications}

\section{$\underline{\text { PAPERS }}$}

Panova-Noeva M, Marchetti M., Buoro S. et al. JAK2V617F mutation and hydroxyurea treatment as determinants of immature platelet parameters in Essential Thrombocythemia and Polycythemia Vera patients. Blood. 2011 Jul 12. [Epub ahead of print]

Panova-Noeva M, Marchetti M, Spronk HM. et al. Platelet-induced thrombin generation by the calibrated automated thrombogram assay is increased in patients with essential thrombocythemia and polycythemia vera. Am J Hematol. 2011 Apr;86(4):337-42. doi: 10.1002/ajh.21974. Erratum in: Am J Hematol. 2011 May;86(5):466.

Panova-Noeva M..Falanga A. Treatment of Venous Thromboembolism in Cancer. Expert Opin Pharmacother. 2010 Aug;11(12):2049-58.

Cella G, Marchetti M, Vianello F, Panova-Noeva M at al. Nitric Oxide and soluble selectins in patients with Myeloproliferaive disorders. Thromb Haemost. 2010 Apr 29;104(1).

Spronk HM, Dielis AW, Panova-Noeva M van Oerle R, Govers-Riemslag JW, Hamulyák K, Falanga A, Cate HT. Monitoring thrombin generation: is addition of corn trypsin inhibitor needed? Thromb Haemost. 2009 Jun;101(6):1156-62.

Falanga A, Panova-Noeva M, Russo L. Procoagulant mechanisms in tumour cells. Best Pract Res Clin Haematol. 2009 Mar;22(1):49-60. Review.

\section{ORAL PRESENTATIONS}

Panova-Noeva M, Baldoli E, Marchetti M, and Falanga A. Platelet function by PFA-100 and Thrombin Generation Assay in patients with Essential Thrombocythemia (ET) and Polycythemia Vera (PV) on Aspirin prophylaxis. ). Italian Society of Hemostasis and Thrombosis (SISET), Vicenza, Italy, October 2012.

Panova-Noeva M, Marchetti M, Spronk H, Finazzi G, Rambaldi A, Barbui T, ten Cate $\mathrm{H}$, and Falanga A. Characterization of the thrombin generation (TG) potential of platelets from essential thrombocythemia (ET) and polycythemia vera 
(PV) patients. International Society of Thrombosis and Hemostasis (ISTH) congress, Boston, USA, July 2009.

Panova-NoevaM MarchettiM, RussoL, DianiE, VignoliA, FalangaA. Thrombin generation induced by cell lysates from either platelets, or mononuclearcells, or polymorphonuclear cells of patients with EssentialThrombocythemia and PolycythemiaVera. Italian Study Group on Platelets (GSP) meeting, San Pellegrino Terme, Italy, October, 2008.

Panova-Noeva M, Marchetti M, Spronk MH, Finazzi G, Rambaldi A, Barbui T, ten Cate $\mathrm{JH}$, and Falanga A. Thrombin generation in platelet rich plasma of patients with essential thrombocythemia (ET) and polycythemia vera (PV). Italian Society of Hemostasis and Thrombosis (SISET), Florence, Italy, September 2008.

\section{$\underline{\text { ABSTRACTS }}$}

Panova-Noeva M, Marchetti M, Leuzzi A.M, Russo L, Finazzi G, Rambaldi A, Barbui T, ten Cate H, Falanga. ADP-Induced Whole Blood Aggregometry and Platelet-Associated Thrombin Generation (TG) In Essential Thrombocythemia (ET) and Polycythemia Vera (PV) Patients. Blood (ASH Annual Meeting Abstracts) 2010 116: Abstract 1981.

A. Leuzzi, M.Marchetti, M.Panova-Noeva, et al. Microparticle-Associated Thrombin Generation and Procoagulant Activity Is Increased In Patients with Essential Thrombocythemia. Blood (ASH Annual Meeting Abstracts) 2010 116: Abstract 1985.

M.Marchetti, L.Russo, M. Panova-Noeva et al. ADAMTS-13, vWF and Platelet activation in patients with Essential Thrombocythemia (ET). Pathophysiol Haemost Thromb 2010; 37(suppl 1): A5, OC646.

A. Leuzzi, M.Marchetti, M.Panova-Noeva, et al. Determination of Microparticles (MP)-associated thrombin generation (TG) and procoagulant activity (PCA) in Essential Thrombocythemia (ET) patients. Pathophysiol Haemost Thromb 2010; 37(suppl 1): A153, P614.

M Panova-Noeva M Marchetti, S Buoro, L Russo, G Finazzi, A Rambaldi, T Barbui, C Ottomano, $\mathrm{H}$ Ten Cate, A Falanga. Thrombin generation in platelet rich plasma is increased and correlate to immature platelets in patients with Essen- 
tial Thrombocythemia and Polycythemia Vera. Haematologica 2010; 95[suppl.2]:400, abs. 0965

Leuzzi, M. Marchetti1, M. Panova-Noeva, L. Russo, A. Rambaldi, G. Finazzi, B. Woodhams, A. Falanga. Determination of thrombin generation (TG) and procoagulant activity (PCA) expressed by circulating microparticles (MP) in essential thrombocythemia (ET) patients. Thrombosis Research 2010; 125 (Suppl. 2): S179-180 (abstract P0-52).

M. Panova-Noeva, M. Marchetti, H.M. Spronk, G. Finazzi, A. Rambaldi, T. Barbui, H. ten Cate, A. Falanga. Increased thrombin generation (TG) potential of platelets from myeloproliferative neoplasm. Thrombosis Research 2010; 125 (Suppl. 2): S173 (abstract P0-28).

Panova-Noeva M, Marchetti M, Spronk H, Finazzi G, Rambaldi A, Barbui T, ten Cate $\mathrm{H}$, and Falanga A. Characterization of the thrombin generation (TG) potential of platelets from essential thrombocythemia (ET) and polycythemia vera (PV) patients. Journal of Thrombosis and Haemostasis 2009; 7 Suppl. 2 (Abstract AS-TU-048).

Cella G, Vianello F, Marchetti M, Vignoli A, Panova M Barbui T, and Falanga A. Nitric oxide and soluble plasma selectins in patients with essential thrombocythemia (ET) and polycythemia vera (PV). Journal of Thrombosis and Haemostasis 2009; 7 Suppl. 2: (Abstract PP-MO-867)

Vignoli A, Marchetti M, Russo L, Panova-Noeva M, Salmoiraghi S, Barbui T, Rambaldi A, ten Cate $\mathrm{H}$, and Falanga A. Monocyte (MNC) hemostatic profile in essential thrombocythemia (ET) or polycythemia vera (PV) patients is influenced by JAK2V617F mutational load. Journal of Thrombosis and Haemostasis 2009; 7 Suppl. 2 (Abstract AS-TU-050)

Falanga A, Vignoli A, Marchetti M, Russo L, Panova-Noeva M. Balducci B, Salmoiraghi S, Barbui T, ten Cate H, and Rambaldi A. Impact of V617F JAK2 mutation on monocyte tissue factor and procoagulant activity in patients with Essential Thrombocythemia(ET) or Polycythemia VERA (PV). Blood 2008; 112 (Abstract 3736).

Panova-Noeva M, Marchetti M, Spronk MH, Finazzi G, Rambaldi A, Barbui T, ten Cate $\mathrm{JH}$, and Falanga A. Thrombin generation in platelet rich plasma of pa- 
tients with essential thrombocythemia (ET) and polycythemia vera (PV). Haematologica 2008; 93 Suppl 342 (Abstract C125)

\section{$\underline{\text { AWARDS }}$}

2002: WHO Collaborative center for cancer education award, Groningen, Netherlands

2004: Fellowship from the Italian Ministry of Foreign Affairs, La Sapienza University, Rome, Italy.

2005: Erasmus Mundus fellowship (European commission).

2010: Young Investigator Award. 56th Annual Meeting of the Scientific and Standardization Committee of ISTH, Cairo, Egypt.

2010: Travel award. 15 ${ }^{\text {th }}$ Congress of the European Hematology Association, Barcelona, Spain.

2012: Grant Award. ISTH Advanced Course in Haemostasis and Thrombosis, Belgrade, Serbia. 


\section{Acknowledgements}


I have been fortunate to be part of a very productive collaboration between Maastricht University and Ospedali Riuniti of Bergamo. The work presented in this thesis would not have been possible without the help and support of the wonderful people from Bergamo and Maastricht. I feel so privileged to know you all and here I want to express my deepest gratitude.

My sincere gratitude goes to all patients and healthy controls that generously provided their blood samples and agreed to participate in the studies described in this thesis.

I would like to express my deepest gratitude to my supervisors, two remarkable people, Doctor Anna Falanga from Bergamo and Prof. Hugo ten Cate from Maastricht.

Thank you Anna for giving me the excellent opportunity to work in your group, I greatly appreciate your constant guidance, support and interest in my work and my life. I enjoyed so much our work together, and truly admire your detailed and careful correction of my work and writings. Thank you for always having your door open for me. My special thanks to Arrigo, il maestro di cucina. I have been very fortunate to have as my promoter Prof. Hugo ten Cate. Thank you Hugo for your continuous interest in the progress of my work, your constructive advices and very helpful suggestions! Your encouragements, patience and trust contributed greatly in achieving my goal. My greetings to Arina!

I would like to express my special gratitude to my co-supervisor dottoressa Marina Marchetti. Thank you Mari for your daily support, teaching and guiding! Your have influenced me with your passion and commitment in science, and I am very grateful for this. Tanti abbracci a mio amico Marco!

I would also like to thank Prof. dr. J. Rosing, Prof. dr. H.C.J. Eikenboom, Prof. dr. S. Middeldorp, Prof. dr. H.C. Schouten, Dr. W. van Werkum from the Assessment Committee for critically evaluating my thesis.

I am grateful to Prof. Barbui, Prof. Rambaldi, Dr. Finazzi and the nurses of the hematology ambulatory for their contribution and help with the patients.

Dear Laura! I wondered how to thank my best Italian friend. From the first day we met, when you brought me for a welcome a delicious Italian brioche, I knew you are special $\odot$. I learned so much from you! I truly miss our time together.

My big thank you to Alfonso for introducing me to the platelet cytofluorimetry, for his help with all of my Italian administrative issues! I am grateful for your professionalism and friendship.

I would like to thank my colleagues and friends from Bergamo lab: Anna, Carmen, Donatella, Erika, Elena G., Elena C., Ilaria, Rosanna and Sara. Thank you for all the help in and outside the lab. You have all made my stay in Bergamo a unique, wonderful experience. Mi mancano tantissimo le nostre merende! To Anna and Damiano, thank you for all the hints about the flowcytometry. 
My special thanks to Dr. Henri Spronk. I am very grateful for being always ready to help me with any of my requests (TG, reagents, library and for much more). To Paola, thank you so much for reviewing my thesis and distributing it to the reading committee. I would also like to thank Trees for helping with all the necessary documents.

To my Bulgarian friend Julian! Thank you for your exhausting tips on how to go through the last thesis preparation.

To my loving husband and my best friend Igor, for taking care of my thesis layout and cover design and for much much more!

Конечно, му благодарам бескрајно на моето семејство без кои ќе беше невозможно да истраам до крај. На мама Кате за подршката, љубовта и вербата во мене. На баба Пале, баба Маре, Тоше и Ане. Големо благодарам за подршката и помошта на Лиле, на баба Вера, Ели и Владо. На мојата тета Блага, која ме инспирира да се занимавам со медицината. Многу бакнежи и гушки за моите сакани, Игор и Матеј, кои го прават секој мој ден посебен и полн со љубов.

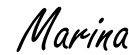


